ESRI

SURVEY AND

STATISTICAL

REPORT SERIES

NUMBER 92

JUNE 2020

\title{
LEARNING FOR ALL? SECOND-LEVEL EDUCATION IN IRELAND DURING COVID-19
}

GRETTA MOHAN, SELINA MCCOY, EAMONN CARROLL, GEORGIANA MIHUT, SEÁN LYONS AND CIARÁN MAC DOMHNAILL

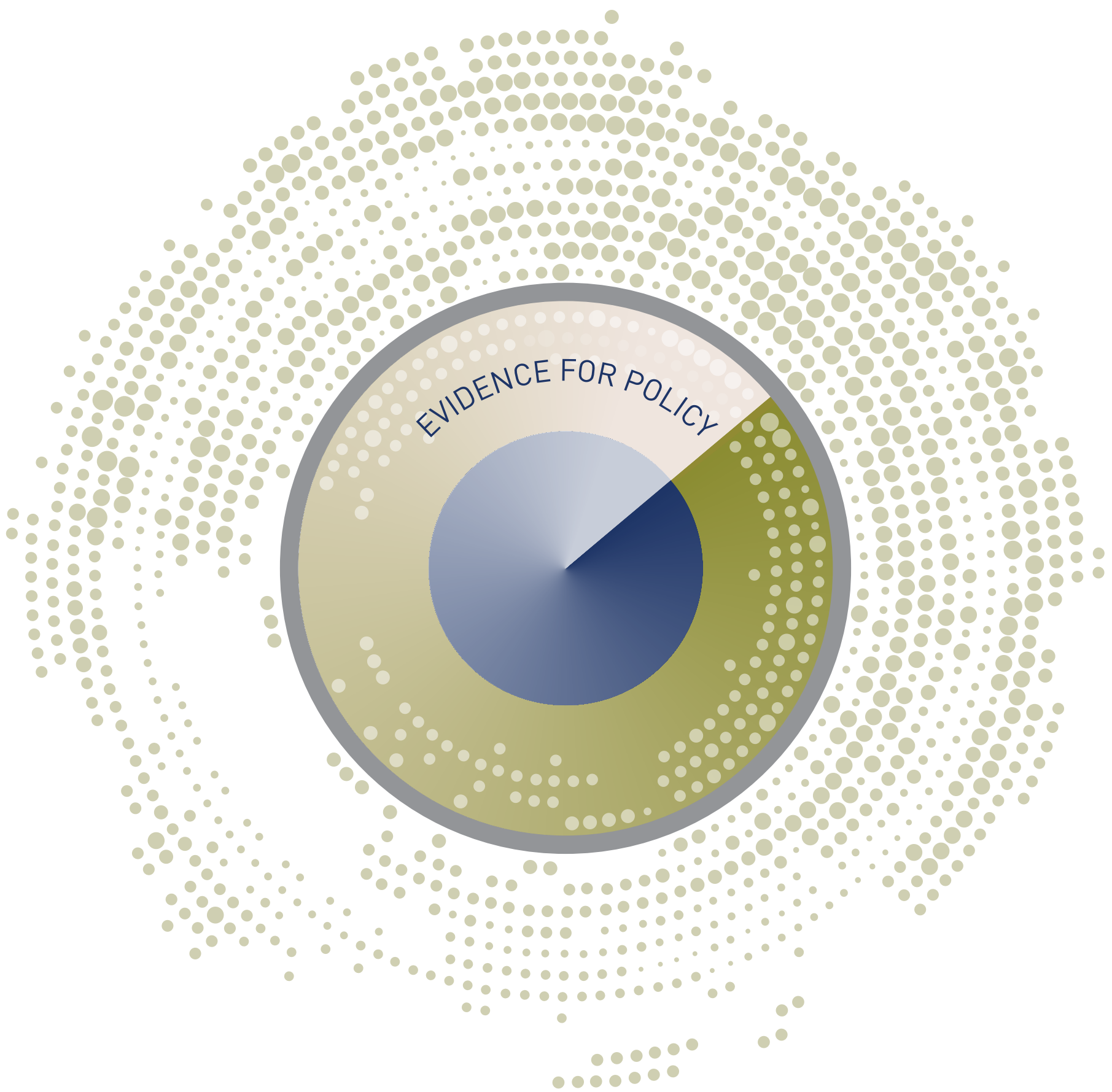




\title{
LEARNING FOR ALL? SECOND-LEVEL EDUCATION IN IRELAND DURING COVID-19
}

\author{
Gretta Mohan \\ Selina McCoy \\ Eamonn Carroll \\ Georgiana Mihut \\ Seán Lyons \\ Ciarán Mac Domhnaill
}

June 2020

\section{ESRI SURVEY AND STATISTICAL REPORT SERIES}

\section{NUMBER 92}

Available to download from www.esri.ie

The Economic and Social Research Institute

Whitaker Square, Sir John Rogerson's Quay, Dublin 2

ISBN 978-0-7070-0529-4

https://doi.org/10.26504/sustat92.pdf

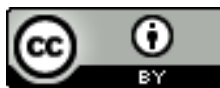

This Open Access work is licensed under a Creative Commons Attribution 4.0 International License (https://creativecommons.org/licenses/by/4.0/), which permits unrestricted use, distribution, and reproduction in any medium, provided the original work is properly credited. 


\section{ABOUT THE ESRI}

The mission of the Economic and Social Research Institute is to advance evidencebased policymaking that supports economic sustainability and social progress in Ireland. ESRI researchers apply the highest standards of academic excellence to challenges facing policymakers, focusing on 12 areas of critical importance to 21st Century Ireland.

The Institute was founded in 1960 by a group of senior civil servants led by $\mathrm{Dr}$ T. K. Whitaker, who identified the need for independent and in-depth research analysis to provide a robust evidence base for policymaking in Ireland.

Since then, the Institute has remained committed to independent research and its work is free of any expressed ideology or political position. The Institute publishes all research reaching the appropriate academic standard, irrespective of its findings or who funds the research.

The quality of its research output is guaranteed by a rigorous peer review process. ESRI researchers are experts in their fields and are committed to producing work that meets the highest academic standards and practices.

The work of the Institute is disseminated widely in books, journal articles and reports. ESRI publications are available to download, free of charge, from its website. Additionally, ESRI staff communicate research findings at regular conferences and seminars.

The ESRI is a company limited by guarantee, answerable to its members and governed by a Council, comprising 14 members who represent a cross-section of ESRI members from academia, civil services, state agencies, businesses and civil society. The Institute receives an annual grant-in-aid from the Department of Public Expenditure and Reform to support the scientific and public interest elements of the Institute's activities; the grant accounted for an average of 30 per cent of the Institute's income over the lifetime of the last Research Strategy. The remaining funding comes from research programmes supported by government departments and agencies, public bodies and competitive research programmes.

Further information is available at www.esri.ie 


\section{THE AUTHORS}

Selina McCoy and Seán Lyons are Associate Research Professors at the Economic and Social Research Institute (ESRI) and Adjunct Professors at Trinity College Dublin (TCD). Gretta Mohan is a Research Officer at the ESRI and an Assistant Adjunct Professor at TCD. Georgiana Mihut is a Postdoctoral Research Fellow at the ESRI. Eamonn Carroll and Ciarán Mac Domhnaill are research assistants at the ESRI.

\section{ACKNOWLEDGEMENTS}

This research forms part of the Electronic Communications Programme at the ESRI, jointly funded by the Department of Communications, Climate Action and the Environment (DCCAE) and the Commission for Communications Regulation (ComReg). The authors would like to acknowledge the contribution of the survey participants who gave their time to inform this work and the support of the National Association of Principals and Deputy Principals (NAPD) in Ireland.

This report has been accepted for publication by the Institute, which does not itself take institutional policy positions. The report has been peer reviewed prior to publication. The authors are solely responsible for the content and the views expressed. 



\section{TABLE OF CONTENTS}

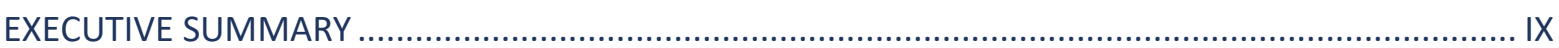

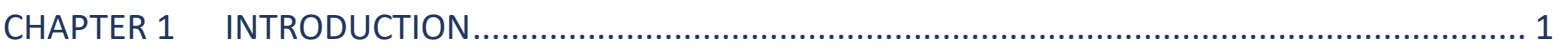

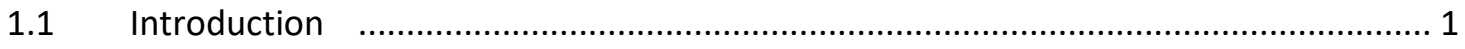

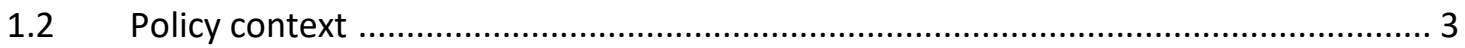

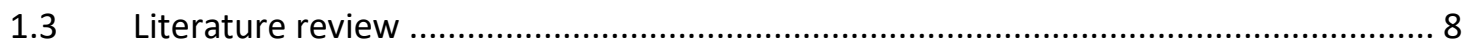

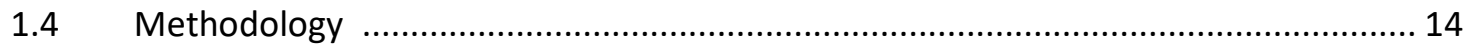

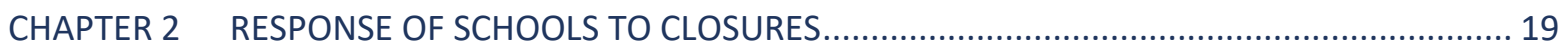

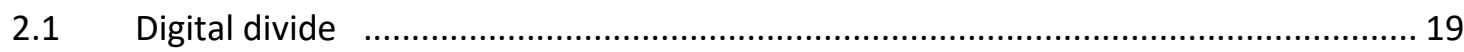

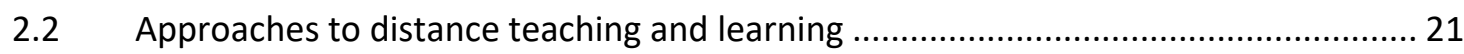

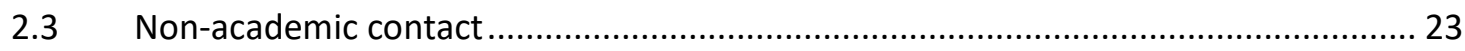

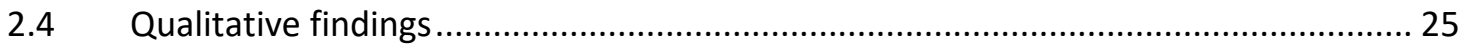

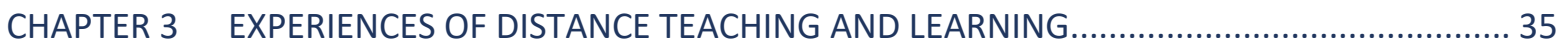

3.1 Relative quality of distance teaching and learning ................................................. 35

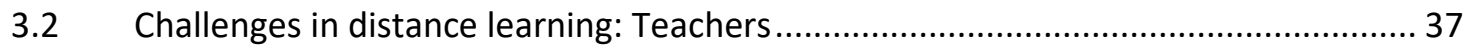

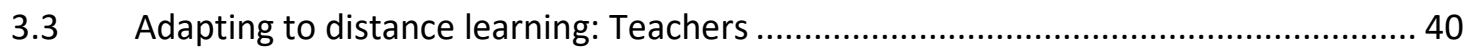

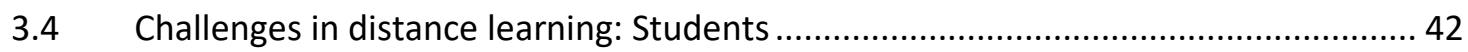

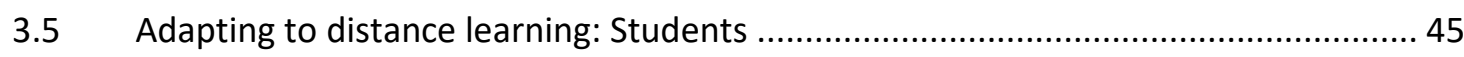

3.6 Abilty of schools to cover practical work .................................................................. 46

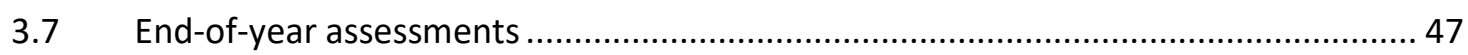

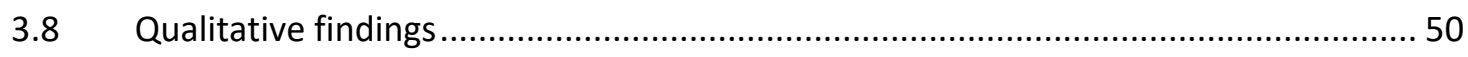

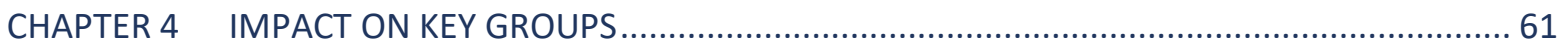

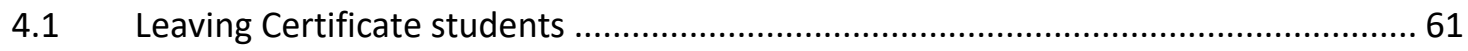

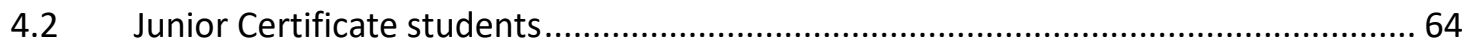

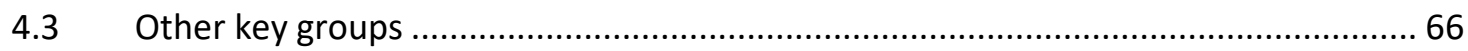

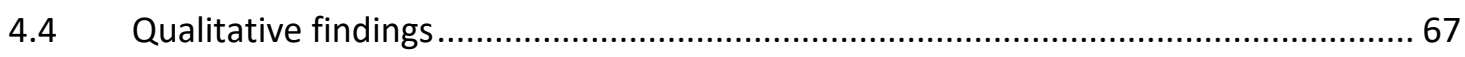

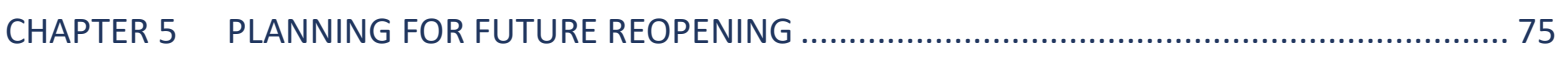

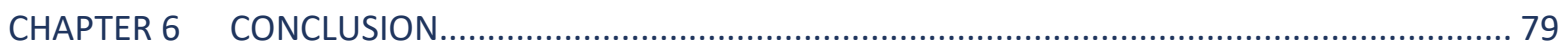

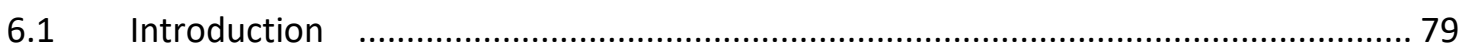

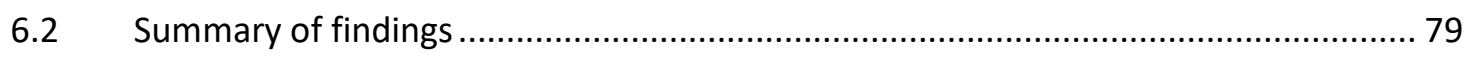

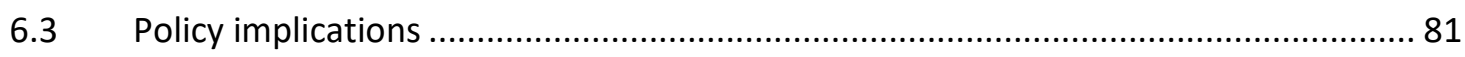

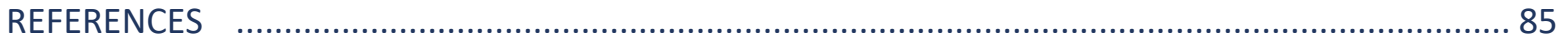

APPENDIX MEASURING BROADBAND AVAILABILITY AND HOUSEHOLD INCOME ....................... 91 


\section{LIST OF TABLES}

Table 1 Comparison between sample and population of schools by region ........................... 16

Table 2 Comparison between sample and population of schools by school type ................... 16

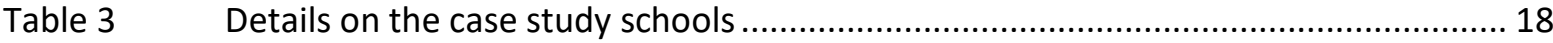

\section{LIST OF FIGURES}

Figure 2.1 In your opinion, is there a digital divide among students of your school?................. 20

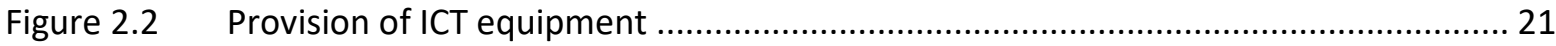

Figure 2.3 Live Virtual learning via live video e.g. Zoom, Google Hangouts................................ 22

Figure 2.4 Participation in free school meals by DEIS status ..................................................... 24

Figure 3.1 How distance learning compares to standard practice ............................................... 35

Figure 3.2 Group work by availability of high-speed broadband ............................................... 36

Figure 3.3 Student attendance and participation in lessons by DEIS status ............................... 37

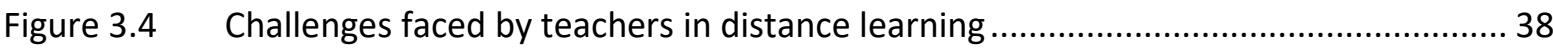

Figure 3.5 Insufficient home internet speed among teachers by availability of high-speed

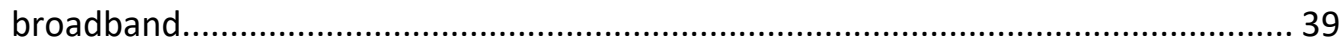

Figure 3.6 Insufficient home internet speed among teachers by average household income

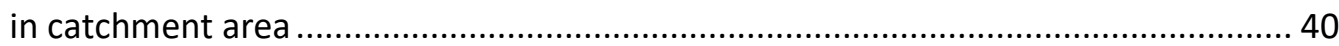

Figure 3.7 How teachers have adapted to distance learning ................................................. 41

Figure 3.8 Factors impacting teachers' adaptation to distance learning ................................. 42

Figure 3.9 Challenges faced by students in distance learning ................................................. 43

Figure 3.10 Insufficient ICT equipment at home among students by average household income

Figure 3.11 Insufficient home internet speed among students by availability of high-speed

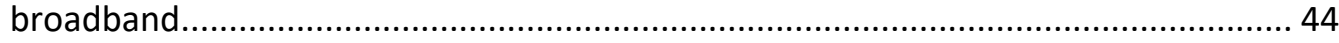

Figure 3.12 How students have adapted to distance learning ................................................... 45

Figure 3.13 Percentage of students who have adapted 'very well' by DEIS status....................... 46

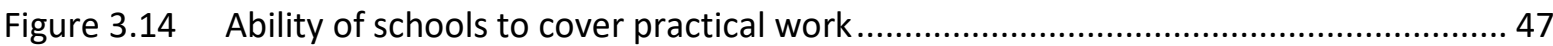

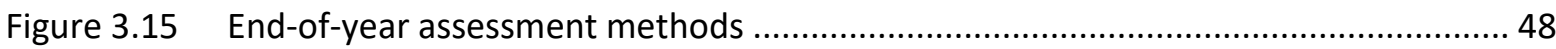

Figure 3.16 How end-of-year assessment will compare to normal ............................................. 49

Figure 3.17 How end-of-year assessment compares to normal for critical thinking by availability of high-speed broadband .................................................................... 50

Figure 4.1 Impact of shutdown on Leaving Certificate students............................................. 62

Figure 4.2 Impact of shutdown on Leaving Certificate student learning by DEIS status.............. 63

Figure 4.3 Impact of shutdown on Leaving Certificate student engagement by DEIS status....... 64 


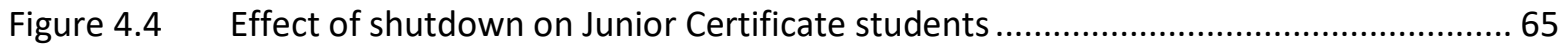

Figure 4.5 Impact of shutdown on Junior Certificate student engagement by DEIS status ......... 66

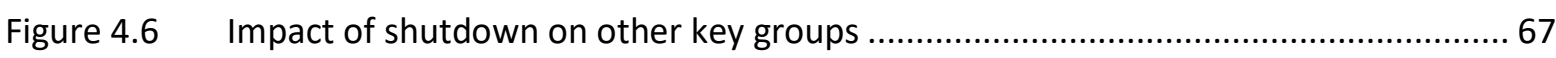

Figure A.1 National Broadband Plan map for Republic of Ireland, Quarter 32019 .................... 91

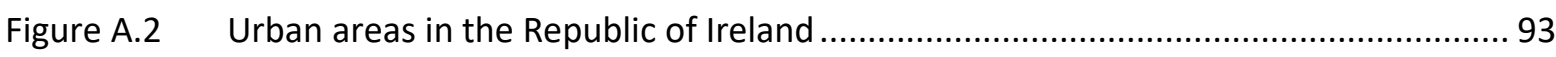

Figure A.3 Household median gross annual income by electoral division in Republic of Ireland,

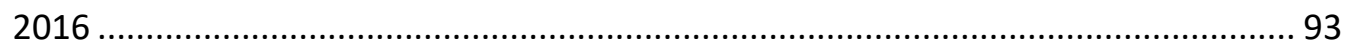

Figure A.4 Linking residences to second-level schools using circular buffers............................. 94

Figure A.5 Scatter plot of proportion of residences in school catchment areas for which high-speed broadband is available and average of electoral division level median gross household income 



\section{ABBREVIATIONS}

ComReg

CSO

CAMHS

CPD

DCCAE

DEIS

DES

DLF

EC

ESRI

ETB

GDPR

GUI

ICT

ITE

JCT

TD

TCD

Mbps

NAPD

NBP

NCCA

NEPS

OECD

PDST

PISA

SAPS

SEC

SEN

SSE

SNA

UK

UNESCO

US

VLE
Commission for Communications Regulation

Central Statistics Office

Child and Adolescent Mental Health Service

Continued Professional Development

Department of Communications, Climate Action and the Environment

Delivering Equality of Opportunity in Schools

Department of Education and Skills

Digital Learning Framework

European Commission

Economic and Social Research Institute

Education and Training Board

General Data Protection Regulation

Growing Up in Ireland

Information Communications Technology

Initial Teacher Education

Junior Cycle Teaching

Teachta Dála: member of Dáil Éireann, the lower house of the Oireachtas (the Irish Parliament)

Trinity College Dublin

Megabytes per second

National Association of Principals and Deputy Principals

National Broadband Plan

National Council for Curriculum and Assessment

National Educational Psychological Service

Organisation for Economic Co-operation and Development

Professional Development Service for Teachers

Programme for International Student Assessment

Small Area Population Statistics

State Examination Commission

Special Education Needs

School Self Evaluation

Special Needs Assistant

United Kingdom

United Nations Educational, Scientific and Cultural Organization

United States

Virtual Learning Environment 



\section{EXECUTIVE SUMMARY}

\section{COVID-19 school closures and second-level education}

This report documents the wide-ranging impact of school building closures on teaching and learning in second-level schools in Ireland. The closure of all educational settings was mandated by the Irish government from 12 March 2020 as part of the government response to contain the spread of COVID-19. The closures occurred with immediate effect on the day of the government announcement. In drawing on primary mixed-methods research with school leaders, this study provides a robust and informative insight into how this dramatic period shaped second-level education in Ireland. The study also provides insights into the supports schools need for the commencement of the new academic year.

The study began with an online survey of leaders of second-level schools, fielded two months after the shutdown, over the period 13-29 May 2020. According to the census records of the Department of Education and Skills (DES, 2019a) there were 723 second-level schools in the Republic of Ireland in the academic year of 2019/2020. The online survey secured a 33 per cent response rate, with the sample highly representative of the national population of schools across key characteristics. The survey responses were linked to administrative data on the availability of high-speed broadband in the vicinity of each school, permitting analysis of how variations in broadband availability might have affected the teaching and learning options available to schools. Upon completion of the survey, participants were invited to nominate themselves for a follow-up, in-depth qualitative interview to greater explore the experiences and challenges faced by schools. In total ten school leaders were interviewed; a theoretical sampling frame ensured a diversity of school settings were captured.

This report provides an initial exploration of the impact of a sudden shift to distance learning on students, teachers and school ecosystems. The study provides insights from those at the coalface in addressing this unique period in Irish education. The evidence can shape policy in both the immediate planning and support of schools and (distance) learning strategies, but also in terms of broader policies and practices that can act as 'drivers' of improvement. The key findings of the research may be summarised according to the following themes:

\section{Response of schools to closures}

As a result of the national response to the coronavirus pandemic, second-level schools, staff and students were thrust into remote learning environments with minimal preparation. The ability of schools to act in response to this was impacted by households' access to digital technologies and local broadband availability. In a 
very short period, teachers and students were challenged to upskill their digital competencies, typically in a 'learning by doing' fashion. Live online videos and the use of virtual platforms appeared to be the distance learning tools of choice, though schools with catchments characterised by lower coverage of high-speed broadband and lower average household incomes availed of these means to a lesser extent, providing evidence of digital exclusion. Many schools provided ICT equipment to students and it was clear that schools made great efforts to overcome the barriers experienced by some students. Schools also endeavoured to foster a sense of school community and non-academic contact, be that online or through other channels, to ensure that physical distancing did not result in relational separation.

\section{Experiences of distance teaching and learning}

Distance learning was regarded by school leaders as either similar to, or worse than, standard practice. The sudden move to distance learning negatively impacted on group work and practical work in particular, in addition to student participation and engagement. Some of these impacts appear to have been more pronounced among schools in areas with lower availability of high-speed broadband, DEIS schools and schools in areas of lower household income. Some of the most pertinent challenges faced by both teachers and students were found to be uncertainty around State examinations, difficulties related to working at home, and insufficient home internet speed. Slow internet speed at home was considered problematic by a higher percentage of schools in areas of lower broadband availability as well as schools in areas of lower household income, suggesting the possibility of a two-dimensional problem of local broadband availability and access to suitable devices. The ability of schools to cover practical elements of the curriculum was found to be significantly hampered, while the most popular methods for assessing students at the end of the year were final presentations and open-book exams. This study also identified several key components to effective distance learning, including planning and organisation, the support of staff, and effective communication and feedback.

\section{Impact on key groups}

Several key groups in the school population were particularly impacted by the shutdown of school buildings and the move to distance learning. These include Leaving Certificate and Junior Certificate students, for whom State examinations were cancelled. School closures appear to have particularly affected learning, wellbeing, motivation and engagement of Leaving Certificate and Junior Certificate students, with more severe impacts being reported among DEIS schools. Other key impact groups were found to include students with special educational needs (SEN), students from low-income backgrounds and students studying English as a foreign language. Risks of learning regression among disadvantaged groups of students are of concern. 


\section{Planning for future reopening}

In anticipating the commencement of academic year 2020/2021 and the future operation of second-level schools amid a continuing global pandemic, widespread uncertainties remain. The views captured in this research demonstrate that school leaders are contemplating a full range of possibilities, from fully online provision to a return to normality. In this regard, a key concern for second-level schools was the need for greater clarity. The need for centralised guidelines to guide decisionmaking was expressed, though alongside these, flexibility and autonomy to act in response to the local context and use their own best judgment was also considered important. In addition to enhanced communication from the DES, schools indicate that they will require a range of concrete supports in order to best prepare and provide for students in late August and September. These will include resources for ICT, professional development, COVID-19 management supports, and wellbeing supports. For students entering sixth year, measures will also need to be put into place to maximise teaching time in examination subjects. 



\section{Introduction}

\section{$1.1 \quad$ INTRODUCTION}

As in many other countries, students in Ireland have not physically attended school since mid-March. School premises were closed in an attempt to contain the spread of COVID-19. While the closure of schools may well entail predictable risks, particularly in terms of the extent of educational inequality, these risks and ways to mitigate them are also likely to be context specific. We can certainly learn from international experience and policy responses, but there is a crucial need to guard against policy borrowing and introducing policies which are not sufficiently reflective of the national context (Raffe, 2011; Lingard, 2010; McCoy and Smyth, 2013). Hence, while much of the discourse and commentary in Ireland thus far has reflected international responses and evidence, there is an urgent need for a robust evidence base within Ireland, from those on the ground, to guide our reflections on this momentous period and the policy learnings we glean. It is also vital that this moment in time is examined in terms of how it might inform other key developments in national policies on areas as varied as second-level education and investment in broadband provision for underserved areas. These include reforms in provision for students with additional needs (particularly the pilot School Inclusion Model); refinements to the identification of schools for the DEIS (Delivering Equality of Opportunity in Schools) programme currently out for consultation; the Framework for Junior Cycle in the final stages of implementation; and the review of Senior Cycle due for completion later in the year. Ultimately, assessment of the experiences of, and the challenges encountered, in distance learning ${ }^{1}$ over recent months, should be guided by both immediate mitigation needs and supports for schools and the potential to lay the foundation for broader policy goals around a more inclusive, responsive and effective education system in Ireland (DES, 2019b).

As one of several measures to slow the spread of COVID-19, An Taoiseach Leo Varadkar TD announced the closure of schools, pre-schools, further and higher education settings on the morning of 12 March 2020, to take effect from 6pm the same day. The decision was made upon advice of the National Public Health Emergency Team, with the objective of reducing the transmission of the

Throughout this report we draw on the UNESCO definition of distance learning, which is often used synonymously with e-learning, online learning and distance education. 'Common features of any form of distance learning are: the teacherlearner separation by space or time, or both, and the use of media and technology to enable communication and exchange during the learning process despite this separation. This may be achieved through print-based learning materials, or one-way massive broadcasting (TV and radio programmes), or through web-based exchange using social media channels or learning platforms. Distance learning tends to require a high level of self-directed learning on the part of the learner, and study skills, which must be supported through new teaching, learning and guidance strategies.' (UNESCO, 2020a). 
SARS-Cov-2 virus by limiting close physical proximity and contact between people. School continuity planning has been supported by extensive guidance from the DES (2020a), ${ }^{2}$ published 2 April. The supports included a dedicated webpage of curated content, developed by the Professional Development Service for Teachers (PDST), to support schools and teachers engaged in distance learning and information on the range of curriculum tagged digital content (available on www.Scoilnet.ie, the DES official online education portal). To assist families of children with special needs, specific guidance was published on 22 April (DES, 2020b), along with guidance to support students at risk of educational disadvantage (DES, 2020c). Additional guidance to support the wellbeing of students was issued in May 2020. Schools have been asked to be conscious of students who may not have access to online facilities or where digital solutions may not be appropriate, and to consider this actively in their approaches to delivering remote learning.

The policy response also led to changes in plans for State examinations, the Junior and Leaving Certificate examinations. Following discussion, it was finally announced by the Minister for Education on 8 May 2020 that the Leaving Certificate examinations would not be held this year. Given the considerable concerns over the feasibility of safely conducting such examinations for approximately 60,000 students (DES, 2020d), it was decided that teachers would submit Calculated Grades for each student (DES, 2020e). Guidelines and advice were prepared for teachers, students and their parents, and a circular was issued to all schools on 21 May 2020 (DES, 2020f). Results will be issued to students allowing their progression to further and higher education in September 2020.

With second-level students not attending school for over two and a half months, education has been taking place remotely. This involves significant changes to the mode, and frequency, of contact between students and their teachers. While schools in Ireland have developed ICT plans as part of their whole school planning (McCoy et al., 2016), such plans are unlikely to have envisaged a scenario like this. Despite the disruption, schools have continued to teach, albeit in new and perhaps unfamiliar ways. For students (and teachers) at home, digital resources including access to devices and broadband connectivity have assumed a far greater significance in their educational lives. Furthermore, while no doubt physical distancing from school and their teachers affects students, the emotional effects of separation from friends and peers for such an extended time could have an even greater impact. This moment in time provides an opportunity to take stock and

From 13 March, DES published a series of Continuity of Learning Guidance documents to support continuity in students' learning. Those Guidance documents, together with other advice and the details of supports provided by the Department and its support services/agencies are available at: https://www.education.ie/en/TheDepartment/Announcements/information-for-schools-preschools-and-third-level-institutions-on-the-

coronavirus.html\#guidance 
reflect on how schools, and students, have adapted, what lessons can be learned and how any adverse impacts might be ameliorated in the longer term.

The study is guided by five overarching research questions:

1. How have second-level schools responded to the move to distance learning?

2. How has access to digital resources impacted on teaching and learning?

3. To what extent have students engaged with distance learning? Do the additional pressures stemming from school closures fall disproportionately on already vulnerable groups?

4. What supports do schools require in advance of the next school year?

5. What lessons can be learned for teaching and learning more broadly and for key longer-term policy development? Can compensatory policy measures ameliorate the impact of the period of school closure?

The next section provides an overview of the policy context, particularly focused on the role of digital technologies in Irish second-level education. An overview of the academic literature on key aspects of school closures is then presented. The chapter concludes with a description of the methodology the study adopts.

\subsection{POLICY CONTEXT}

The way in which distance learning can be provided is likely to depend partly upon availability of, and access to, adequate broadband in the home. As is the case in most countries, broadband connectivity is not uniform across Ireland. While mobile broadband and lower bandwidth fixed line services are available almost everywhere, many areas still lack access to high-speed broadband. This limits the scope for households in these areas to use high-bandwidth services such as videoconferencing. By November 2019, 23 per cent of premises in Ireland did not have access to high-speed broadband (DCCAE, 2019a). To address gaps in coverage, the National Broadband Plan (NBP) is an Irish government initiative to deliver high-speed broadband to all premises in Ireland by 2026 (DCCAE, 2019b). Through a combination of private sector investment and state intervention, the investment aims to extend high-speed broadband coverage (150 Megabits per second (Mbps)) to all parts of the country where there are no plans for commercial deployment. The potential benefits for education, including equal engagement in distance learning is recognised in the plan. The availability of online educational tools to complement classroom learning and enabling all students to participate fully in the digital revolution is acknowledged, along with greater access for teachers to specialist teaching resources via online media.

Innovation in teaching and learning, and a need to fully avail of educational services online have also previously been recognised in the European Commission's (EC) 
vision to turn Europe into a Gigabit Society by 2025 (EC, 2016). This includes providing access to a connectivity offering of at least $100 \mathrm{Mbps}$ for all European households, both urban and rural. Moreover, in considering the coronavirus pandemic, the EC advises that emergency situations demonstrate a necessity for every citizen in Europe to have access to high-speed connectivity, with e-education identified as a key area (EC, 2020).

A survey in April 2020 by the Commission for Communications Regulation (ComReg) found that home broadband use increased substantially in Ireland during the COVID-19 restrictions period, with 61 per cent of households increasing their usage (ComReg, 2020). However, the adequacy of home broadband was an issue for one-in-five homes (20 per cent), rising to one-in-four households in rural areas (24 per cent).

To improve broadband connectivity of school premises, as part of Ireland's National Digital Strategy the Irish government invested substantially in a national roll-out of high-speed broadband to all second-level schools in the country in 2013 and 2014. This investment signalled a move from a slow and often unreliable broadband connection that inhibited the use of $\mathrm{ICT}^{3}$ within education (Coyne et al., 2016), to high-speed broadband connection with connectivity support. An evaluation of this programme found that while the broadband removed a significant barrier for schools, namely inadequate and unreliable internet connection, other infrastructural issues became more salient (McCoy et al., 2016).

The DES published two documents in recent years, the Digital Strategy for Schools 2015-2020 Action Plan (DES, 2015a) and the Digital Strategy for Schools 2018-2020 Enhancing Teaching Learning and Assessment (DES, 2015b), which sets out the DES current policy on the use of digital technologies in teaching, learning and assessment. The Strategy, which is in its final year of implementation, sets out a broad range of policy objectives addressing four key themes: (1) Teaching, learning and assessment using ICT; (2) Teacher professional development; (3) Leadership, research and policy; and (4) ICT infrastructure. Arising from Theme 1, a Digital Learning Framework (DLF) has been made available to all schools, accompanied by an extensive Continuous Professional Development (CPD) programme, providing guidance on how to embed digital technologies in teaching and learning and in leadership and management. The PDST and other DES funded teacher support services continue to offer professional learning opportunities to teachers and school leaders in a range of pedagogical, curricular and educational areas including a wider range of CPD on the effective use of digital technologies in teaching, 
learning and assessment. The Strategy also provides grants worth $€ 210$ million for ICT infrastructure to schools over the five years of the Strategy. Some $€ 160$ million of this funding has issued to date to schools for ICT infrastructure. This includes a fund of $€ 40$ million recently issued in the form of grant payments to all eligible schools and a further $€ 10$ million fund disbursed as top-up funding to enable schools to specifically support any of their students experiencing difficulty in engaging with remote learning. In the context of the current public health crisis the funding can be focused on assisting schools to address ICT needs including the purchase of digital devices, software, essential learning platforms and other ICT solutions as determined by the needs of the individual school (DES, 2020g).

Digital skills have become an increasing focus within the Irish curriculum in recent years, in line with the Digital Strategy for Schools and Action Plan for Education (DES, 2018a). It is DES policy that clear statements and objectives on the use of ICT and the development of digital literacy competencies are included in all new/revised curriculum specifications. Competencies in digital skills feature strongly in the new Framework for Junior Cycle (DES, 2015c). In particular, students are expected to use technology and digital media tools to learn, work and think collaboratively and creatively in a responsible and ethical manner. They are assessed on the basis of being able to source information and share content online; recognise and respect their own rights and the rights of others in using technology and digital media; evaluate online information and content; and use technology and digital media to read, think, express oneself and work with others (DES, 2018a; 2018b). Schools can also offer a short course in Digital Media Literacy, supporting students to learn to use digital technology, communication tools and the internet to engage in self-directed enquiry (NCCA, 2016). In September 2018, a Leaving Certificate course in Computer Science was introduced on a phased basis, commencing in some 40 schools. Students were due to sit, for the first time, Leaving Certificate exams in Computer Science in June 2020 (but, as for all subjects, will be awarded Calculated Grades). In addition, in the ongoing reviews of the Primary Curriculum and of the Senior Cycle, the skills of - or skills closely related to - digital literacy have featured strongly in all discussions on future provision. Digital technologies comprise an integral part of all DES funded CPD programmes. Finally, the School Digital Champion Programme has been jointly established by the DCCAE and DES, designed to enable students to develop their creativity, criticalthinking and communications skills. Students are asked to use their digital and communications skills to develop a project with teammates that could benefit their school, local community or local business (DCCAE, 2019c).

Key to the provision of effective distance teaching approaches is the development and availability of relevant online learning resources. This has been the subject of some criticism in Ireland in recent years (Marcus-Quinn et al., 2019a). There is an emerging expectation that teachers will not only incorporate more digital 
resources into their practice but that they also become producers of such digital content. Many teachers, however, do not have training in the design and development of digital resources. As a result, many design features can be overlooked, and classroom resources may not be as effective as anticipated (Marcus-Quinn et al., 2019c). The Department's official portal for Irish education content (Scoilnet.ie) has grown significantly in the last three years and now provides in excess of 19,000 digital resources aligned with second-level subject specifications which can be used by teachers for teaching and learning (MarcusQuinn et al., 2019b).

In its guidelines for Initial Teacher Education (ITE) at both primary and second level, the Teaching Council of Ireland requires that student teachers are able to use technology, including multimedia resources in the areas of planning, teaching and assessment. There are also support measures for continuing professional development delivered by the PDST (PDST, 2017). While there is specific CPD targeted at the effective use of digital technologies in teaching and learning and in leadership and management, digital technologies comprise an integral part of all DES funded CPD programmes with the aim that the use of digital technologies is seamlessly integrated into all teacher and school activity. As regards CPD directly targeting digital technologies, there are differentiated models of CPD available to teachers including face-to-face, online courses/webinars, sustained and direct school support. This is to ensure that teachers can avail of a range of opportunities for professional development. This professional development includes sufficient pedagogical, technological and organisational dimensions. While the content of these courses is largely determined by the requirements of the schools/ participants, the service can also provide a bespoke level of support (Marcus-Quinn et al., 2019a; Marcus-Quinn and McGarr, 2015). In the context of COVID-19, PDST has provided additional online resources to support distance learning, some of which are targeted at second-level teachers (www.pdst.ie/DistanceLearning).

Finally, in 2018, the DES issued a directive to all schools requesting that schools consult with their school community (including teachers, students and parents) regarding the use of smartphones, tablets, and video recording devices (DES, 2018c). The purpose of this was to work towards developing a (or updating an existing) whole-school policy for their use. Distraction is emerging as a key concern for both parents and teachers as more schools embrace a one-device-per-student policy (Dunne et al., 2020; Dempsey et al., 2019). However, the debate has often been preoccupied with whether to ban mobile phones and other personal digital devices in schools. Some commentators have argued that this misses the point, and that the merits or otherwise of digital technologies in schools and classrooms are far more complex than the debate suggests (Marcus-Quinn et al., 2019b). The changes around General Data Protection Regulation (GDPR) have also created more of an administrative load on all stakeholders and online safety is an ongoing 
concern for all. The Webwise programme, which is managed by the PDST, is a key online safety educational resource. The website (www.webwise.ie) promotes the autonomous, effective and safe use of the internet by young people through a sustained information and awareness strategy targeting school leaders, teachers, parents and young people themselves with consistent and relevant messages.

Curricular and assessment policy reforms in recent years have underpinned moves to embed technologies into classroom practice in Ireland. But, as discussed in the literature review, the evidence suggests that students' experience of technology at school varies hugely, as school autonomy allows some to market themselves as 'tech driven', while others take a more blended or traditional approach (MarcusQuinn et al., 2019a; McCoy et al., 2016). Some schools have rapidly adopted new technologies, but subsequently took a U-turn (Dunne et al., 2020). Evidence also highlights that the challenge of integrating technology is no longer understood as simply a challenge of 'integration' but rather as a realignment of the existing education system toward a more student-centred experience (McGarr and Johnson, 2019). At both primary and second levels, teachers' ICT competencies are not formally assessed. However, within the context of a school inspection, ICT use is noted (Marcus-Quinn et al., 2019b). While schools are moving towards a culture of self-evaluation, it has been noted that there is still an unclear understanding of the extent and nature of technology integration in schools and the role that technology plays in school improvement (Marcus-Quinn et al., 2019c). However, a Digital Learning Framework (DLF), informed by the UNESCO ICT Competency Framework and other European and International frameworks, has been available to all schools since 2018. This is intended to guide them on how to embed digital technologies in their teaching and learning practices and in leadership and management and provides a common reference/language for schools to understand what embedding digital technologies means. The DLF supports and complements the School Self Evaluation (SSE) process and is intended to allow schools to evaluate their own progress and measure where they stand against benchmarks of effective and highly effective practices in the use of digital technologies in teaching and learning and leadership and management. It is intended to help schools to identify their own training needs and guide the DES funded support services to target their CPD programmes to meet those needs. The DES acknowledges that the embedding of digital technologies in school practice will take time and is committed to ensuring that differentiated models of CPD continues to be made available to schools for the implementation of the DLF and the embedding of digital technologies across all school activity.

These distinct features of policy and provision at second level provide a valuable backdrop to the next section which assesses empirical evidence on the role and impact of digital technologies in teaching and learning, with a particular focus on the potential impact of the mass shift to distance learning modes. 


\subsection{LITERATURE REVIEW}

Worldwide, school closures aimed at slowing the spread of COVID-19 are estimated to have affected the lives of over 60 per cent of the student population, impacting more than one billion learners (UNESCO, 2020b). School closures are expected to particularly affect disadvantaged populations, thus exacerbating existing inequalities. Yet the closing of schools has not halted teaching and learning. Instead, education systems have mobilised to transition to distance education. To support rapid policymaking, research has rallied to both gather data to better understand the situation as it is unfolding, and to draw on existing research that provides insights into how to address these momentous developments. The emerging body of research illustrates key aspects that policymakers might consider as they support the transition to distance learning and plan for schools to reopen. These aspects are covered in the current literature review.

First, as we will discuss in the next subsection, some studies have emphasised the potential for learning loss among students. ${ }^{4}$ These studies suggest that school closures will likely amplify existing inequalities, may result in higher drop-out rates, as well as increased learning loss for particular subjects, most notably Mathematics. Second, it is important to note that the estimated loss of learning and negative consequences of school closure are predicated on two factors: (1) the effectiveness of distance education provision compared to face-to-face instruction; and (2) the organisation of distance education in the context of COVID-19. Studies have shown that distance education can be as effective as faceto-face instruction, offering some hope that the impact of school closures can be mitigated (see Section 1.3.2). However, existing studies on the effectiveness of distance education are not fully representative of the realities posed by the rapid shift to distance education - with inequalities evident between groups - as discussed in Section 1.3.3. Section 1.3.4 aims to provide an overview on the readiness of Ireland to transition to distance education, drawing on past studies as well as data on technology access. As schools consider reopening, research suggests that a range of areas needs to be considered by schools and policymakers, including the timing and staging of student return, the nature of teaching and prioritisation of curricular areas, and the potential use of the summer period (Section 1.3.5).

The closure of schools causes major (and unequal) interruption in students' learning; even a relatively short period of missed school has been shown to have consequences for skill growth (Burgess and Sievertsen, 2020). The term 'learning loss' is defined as a measure or estimate of the impact of school interruption, in this case due to the shift to distance learning. 


\subsubsection{Estimated effects of school closures on learning and wellbeing}

Several studies have focused on estimating the loss of learning due to school closures. While some commentators have expressed concern about this line of research, particularly the validity of equating school absence with a gap in learning, such studies point towards some useful policy areas. Using two distinct methods, Burgess and Sievertsen (2020) estimate a 6 per cent loss in learning over a 12-week period of school closure. The authors draw from similar research conducted in Sweden, as well as the documented positive relationship between instructional time on Programme for International Student Assessment (PISA) test scores. The relationship between instructional time and test scores is weaker in developed countries (Lavy, 2015). Notably, there is no consensus in the literature on the relationship between instructional time and academic performance (Sahlberg, 2015). Drawing on previous studies that look at the effect of learning loss during the summer, research on school closure during natural disasters and the effect of school absences, Kuhfeld et al. (2020) estimate that, in the US, across the whole academic year students will only experience 63-68 per cent of learning gains compared with a typical school year in reading and 37-50 per cent in Mathematics. In another US-based study, Dorn et al. (2020) estimate that drop-out rates among high-school students will increase between 2-9 per cent due to school closures. Both studies highlight that negative effects of school closure are most likely to affect ethnic minorities and amplify existing inequalities. Loss of learning can also be exacerbated by the cancellation of exams. Prior studies have also shown that exam cancellations may lead to decreased exam performance in the following years due to the loss of information associated with exam results. This effect is stronger for disadvantaged populations (Andersen and Nielsen, 2019).

School closures are likely to add to the significant existing inequalities for which education has traditionally been viewed as a solution. Notably, the financial, cultural and educational characteristics of home environments are likely to add to the effects of school closure (Dahl and Lochner, 2012). In Ireland, socio-economic characteristics have been shown to reflect in the quality of the out-of-school activities among students, which in return affect academic performance (McCoy et al., 2012).

There may also be significant challenges to mental health and wellbeing in schools after the pandemic (Lee, 2020). School provides an important community for young people, as well as structure for their everyday lives. Over recent months they may have experienced exposure to personal and family stressors, impacting on their mental health and wellbeing. A recent Central Statistics Office survey on life satisfaction during the pandemic (CSO, June 2020) showed those aged 18-34 years were the least likely to report high overall life satisfaction and had the largest decrease of all age groups between 2018 and April 2020. Adverse events, environments, and family stressors in childhood and adolescence are also 
associated with increased academic and developmental risk (Blodgett and Lanigan, 2018; Mayer, 2002). Socio-emotional wellbeing is fundamental to student learning (Panayiotou et al., 2019), so the evidence points to the importance of prioritising social and emotional supports once schools reopen.

\subsubsection{Effectiveness of distance education}

Several meta-analysis studies offer ample and consistent evidence to suggest that, on average, there is no statistically significant difference in effectiveness between distance education and face-to face education as modes of instruction (Allen et al., 2004; Cavanaugh, 2001; Cavanaugh et al., 2004; Means et al., 2013; Zhao et al., 2005). Effectiveness is not affected by synchronous or asynchronous provision (Means et al., 2013). These studies have also identified key research gaps. First, this research primarily evaluates the effectiveness of distance education with adult learners, with primary and second-level studies being under-represented (Cavanaugh, 2001; Cavanaugh et al., 2004; Means et al., 2013, Allen et al., 2004). Second, not enough is known more broadly about the student characteristics that lead to effective distance education (Zhao et al., 2005). Some evidence in this space suggests that online learning success is influenced by four student characteristics: (1) achievement and self-esteem beliefs, (2) responsibility/risk taking orientation,

(3) technology skills and access, (4) organisation and self-regulation skills (Roblyer and Marshall, 2002).

A few meta-analysis studies have particularly focused on the effectiveness of distance education in the primary and second-level space (Cavanaugh, 2001; Cavanaugh et al., 2004). Similarly, these studies found no statistically significant difference in effectiveness between distance education programmes and face-toface instruction. While comparing the effectiveness of online education provision by learner type, Means et al. (2013) found no statistically significant difference between primary and second-level students and college students. In one review, programmes that supplemented classroom instruction and were taught less frequently were most effective (Cavanaugh, 2001). Cavanaugh et al. (2004) suggest that:

as distance education is currently practiced, educators and other stakeholders can reasonably expect learning in a well-designed distance education environment to be equivalent to learning in a well-designed classroom environment. (p. 20).

Studies on the effectiveness of distance education have become less prevalent after the early 2000s, leaving a gap in the literature on understanding the effects of full-time distance education provision at the primary and second level (Rice, 2006). 
None of the meta-analyses on the effectiveness of distance education include findings on students with special educational needs (SEN). Some recent evidence suggests that online courses may decrease the likelihood of drop-out among US high-school students with disabilities (Sublett and Chang, 2019). In a review of the literature on online instruction for special education at the primary and second level, Vasquez and Straub (2012) identify only six empirical studies that explore this question. The authors conclude that the existing literature does not offer enough evidence to ascertain the effectiveness of online instruction for SEN students.

While well-designed distance education programmes are effective, the swift transition to distance education during a pandemic did not necessarily provide suitable conditions for putting such programmes in place. Existing literature has also not been able to document the effectiveness of fully online programmes, as well as the student characteristics that make success in online programmes more likely. As such, it is particularly important to document how distance education is provided during COVID-19 and how it affects key populations - particularly students with SEN. Our study aims to address this gap.

\subsubsection{Distance education during COVID-19}

Research with school stakeholders in Ireland and other countries following school closures indicates that schools have shifted to distance education, but also that they face challenges in this transition. As previously suggested by the academic literature, these challenges are more likely to affect socio-economically disadvantaged populations, including students whose parents did not complete third-level education, those from working class families and students with SEN.

A study based on multiple surveys with teachers and other stakeholders in the UK found that pupils from middle class homes are twice as likely (30 per cent) as students from working class homes (16 per cent) to take part in live and recorded lessons online every day. The study also finds that students from working class backgrounds spend less time on learning everyday than students from middle class families. Divergences between schools can also be seen across other indicators, including the amount of work teachers received back from students, and the quality of work received (Cullinane and Montacute, 2020). Gaps between free lunch beneficiaries and their peers are also noted in the UK (Montacute, 2020). Another study with school leaders and teachers in primary and secondary schools in the UK found similar gaps. Respondents noted increased disengagement among disadvantaged pupils and among students who have limited ICT access and lack space to study at home (Lucas et al., 2020).

Differences are not only visible in school-level provision, but also in homeschooling provision. In the UK, parents with graduate level education were found 
to engage in home-schooling for a greater number of days a week than parents without such education (Anders et al., April 2020). Using nationally representative data from parents in the Netherlands, Bol (2020) finds that students from more advantaged backgrounds 'receive much more parental support and have more resources'. While 75 per cent of parents with higher education feel equipped to support their children, only 40 per cent of parents with lower levels of education express confidence in their ability to offer support. The study also finds that parents feel more equipped to support girls rather than boys.

Evidence on gaps between groups also emerged in recent Irish research based on 2,808 primary school leaders. Using a rapid survey, Burke and Dempsey (2020) report that 63.3 per cent of school leaders believe that the school closures will have a 'negative' effect on pupils. Moreover, 71 per cent of school leaders at mainstream schools with special classes and 79.4 per cent at special schools anticipate a negative impact on pupils. In a follow-up study conducted two months after the initial survey, the authors have found that difficulties persist for SEN students and their parents, as well as students in overcrowded accommodation (Dempsey and Burke, 2020). In both surveys, primary school leaders expressed considerable concerns about the digital divide they see among students - including broadband and digital device access. These concerns are seen to particularly impact on students at DEIS schools. There is also some evidence to suggest that there is relatively low engagement with home-schooling in Ireland, as parents are juggling multiple responsibilities, including work (Doyle, April 2020).

\subsubsection{Distance education readiness in Ireland}

Laprairie and Hinson (2006) argue that schools need to develop plans to ensure they are able to transition to distance education 'when disaster strikes'. Based on consultations with local stakeholders following Hurricane Katrina, the authors suggest that schools should ensure two basic conditions are in place to support this transition. First, it is important to develop the necessary infrastructure. This includes ensuring that students (and teachers) have access to affordable internet service and modern devices with proper licenses (including educational software, virus protection, and internet filters). At the same time, unintended consequences regarding access to devices - particularly mobile phones - and screen time more generally, need to be considered (Dempsey et al., 2019; 2020). While Ireland has made substantial progress in recent years both in ensuring that schools have access to broadband and equipping teachers with the relevant ICT skills (McCoy et al., 2016), the quality of ICT that students have access to at home has not received extensive policy attention.

Second, it is important to offer appropriate ICT training to students and teachers. Prior research has emphasised that technology-focused professional development 
is one of the factors that increases the likelihood of teachers adopting and integrating ICT in their teaching (Buabeng-Andoh, 2012). In a study on how teachers viewed professional development opportunities made available online and aimed to upskill their technology use, Irish teachers particularly valued the flexibility that the online environment provides and appreciated being able to take advantage of extra personal vacation days in lieu of their training (Hagan, 2013). A separate study found that Irish teachers had positive attitudes towards ICT, but that they were most likely to use ICT in prepping for classes rather than in the classroom (Coyne et al., 2016). Research based on the Irish context has long argued that more professional development opportunities are needed for teachers to better make use of ICT (McCoy et al., 2016).

More broadly, comparative data collected by the $\operatorname{OECD}(2015 ; 2020)$ through the PISA assessment and data from the nationally representative Growing Up in Ireland study (GUI) provide some useful evidence on the digital readiness of Irish students. In 2011-2012, 95.8 per cent of 13-year-olds included in the GUI study had a computer at home. However, only 34.4 per cent had a computer or laptop in their bedroom, suggesting that they may have to share usage with another family member. While the GUI study tracked students at 17, no data about computer availability at home or in their rooms were collected. PISA data collected in 2012 are relatively consistent with the GUI figures, illustrating that 98.7 per cent of 15 -year-olds in Ireland had at least one computer at home. This places Ireland above average across OECD countries. In the same year, Irish students also had a higher performance in digital reading than the OECD average. Similarly, a higher fraction of Irish disadvantaged students had an internet connection at home (94.8 per cent) than the OECD average.

However, 2018 PISA data (OECD, 2020) suggest that for those from the bottom quartile of the socio-economic distribution, only 73 per cent of students reported having a computer they could use for schoolwork at home. This figure is lower than the OECD average, which stood at 78 per cent. In 2018, 47 per cent of students in Ireland studied at a school whose principal 'agreed' or 'strongly agreed' that 'effective professional resources designed to help teachers learn how to use digital devices were available'. This figure was lower than the average across OECD countries (65 per cent). These figures suggest that access to suitable digital devices in Ireland may be lacking among poorer students. They also suggest that there was a mixed level of readiness among teachers to transition to distance education prior to school closure, reemphasising the need for targeted professional development.

\subsubsection{Considerations for school reopening}

It is paramount that policies and structures are put in place to support the effective provision of distance education both to minimise learning loss and the 
exacerbation of existing inequalities, but also to prepare for scenarios in which distance learning needs to continue for an extended period. Infrastructure and training considerations need to be addressed (Laprairie and Hinson, 2006). Several studies have particularly emphasised the need for additional professional development opportunities for teachers (Buabeng-Andoh, 2012; Coyne et al., 2016; Dempsey and Burke, 2020; Hagan, 2013).

The academic literature has started to consider what steps education systems and schools need to take in order to reopen. However, across most countries, these steps have not yet been taken in practice. Hallas (2020) notes that key aspects need to be addressed before reopening schools, arguing that antibody testing may need to be put in place for students, protocols may need to be designed for students that test positive, and the risks to teachers need to be considered. Notably, research also shows that students may not respect stay-at-home regulations, indicating that social contact continues to occur among students even after school closures (Brooks at al., 2020).

Multiple studies suggest a key priority for schools and education systems is to address the multiple inequalities that were compounded during school closure. Several approaches have been proposed:

- A more extensive implementation of differentiated teaching methods and use of universal design learning once schools open (Kuhfeld et al., 2020);

- Enhanced learning opportunities over the summer (including by recruiting volunteer tutors) and through organising virtual summer camps (Dorn et al., 2020);

- Operating staggered school opening dates, with students that have been most impacted joining school first (Cullinane and Montacute, 2020);

- Ensure that learning interventions target subjects that are most affected by loss of learning, particularly Mathematics (Kuhfeld et al., 2020);

- Mediate possible negative effects that derive from the cancellation of national testing (Andersen and Nielsen, 2019). It is however unclear if estimated/ projected grades would mitigate some of this effect.

\subsection{METHODOLOGY}

Increasingly, mixed-method research designs are seen as the gold standard for examining interventions and practices in heterogeneous environments, with this becoming a highly valued research approach in the Irish context over the last ten years. Most recently, mixed-method research has examined the impact of the changes in the Leaving Certificate grading scheme to student perceptions and behaviour (McCoy et al., 2019a). Of particular relevance to this study, a large-scale 
study on the role and impact of digital technologies in teaching and learning across second-level schools also adopted a mixed-method design (McCoy et al., 2016). There has been considerable international debate about 'what evidence counts', and a lack of consensus over the relative benefits of different sources and types of information. In particular, there has been disagreement over the relative value of randomised controlled trials (where particular interventions are introduced in 'experimental' conditions) and research which depicts 'real-life' qualitative variation (see, for example, Slavin, 2004; Bridges, 2008; and Wiseman, 2010). However, it is increasingly acknowledged that it is vital to understand local context, highlighting the importance of a mixed-method approach. Evidence repeatedly highlights that:

school leadership, school ethos, school context, teacher competence and conviction, the composition of the students - all of these are pertinent to the success or failure of different educational practices or to the adaptations of those practices that are necessary if they are to succeed. This is why case studies, 'thick descriptions' in Bob Stake's term, are so important as a source of understanding of educational practice. (Bridges, p.130, 2008).

In adopting a mixed-method approach, we combine the breadth of nationally representative survey data with in-depth case study research, providing the 'thick descriptions' which offer valuable insights into experiences and responses across different school settings at this extraordinary time.

\subsubsection{Survey phase}

All of Ireland's 723 second-level schools were in the sampling frame for the online survey. To raise awareness and to promote engagement, an email containing the online survey link was first sent out to principals on 13 May 2020 via the National Association of Principals and Deputy Principals (NAPD). Direct emails were subsequently sent to schools with the survey closing on 29 May 2020. During the period the survey was in the field, schools would have had approximately two months of experiences of post-closure distance learning.

The 15-minute online survey contained a mixture of quantitative and open-ended qualitative questions developed by the research team, drawing on international research and policy issues particular to Ireland. A 33 per cent response rate was achieved upon the closing of the survey, with 236 responses submitted. ${ }^{5}$ The survey achieved responses from a wide geographical spread across the Republic of

We took the decision to exclude respondents who responded to few questions. In a small number of cases, two leaders responded on behalf of one school. In these cases, we retained the information for the respondent who completed more questions. 
Ireland (see Table 1), and a representative sample in terms of key characteristics, including DEIS status and school type (see Table 2).

TABLE 1 COMPARISON BETWEEN SAMPLE AND POPULATION OF SCHOOLS BY REGION

\begin{tabular}{|l|c|c|}
\hline \multicolumn{1}{c|}{ Region } & Survey sample \% & School population \% \\
\hline Connacht & 13.2 & 14.1 \\
\hline Dublin & 27.8 & 25.3 \\
\hline Leinster excluding Dublin & 25.2 & 25.4 \\
\hline Munster & 26.9 & 28.2 \\
\hline Ulster & 6.8 & 6.9 \\
\hline
\end{tabular}

Source: Authors' analysis.

TABLE 2 COMPARISON BETWEEN SAMPLE AND POPULATION OF SCHOOLS BY SCHOOL TYPE

\begin{tabular}{|l|c|c|}
\hline \multicolumn{1}{c|}{ School type } & Survey sample \% & School population \% \\
\hline DEIS school & 28.2 & 27.3 \\
\hline Community & 10.7 & 11.3 \\
\hline Comprehensive & 3.0 & 1.9 \\
\hline Voluntary secondary & 49.6 & 52.6 \\
\hline Education Training Board (ETB) & 36.8 & 34 \\
\hline
\end{tabular}

Sources: Authors' analysis; DES (2019a).

For much of the analysis in this report, the responses from all schools are used. As a small number of schools did not provide their Roll Number, where analyses are done based on School Roll Number the sample size is slightly reduced.

Upon completion of the online survey, participants were invited to voluntarily nominate themselves for a follow-up, in-depth qualitative interview to greater explore the issues they face.

Of particular interest to this research report is the potential for teaching and learning via online platforms to facilitate education at a distance. Within this, home access to and use of broadband by teachers and students is of relevance, as well as access to and use of electronic ICT devices. A number of questions in the survey and interviews attempt to explore these topics. In addition, indicators of the coverage of high-speed broadband available in the catchment areas of schools were devised using broadband coverage maps provided by DCCAE (DCCAE, 2019a). An indicator was created for a 'low broadband availability' catchment area where high-speed broadband was available to less than 90 per cent of residences in the catchment area of schools according to the NBP map. The socioeconomic profile of the school catchment areas is also of interest, indicated by the median gross 
annual household income from Census 2016 Small Area Population Statistics (SAPS). An indicator of 'lower' incomes in the school's catchment area was created where incomes in the school's catchment area were lower than the average across all school catchment areas. ${ }^{6}$ This socioeconomic indicator may also provide a proxy for the availability of ICT devices in the home. Details of the demarcation of school catchment areas and the broadband indicators are provided in the accompanying Appendix.

\subsubsection{Case study interviews}

The research team carried out qualitative interviews across ten schools in the last week of May and first week of June 2020. Previous research has shown that it is possible to capture a good deal of variation using ten schools (see for example McCoy et al., 2014). The schools were selected to represent important dimensions of variation in school composition and organisation. The schools were selected on the basis of two key dimensions: social mix and region. Over and above these two dimensions, schools were selected to capture a variety in terms of school sector and size. As shown in Table 3, the final sample included two DEIS schools; voluntary secondary, Education and Training Board (ETB) and community schools; and a geographical spread (three schools from Dublin, three from Leinster (excluding Dublin), one Connacht and three Munster). No Irish-medium schools or fee-paying schools were included in the case-study research.

Interviews were recorded, by consent, and transcribed verbatim. Members of the research team conducted all interviews. The qualitative data were analysed in NVivo across a range of key themes. At no time are individual schools identified, the objective being to unpack experiences and challenges across diverse school settings. For each of the four thematic sections of this report the quantitative data and open-ended responses available from the online survey are combined with the qualitative evidence from the in-depth interviews to provide as rich an evidence base as possible.

There may be potential for both the local area catchment variables of 'lower broadband availability' and 'lower incomes' to measure some degree of urbanity and rurality in a similar way. Some lower-income areas may well also have no high-speed broadband available. A Chi-squared independence test of these two categorical variables, in which the frequency of each value for one categorical variable is compared across the values of the second categorical variable, suggests that there is indeed a relationship (Chi-squared $=65.4, p=0.00$ ). For the continuous version of these variables, the correlation is 0.6. A scatter plot in the Appendix, Figure A.5, demonstrates this relationship. 
TABLE 3 DETAILS ON THE CASE STUDY SCHOOLS

\begin{tabular}{|l|l|l|l|}
\hline \multicolumn{1}{|c|}{ School } & \multicolumn{1}{c|}{ DEIS } & \multicolumn{1}{c|}{ Type } & \multicolumn{1}{c|}{ Region } \\
\hline Principal 1 & Non-DEIS & Voluntary Secondary & Connacht \\
\hline Principal 2 & Non-DEIS & Voluntary Secondary & Leinster excluding Dublin \\
\hline Principal 3 & DEIS & Voluntary Secondary & Dublin \\
\hline Principal 4 & Non-DEIS & Voluntary Secondary & Munster \\
\hline Principal 5 & Non-DEIS & Voluntary Secondary & Munster \\
\hline Principal 6 & Non-DEIS & Community & Leinster excluding Dublin \\
\hline Principal 7 & Non-DEIS & ETB & Dublin \\
\hline Principal 8 & DEIS & Voluntary Secondary & Munster \\
\hline Principal 9 & Non-DEIS & ETB & Dublin \\
\hline Principal 10 & Non-DEIS & Voluntary Secondary & Leinster excluding Dublin \\
\hline
\end{tabular}

Source: Authors' analysis.

\subsubsection{Limitations of research undertaken}

By necessity, there are limitations in the evidence presented. Data were collected within a narrow timeframe, during a period of considerable upheaval for school leaders. Decisions on the unprecedented use of calculated grading for Leaving Certificate students were being agreed and disseminated to management bodies and school leaders. School leaders were tasked with overseeing this process in their schools, managing concerns and expectations from all concerned, teachers, students and parents. Achieving a response rate of 33 per cent in these circumstances reflects the commitment of school leaders in Ireland. It is important to note that the sample is highly representative of the national population of schools, across key organisational characteristics including DEIS status, school types and regional location, allowing confidence in the results emerging.

We also note that school catchment areas used in the analysis of broadband connectivity are imputed rather than directly observed. This likely implies some imprecision in the assignment of local broadband coverage to schools.

The remainder of this report is structured as follows. Chapter 2 outlines the response of second-level schools to the school building closures. Chapter 3 documents the experiences of teaching and learning during the closure period. The impact of the closures on a variety of key groups is explored in Chapter 4 . The views of research participants looking ahead to the future reopening of schools for the academic year 2020/2021 and beyond are reported in Chapter 5. The final section, Chapter 6, concludes with a discussion of the findings and implications for policymaking. 


\section{CHAPTER 2}

\section{Response of schools to closures}

Second-level schools across the country closed their buildings on Thursday 12 March 2020, the same day as the government announced the shutdown. Overnight, teaching and learning switched from face-to-face to home-based settings. In an official statement issued on the day of the mandated closures, DES outlined that

schools will be asked to continue to plan lessons and, where possible, provide online resources for students or online lessons where schools are equipped to do so. Schools are asked to be conscious of students that may not have access to online facilities and to consider this actively in their response. (DES, 2020h)

Furthermore, schools were asked to prioritise supporting exam year students to continue in their preparations for the State examinations. The response of secondlevel schools to maintaining a continuity of education over the closures is documented in this section.

\section{$2.1 \quad$ DIGITAL DIVIDE}

In the online survey and interviews school leaders provided insights to the homebased digital resources to which their students had access. The issue of a digital divide - where a gap in access to ICT, be that due to a lack of access to high-speed broadband and/or a lack of access to digital devices - was a salient issue for schools in implementing distance learning. Figure 2.1 shows that almost half of all schools (48.0 per cent) stated that a digital divide ${ }^{7}$ relating to both broadband and devices existed for their students. For DEIS schools, 57.6 per cent reported that they were affected by both limitations in broadband and device access. Among schools for which the catchment area was characterised by lower high-speed broadband coverage $^{8} 56.7$ per cent reported issues with both types of digital access; significantly different to $\mathbf{3 7 . 1}$ per cent where there was high availability of broadband (Chi-squared ${ }^{9}=25.2, p=0.00$ ). Similarly, 58.0 per cent of schools in which the catchment area was characterised by lower median household

School leaders were asked if a digital divide exists for their students, relating to either access to ICT or access to broadband, or both. We assume that responses reflect whether school leaders believe some of their students have access, but others do not.

8 Catchment with lower broadband availability: high-speed broadband was available to less than 90 per cent of residences in the catchment area of schools according to the National Broadband Plan map (DCCAE, 2019).

9 We employ a Chi-squared $(X 2)$ test to test the hypothesis that there is a difference in the distribution of responses between two sub-samples, for example between schools whose catchment areas have a higher level of high-speed broadband availability and schools with lower broadband availability in their catchment area. In this test, the frequency of each response category for a given categorical variable is compared across two sub-samples. This test calculates a statistic with an associated $p$-value. A p-value indicates the probability of obtaining results as extreme as the observed result of a hypothesis test when the null hypothesis is correct. 
incomes ${ }^{10}$ reported issues with both types of digital access, while 35.9 per cent did so for schools with higher income catchments (Chi-squared $=24.8, p=0.00$ ).

FIGURE 2.1 IN YOUR OPINION, IS THERE A DIGITAL DIVIDE AMONG STUDENTS OF YOUR SCHOOL?

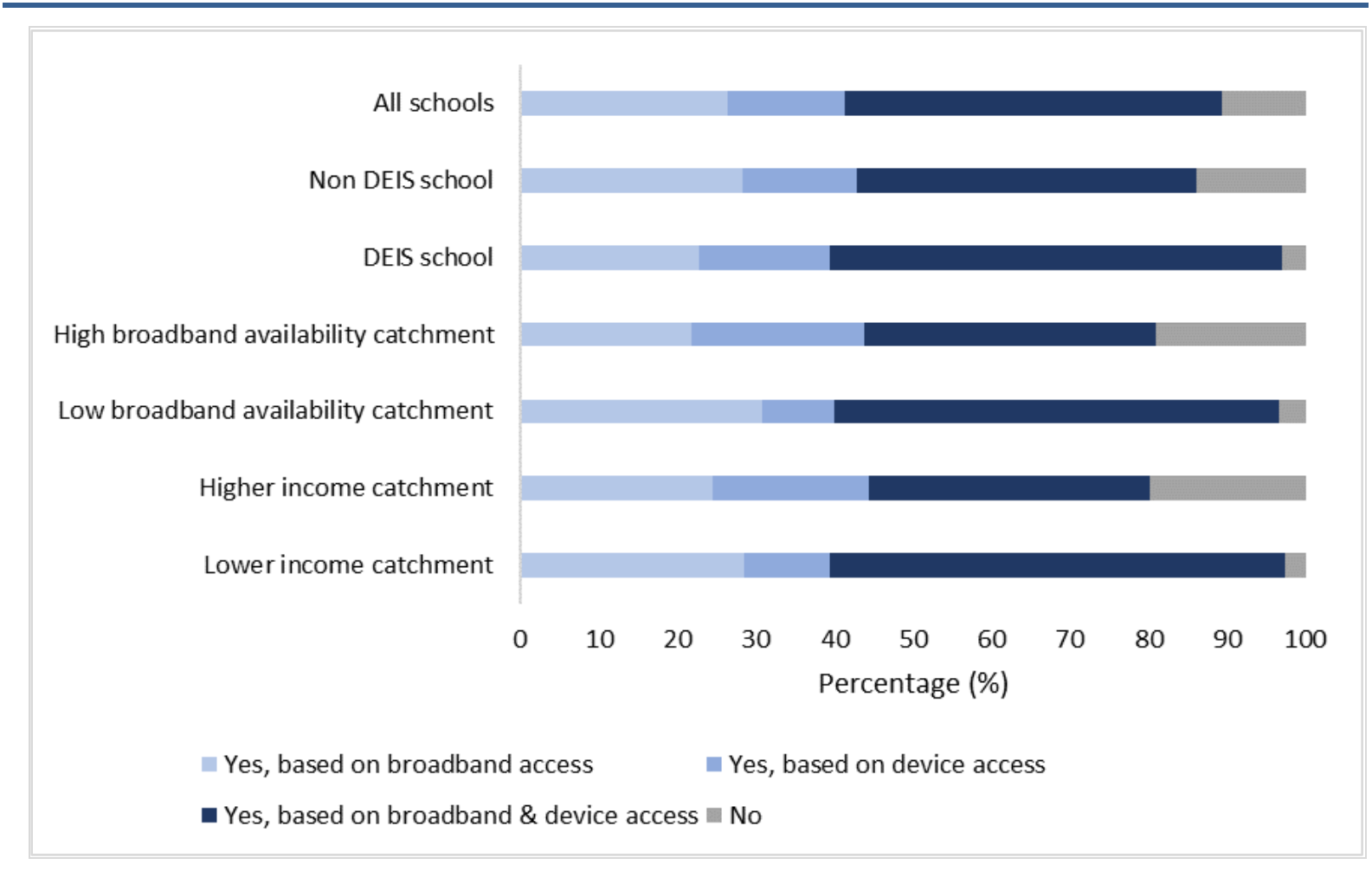

Source: ESRI online survey of school leaders.

Note: $\quad$ Based on 227 responses.

Figure 2.2 shows that more than half of schools surveyed (53.5 per cent) reported providing ICT equipment to pupils in response to the closures, with a fifth (19.9 per cent) of schools in the process of sourcing/acquiring equipment for pupils. Schools typically provided school laptops, school tablets and, to a lesser extent, mobile internet/hotspot devices (e.g. USB dongle). Leaving Certificate sixth year students and students with SEN were identified as priority groups. In open-ended responses it was apparent that students typically had to self-identify their needs and request devices from schools. 


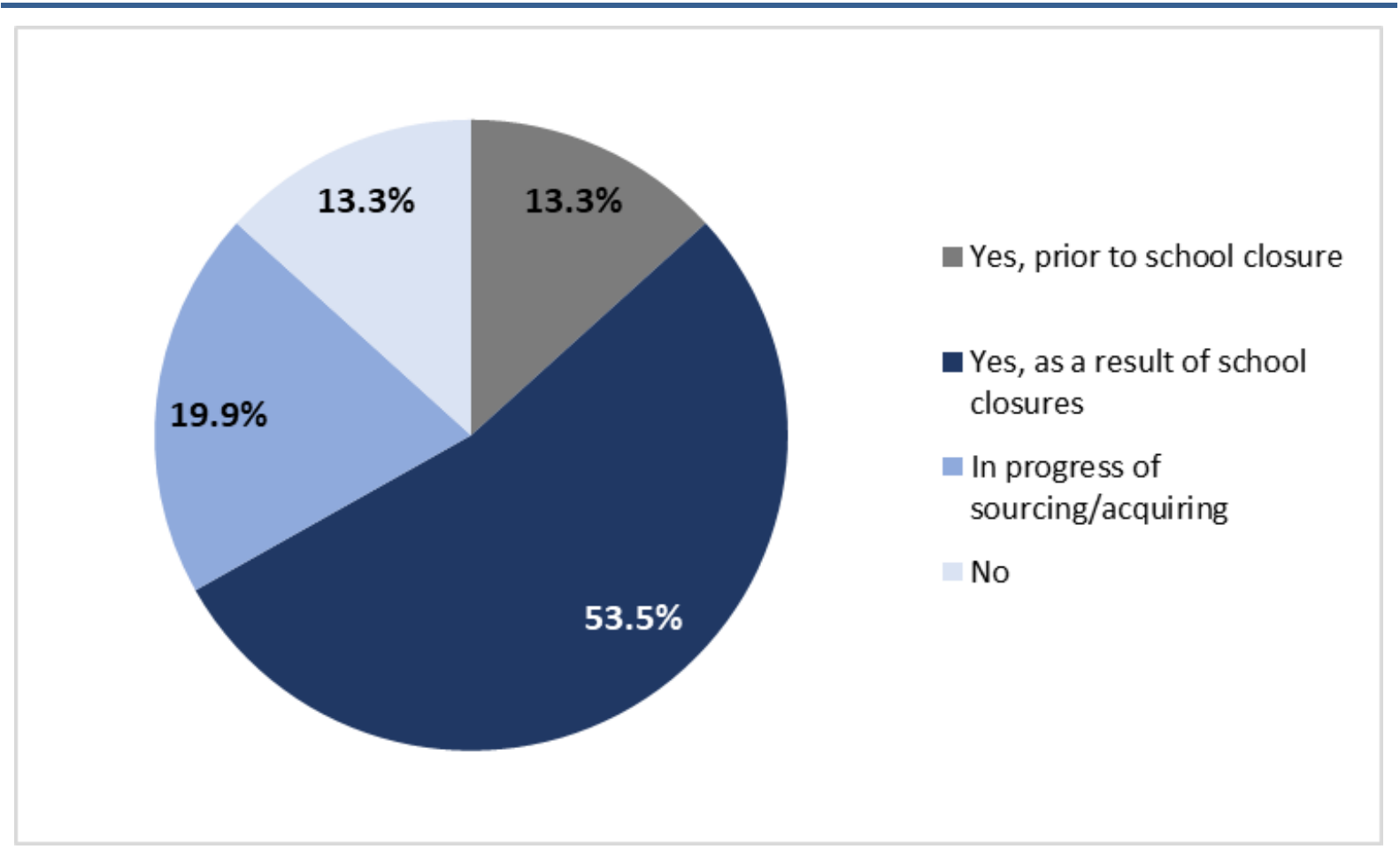

Source: ESRI online survey of second-level school leaders.

Note: $\quad$ Based on 226 responses.

\subsection{APPROACHES TO DISTANCE TEACHING AND LEARNING}

A variety of approaches was adopted by schools to support student's learning. Across all schools, 18.0 per cent reported that the use of live online video classes occurred for 'all classes', 38.9 per cent reported 'most classes' occurred live online and 40.2 per cent reported 'some classes' were held live online. Just 3.0 per cent of schools reported that virtual live teaching did not occur for any classes. However, there were differences in the use of live virtual classrooms across schools with varying broadband coverage and household incomes in the catchment areas (Figure 2.3). In schools for which the catchment area had lower broadband coverage 61.8 per cent delivered 'all' or 'most' classes via live video, compared to 89.9 per cent for schools with good broadband coverage in the catchment area (Chi-squared $=11.4, p=0.01$ ). In schools for which the catchment area was characterised by lower incomes, 'all' or 'most' classes were conducted via live streaming for 49.2 per cent, compared to 65.5 per cent for schools with higher income catchments (Chi-squared $=10.7, p=0.013$ ). 


\section{FIGURE 2.3 LIVE VIRTUAL LEARNING VIA LIVE VIDEO E.G. ZOOM, GOOGLE HANGOUTS}

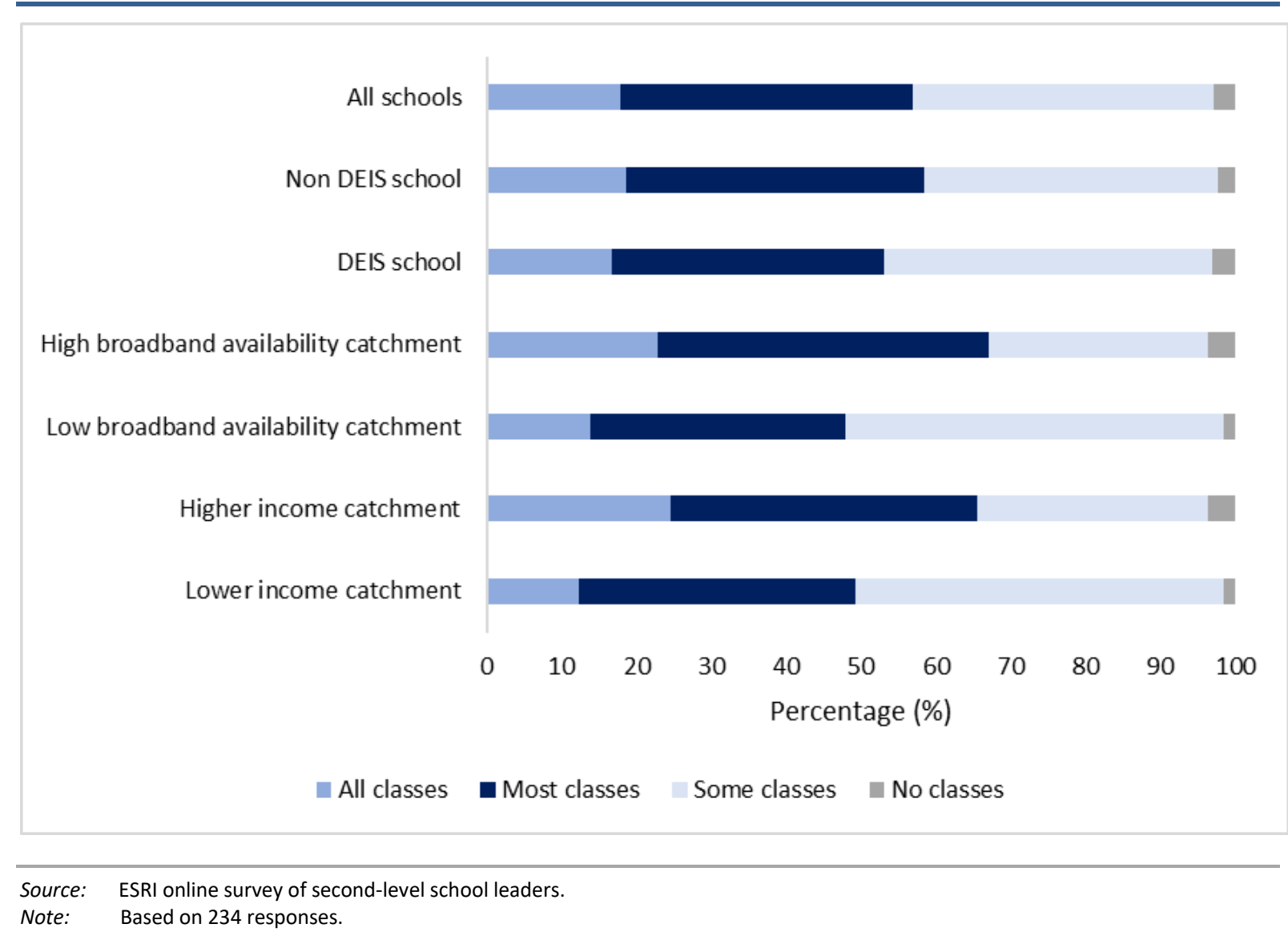

The use of pre-recorded videos and audio, shared presentations (e.g. PowerPoint, Prezi), Google Classroom, and Microsoft Teams were reported for at least 'some' classes in almost all schools. Other online education platforms such as Kahoot and StudyClix were used for at least 'some' classes for over 90 per cent of respondents. The use of more traditional paper-based learning (e.g. textbooks, worksheets) was adopted for 'all classes' in 16.8 per cent of schools, for 'most classes' in 16.8 per cent of schools and for 'some classes' in half of schools (50.4 per cent). The remaining 15.9 per cent of schools reported not using paper-based methods for remote learning. There was no difference in the use of paper-based learning across schools by DEIS status, or by characteristics of the school's catchment area.

In terms of student submission of work and the receipt of feedback, for 97.0 per cent of schools surveyed at least 'some' classes involved handwritten work submitted via email/online platform. Similarly, 97.4 per cent of schools asked for the submission of typed work via the internet for at least 'some' classes. The use of post or other physical means to submit handwritten work was employed by 43.5 per cent of surveyed schools for at least 'some' classes. Feedback for students via online means was reported for all schools, while feedback for students via post or other physical means was reported in $\mathbf{4 2 . 2}$ per cent of schools. There was a greater reliance on post or other physical means to provide feedback to students for at least 'some' classes in DEIS schools (54.8 per cent) compared to non-DEIS 
schools (37.3 per cent) (Chi-squared $=8.8, p=0.04$ ). However, there was no statistical difference in the prevalence of physical forms of feedback between schools characterised by catchments with higher or lower broadband availability nor higher or lower incomes.

Across all schools, the use of phone-based communication for teaching and learning was reported for at least 'some' classes by 60.7 per cent of schools. For DEIS schools there was a greater reliance on phone-based means, with 82.5 per cent of respondents from DEIS schools reporting the use of Text/WhatsApp/Phone call for at least 'some' classes, compared to 52.4 per cent of non-DEIS schools (Chi-squared $=19.2, p=0.00$ ).

\subsection{NON-ACADEMIC CONTACT}

In terms of non-academic contact, 70.1 per cent of schools reported holding virtual assemblies, with a significant difference between schools in areas for which broadband coverage was good (78.9 per cent) relative to those for which broadband coverage was lower (63.0 per cent) (Chi-squared $=6.6, p=0.01$ ). Guidance counselling was offered by 97.4 per cent of schools surveyed, wellbeing supports by 97.8 per cent of schools and physical education by 77.9 per cent of schools. Extracurricular activities were reported for 52.5 per cent of schools, with more DEIS schools reporting extracurricular activities (63.1 per cent) than non-DEIS schools (47.7 per cent). In open-ended responses to describe non-academic contact with students, a variety of initiatives to foster a sense of school community at a distance were reported, including online competitions, quizzes, supportive videos, graduations, remote sports days and wellbeing promotion.

\subsubsection{Free-school meals programme}

Across all schools, one-third reported participation in the free-school meals programme during the shutdown (33.0 per cent), while just 2.6 per cent of schools which usually participated in the free-school meals programme did not participate over the school building closures period. For DEIS schools over the shutdown, 95.5 per cent were participating in the free school meals programme, but 4.6 per cent reported not participating where they usually did. Among non-DEIS schools, 8.0 per cent reported providing free school meals, with 3.1 per cent of schools who usually participated not participating during the period of closure. 


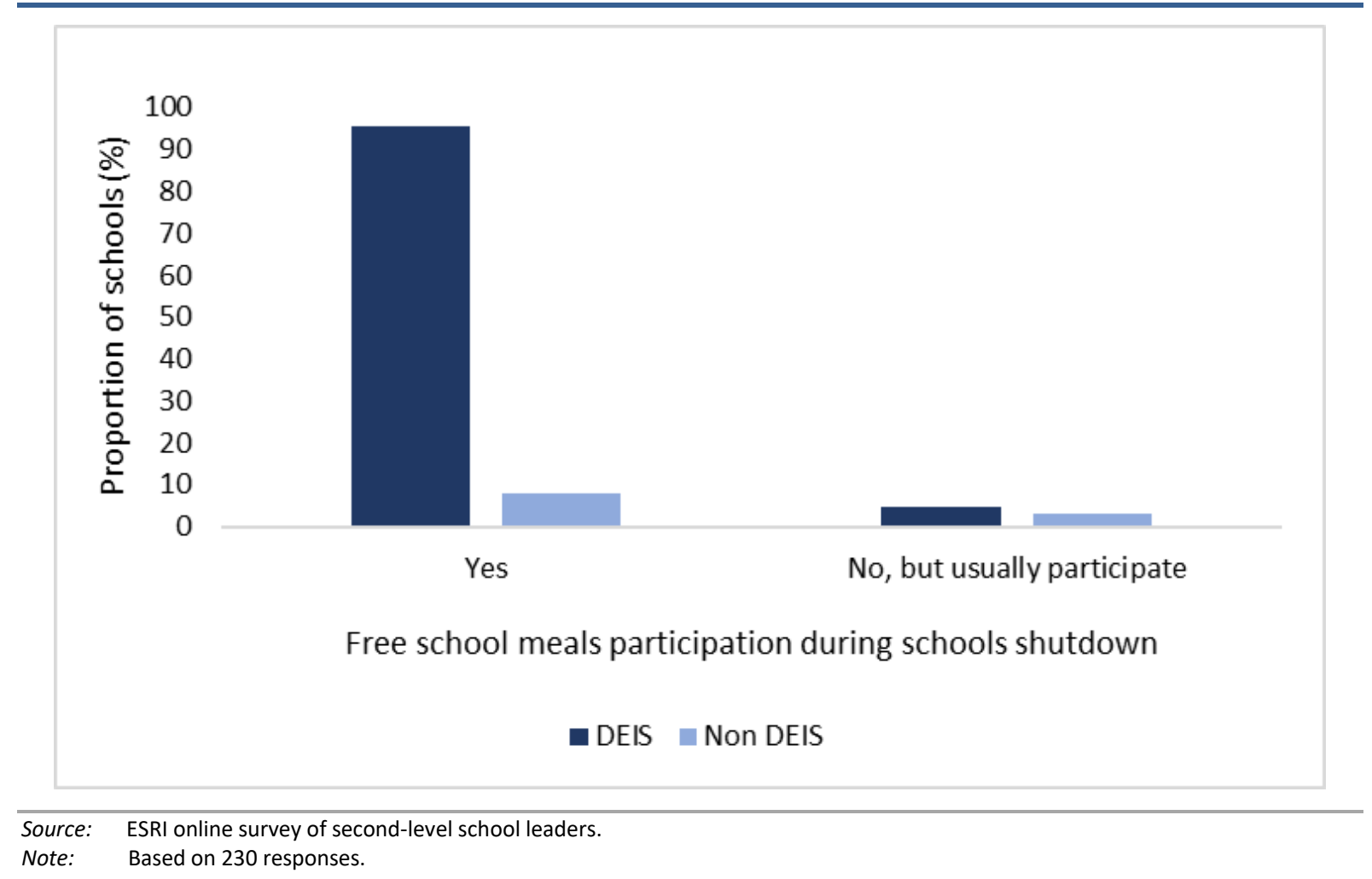

Furthermore, whether the student had a quiet place to study and a suitable desk to sit at was estimated to be much lower in DEIS schools. Among school leaders in DEIS schools, 21.5 per cent estimated that less than one-in-five students had a quiet place to study, compared to 1.9 per cent in non-DEIS schools. Similarly, among school leaders in DEIS schools, 21.5 per cent estimated that less than onein-five students had a suitable desk for studying, compared to 2.5 per cent in nonDEIS schools.

\subsubsection{Contact between groups}

Changes in the level of contact between the various parties involved in secondlevel schooling were reported in the online survey. Across all schools, greater levels of contact between schools and parents was reported for 72.0 per cent of schools, though 11.6 per cent reported less contact. Among the school's leadership, 45.4 per cent reported more frequent contact between school leaders, with 42.4 per cent reporting the same level of contact. More contact was reported between school leadership and teachers for 40.9 per cent of schools, 36.1 per cent reported the same level of contact while over a fifth (21.7 per cent) reported less contact than what had previously occurred between school leadership and teachers.

In terms of instructional contact and feedback between teachers and students, 28.3 per cent of schools reported more one-to-one contact, 18.7 per cent the same amount of contact while 53.1 per cent reported 'less' (35.2 per cent) or 'much less' 
(17.8 per cent) one-to-one contact. Greater group instruction/feedback was reported among 28.8 per cent of schools, while a third maintained similar grouplevel contact (32.3 per cent) and 38.9 per cent reported 'less' (34.1 per cent) or 'much less' (4.8 per cent) group contact.

\subsection{QUALITATIVE FINDINGS}

The impact of the closure of school buildings was starkly laid out across the qualitative responses and the interviews with school leaders. Generally, the shutdown period was a challenging time for schools, reflecting many of the issues facing the country at large - the stress and anxiety caused by the lockdown and the pandemic, the challenges of shifting to remote working and the uncertainty over what the rapidly changing situation would look like from week to week. Beyond this, there were many issues specific to schools, from engaging with some students who may have found it difficult to engage, to catering for large classes with varying levels of access to the devices and broadband necessary for online learning. In addition to these challenges and negative impacts, school leaders also point out positive impacts and important new knowledge gained during this period, especially around their appreciation for their school community and the clearly demonstrated potential of online or blended learning. This chapter will explore the response of schools to building closures and their experience of the lockdown period across three themes identified in the qualitative data; COVID-19 Situation, School Community and The Digital Divide.

\subsubsection{COVID-19 situation}

Along with the rest of Ireland and much of the world, schools were engulfed by the lockdown in March. Beyond the impact of school building closure, many of the sweeping changes to society at large were felt by school staff and students. The sentiments and experiences articulated within the COVID-19 Situation theme show how this wider situation impacted schools and their provision of distance learning, complicating the task of switching to distance learning even further. There were three key contributors to this impact captured by this study; the challenges posed to staff and students by the 'new normal', the lack of an opportunity to prepare for the closure of school buildings, and the difficulty in short-term and medium-term planning under constant uncertainty.

\section{Challenges of 'New Normal'}

The lockdown which closed school buildings also shuttered all but essential businesses, leaving most of the country either unemployed or working from home. For those who continued to work in hospitals, supermarkets and other essential roles there was often a change to working hours or conditions, as well as the possibility of contracting COVID-19 at work. Many students thus had to work in a drastically different home environment to usual, one which was far from ideal for remote learning: 
We've a lot of families here, and a lot of them do go to third level which is fantastic, but it did create issues for families then at home. It became quite apparent that technologically they didn't have enough. So, we had situations where one kid might be doing a college exam in the afternoon so therefore the other students in the family couldn't access the classes in the afternoon. (Principal 8, DEIS, Munster)

[On issues impacting student engagement] Out of school routine, coping with sick parents and family, struggling to manage at home with other siblings. (Survey Response, DEIS, Dublin)

...lack of parental supervision, some working in assisting frontline workers/outlets. (Survey Response, Non-DEIS, Connacht)

Many teachers were doubly affected by these challenges; as professionals they found themselves working from home at a job built around close contact, and as parents they found themselves caring for their own children while trying to teach others from a distance.

[Teachers] had their own kids at home, and they were struggling with trying to teach and likewise trying to mind their kids or in some cases trying to mind elderly parents. So, there was a lot of tension and you were dealing sometimes pastorally, sometimes academically. (Principal 1, NonDEIS, Connacht)

We heard daily about the stress of parents and students. Not so much about the stress of teachers who had to face similar issues as everyone else - issues of childcare, caring for older relatives/parents, partners losing their jobs, bereavement etc. Under these circumstances, I am proud of the staff who have done their best in the circumstances. (Survey Response, Non-DEIS, Connacht)

Behind the lockdown, of course, was the pandemic; for some school leaders this reality gave a sense of perspective. Whatever the effects of distance learning, school leaders recognised the importance of the closure of school buildings and the lockdown in general:

It's an emergency situation, it's a pandemic, and if anything had happened to any of the students or we'd had students who were directly impacted by COVID-19 we'd have a hugely different set of circumstances to be dealing with. (Principal 6, Non-DEIS, Leinster excluding Dublin)

\section{Lack of preparation}

A major factor impacting schools' shift to distance learning was the lack of time to prepare, with the announcement that school buildings were to close made on the 
morning of 12 March and the closure commencing at $6 \mathrm{pm}$ that day. School leaders discussed the difference which a few days to prepare would have made:

I feel that the biggest problem here was the lack of information from the beginning. If I had two days' notice I would have had time to bring all students and staff up to speed on protocols around distance learning. Announcing that schools were closing at 11:30 am on the same day was ridiculous. (Survey Response, DEIS, Leinster excluding Dublin)

Some school leaders began preparations to close in early March as the situation internationally deteriorated. One interviewee linked this last-minute preparation with longer term incorporation of digital learning:

For that last week once the rumour mill was going - we were quite prepared, it was only kind of shoring up the teachers that hadn't engaged very well. I know that other schools were in a better position than us because they had been using their platforms for a number of years... but that's the only reason the schools were prepared and that's why there was a difference in how different schools coped with it. (Principal 5, Non-DEIS, Munster)

\section{Uncertainty}

The lockdown period was (and at the time of writing remains) an uncertain one for the country as a whole, both in terms of the spread of the virus and the attempts to control it. While school leaders accepted that the crisis imposed a certain level of uncertainty on proceedings, many were critical of the DES, who they saw as contributing to rather than mitigating the impact of this uncertainty on schools:

To be honest, my biggest difficulty with the Department, and I think it's shared with other people l've spoken to as well is that communication has been very slow to come and it's often not clear. And I suppose that's something that is a little bit disappointing... We certainly don't expect to have all the answers but even certain things like the timing when they release information, it tends to be 4 or 5 o clock on a Friday evening and if you're trying to get key decisions to staff, it's just not feasible. (Principal 2, Non-DEIS, Leinster excluding Dublin)

There was particular criticism around the handling of the Leaving Certificate and Junior Certificate State examinations, the timeliness of the decision-making and the difficulties this created for teachers and students alike.

In relation to the exams, both Leaving Cert and Junior Cert, they were relying on advice from the committee for COVID coordination, but I just think that they were probably always just a little bit behind what was happening. I can understand why that would be the case because of the extraordinary conditions that they were faced with. The Leaving Cert was 
an obvious one... I just wonder were they overwhelmed with various decisions they felt they had to make and gave datelines that may have tied their hands later on. (Principal 8, DEIS, Munster)

The point of this chapter is not to litigate the decisions made over the course of this lockdown but to record the issues specific to this moment and outline their effects on schools. All interviewees recognised that these were extraordinary and unprecedented circumstances, much of which were beyond anyone's control. This being the case, the importance of clear, definite and prompt guidance in emergency circumstances is made clear by the sentiments expressed above. The communication which schools require now and over the next few months will be outlined in Chapter 5 alongside other supports needed for the resumption of education.

COVID-19 has impacted on the schools' ability to provide distance learning. The provision of distance learning outside an emergency is different from the provision of distance learning during an emergency. This is important to bear in mind during focused discussions of distance learning, as it was the backdrop against which distance learning played out. Any evaluation of the period must factor this into its criticism, and any attempt to plan for similar situations in the future must account for these challenges.

\subsubsection{School community}

Schools are, at heart, communities, and the challenges of maintaining these communities and continuing to provide the usual range of supports to everyone in the community were immense. The school building is a vital location for human contact which many school leaders found difficult if not impossible to replace. Respondents recognised the efforts made by staff to maintain the school community and the associated challenges. Perhaps most importantly, the school's pastoral care for students became exponentially more difficult with the move to distance learning. Wellbeing was an area of concern within the generally successful move to distance learning. Communication both enabled and undermined maintaining the school community. Communication had to be radically rethought to work in a distance learning environment.

\section{Importance of school as space}

While schools continued to run throughout the lockdown period, the loss of the school building was a serious challenge to schools. The value of the social structure of school and informal contact between staff and students has become very clear in their absence:

School structure is what staff and parents and students are most familiar with and I have realised that teachers have a huge influence in the life of 
their students. Nothing replaces the traditional classroom setting. (Survey Response, Non-DEIS, Munster)

Working remotely has its advantages but the reality is the majority of students miss the daily interaction with the teachers and their friends. Irish teachers have always been an advocate for their students - students miss out on all the other non-academic supports that we give our students. (Survey Response, DEIS, Dublin)

We were lucky.... we had been preparing and had been using online platforms for a while, but students could not have known that this was going to last so long and be their exclusive experience of school in their final term of the year. Families are not set up for it. These are children: they are not adults working from home. They rely on relationships of trust with their teachers. (Survey Response, Non-DEIS, Munster)

For many students, the school is at the centre of a wider network of supports including school meals and guidance counselling. While schools endeavoured to continue to provide these supports remotely, it was a much more difficult and tenuous process.

This time period has crystallised the nature of the challenges we all face in the school. The take up on the provision of school lunches/food parcels illustrated how many of our families are struggling financially. One mother said only for this food the family would go hungry. Technological poverty at home has become very apparent. As a DEIS school, having knowledge and a connection with our target group of students was vital because they are the students who have suffered most as a result of schools closing. Our greatest success if any has been, was to keep some connection with these students/parents/guardians so we can re-engage in an easier way next year. (Survey Response, DEIS, Munster)

\section{Staff}

Survey respondents and interviewees were almost unanimous in their praise of their staff, pointing to their dedication to their role and their eagerness to adapt successfully to distance learning.

I have a very supportive BOM [board of management], teachers and colleagues who within the space of a few hours moved the school to the virtual world. I have teachers who are working while caring for children and/or elderly relatives but who continue to put their students to the forefront. Our school is well run, we are not perfect, but I think that we are doing the best that we can in a very difficult situation. (Survey Response, Non-DEIS, Dublin)

Teachers have been doing amazing behind the scenes work to try and connect and reach out to the students. (Survey Response, DEIS, Dublin) 
That teachers are amazingly resilient and adaptable. Their capacity to keep the student at the heart of what they do has been inspirational. (Survey Response, Non-DEIS, Connacht)

However, many also pointed out the difficulty in maintaining staff morale and promoting staff wellbeing during the period and raised questions about the sustainability of schools' efforts to provide distance learning:

...sustainability - I am a mother of 2-year-old twins, I have a school of just under 500 students - this is an insurmountable task of motivating, informing, communicating, contacting, planning, time in online meetings - constant anxiety... (Survey Response, DEIS, Leinster excluding Dublin)

Some interviewees reported an intensification of their own workload during the period, with several working 12-14 hour days or working during weekends. For others, not being in school meant that there were far fewer interruptions, enabling them to complete their day's work quicker and more efficiently than they would in school.

\section{Pastoral role}

Fulfilling the school's pastoral role was a particular challenge during this period for many school leaders. While many felt that academic content could be delivered relatively well remotely, caring for students' wellbeing was much more of a challenge:

Schools are a learning community, not merely a means of delivering a curriculum. The pastoral/wellbeing role of schools is the most difficult thing to replicate remotely. (Survey Response, Non-DEIS, Leinster excluding Dublin)

Some schools reported effective interventions to improve wellbeing. In one school, the Friday academic content was replaced by 'Dé hAointeach', a day dedicated to working on student wellbeing through non-academic activities. The restructuring also reduced the pressure on teachers somewhat, as many were able to dedicate Fridays to correcting student work and organising or recording material for the following week.

On the whole, however, school leaders were very concerned about student wellbeing, especially among those already struggling - students with mental health issues, students from socio-economically disadvantaged backgrounds and students with special educational needs in particular. The experiences of these students will be explored in greater detail in Section 4.4, and schools' needs going forward will be considered in Chapter 5 . 


\section{Communication}

Communication was an issue underpinning other issues, as schools' ability to effectively communicate with staff, students and parents had a significant impact on their ability to engage students, maintain morale and generally operate remotely. The centrality of clear and regular communication among all stakeholders to effective school functioning was articulated by many respondents:

It is vital to keep in touch with your teachers, students and parents. This has been THE most important thing I have learned. When they know what is happening through clear communication then all is well. (Survey Response, Non-DEIS, Dublin)

Regular communication with the school community is essential in keeping the school organisation moving. A combination of phone calls, emails and conference calls (e.g. Zoom) are critical in maintaining contact with students, staff and parents. (Survey Response, Non-DEIS, Leinster excluding Dublin)

We are well organised and the platform we had for communication is working well. And, as before, keeping our lines of communication with all stakeholders is vital. (Survey Response, Non-DEIS, Munster)

Various methods of communication were praised as possible replacements to inperson contact, for the duration of the crisis at least. Online meetings through Zoom or Microsoft Teams were found to be successful platforms by many schools. One school transferred their parents' council meetings to Zoom and reported higher participation than usual. The school website was highlighted as a vital tool by one school, with one staff member charged with updating it daily. Email was vital in communicating with staff, students and parents. Phone calls were highlighted by many school leaders as the best way to maintain the human side of interactions with staff and students. Several schools made contact with every student's family by phone in March as the lockdown commenced to check in and ensure they were ready to transition to distance learning. For those students struggling or disengaging, a phone call to parents was the most widely reported intervention. Often this contact was sufficient to re-engage students, or else to identify further action the school could take to support them.

Drawbacks to many of these methods were also noted. Above all, respondents noted the increased time taken up by communication during this period, as well as the loss of nuance compared to in-person contact and the difficulty in reaching everyone with necessary information:

On any school day I have so many small but useful chances to check in with staff on issues but now everything needs more formal timetabled meetings. I spend huge amounts of time in front of the laptop or desktop communicating with various partners, but I have very little 
feeling for how the students or even the staff really are. Online meetings don't reveal that. (Survey Response, Non-DEIS, Munster)

Meetings via Google and Microsoft are easy to manage but some are reluctant to contribute via this platform. (Survey Response, Non-DEIS, Leinster excluding Dublin)

Routine organisation is very doable remotely, but it is very difficult to engage emotionally with both staff and students when the face-toface piece is missing. (Survey Response, DEIS, Dublin)

\subsubsection{The digital divide}

Technology proved central to the shift to distance learning, as most schools moved their teaching and much of their communication with staff, students and parents online. Access to devices and broadband was a significant issue for students and staff, with a clear 'digital divide' perceived by almost all respondents.

\section{Broadband access}

As can be seen from the quantitative results, a digital divide existed at the school level and at the individual student level. Schools in areas with higher and lower availability of high-speed broadband faced different challenges. For several school leaders in areas with universal availability of broadband networks, access to broadband was still not universal. In these schools, students' access to broadband was tied to their family circumstances rather than their geographic location. The impact this had on these students will be discussed further in Section 4.4.

For schools in areas with lower broadband availability, internet access was a constant worry. Perhaps most importantly, schools felt there was little or nothing they could do to support students without adequate broadband. In extreme cases where students could not access the internet at all, work was posted to them. Some schools bought mobile credit for students so that they could use mobile data, but this was not felt to be a viable solution. For most students and teachers affected, slow or unreliable broadband was another complication in engaging in distance learning.

\section{Devices}

Student access to suitable devices for distance learning was strongly linked to their family circumstances according to school leaders. Even families which had some suitable devices in the home were put under pressure by the widespread nature of the lockdown: devices often had to be shared among parents working from home and children across primary, second-level and further/higher education. As a result, many students who did engage with online learning did so using a smartphone, which school leaders recognised as inadequate for learning but 'better than nothing'. 
Unlike with broadband access, schools were able to take a number of actions to address students' lack of access to devices. Devices were bought by schools using their own resources or the DES ICT grant, which was widely recognised as a vital support. Many schools which had laptops and tablets for classroom learning distributed these to students who needed them. For some schools this was sufficient to cover all students, but for others with a greater level of need among the student body it was not.

Access to suitable devices is a prerequisite for any engagement with online learning, and it is therefore no surprise that support in getting devices to students was central to what school leaders wanted to see in the future. There was a range of suggestions for what this support should look like, and this will be explored in detail in Chapter 5. 



\section{CHAPTER 3}

\section{Experiences of distance teaching and learning}

School leaders provided us with a comprehensive insight into the experiences of both teachers and students in adapting to distance learning. In this section, we explore the main challenges faced by school populations in this process of adaptation, as well as how certain key elements of the second-level curriculum compare with what had been normal, such as assessments and practical work.

\subsection{RELATIVE QUALITY OF DISTANCE TEACHING AND LEARNING}

Distance learning was rated by school leaders across several domains relative to what had been standard practice prior to the shutdown of school buildings. These ratings are summarised in Figure 3.1.

\section{FIGURE 3.1 HOW DISTANCE LEARNING COMPARES TO STANDARD PRACTICE}

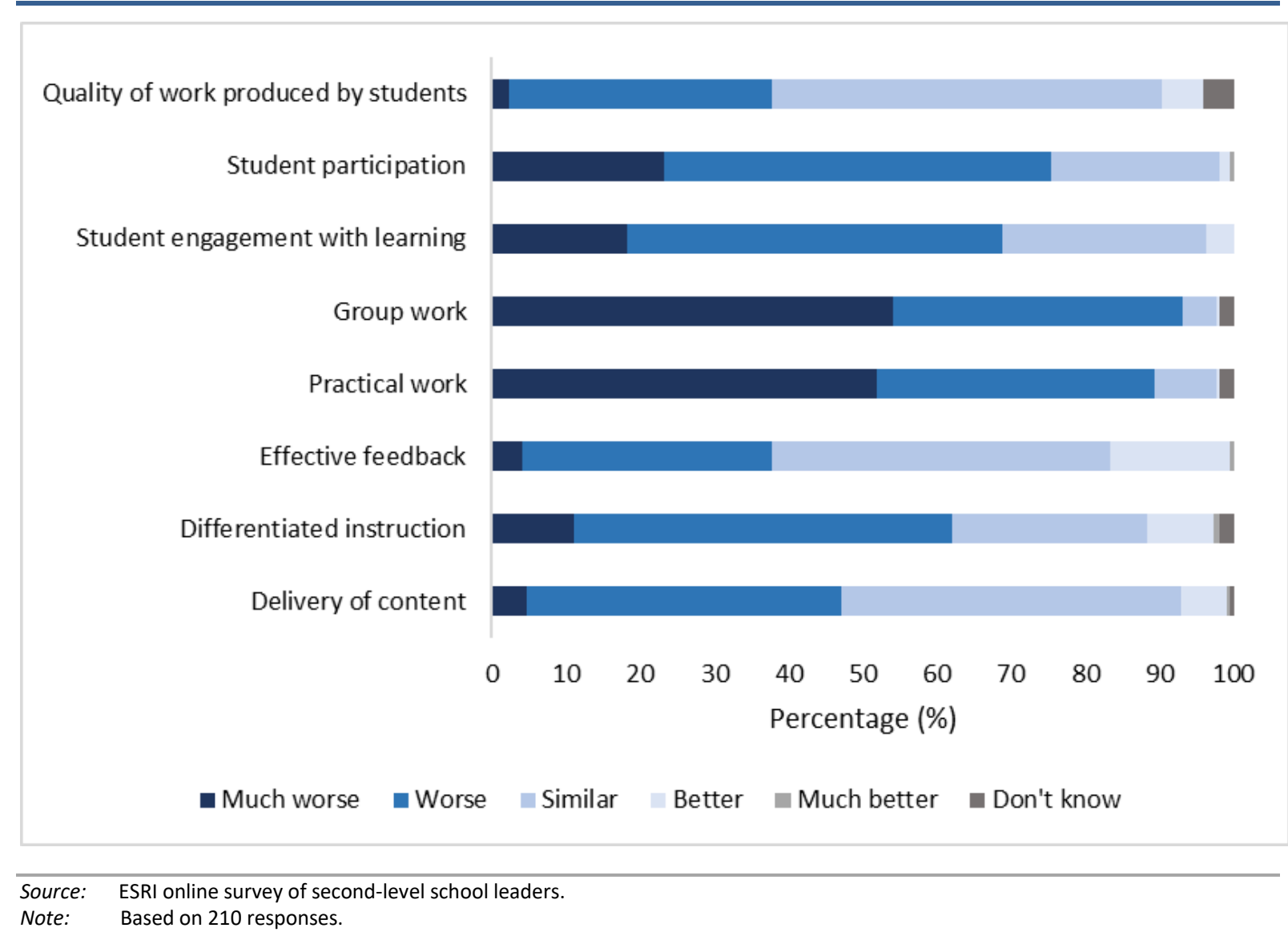

Overall, school leaders indicated that distance learning was either similar to, or worse than, standard practice. As anticipated, distance learning was rated particularly poorly for group work and practical work, with 54.2 per cent of schools reporting group work to be 'much worse' through distance learning. Student 
participation and engagement also appeared to have been negatively impacted by the transition to distance learning, with student participation in lessons rated as either 'worse' or 'much worse' by 75.5 per cent of school leaders. It is worth noting, however, that 58.1 per cent of schools indicated that the quality of work produced by students via distance learning was either unchanged or improved, while 62.3 per cent of schools reported that effective feedback was either unchanged or improved by distance learning.

Survey data suggest that the negative impact of distance learning on group work and student engagement was exacerbated in certain areas with lower levels of access to high-speed broadband. As depicted in Figure 3.2, group work was rated as 'much worse' in 61.7 per cent of schools with lower coverage of high-speed broadband in their catchment area, compared with 45.5 per cent of schools with higher broadband coverage (Chi-squared $=11.7, p=0.02$ ). This is an intuitive finding, suggesting that while group work is more difficult through distance learning, it may be significantly more difficult in the absence of high-speed broadband. Moreover, student engagement was rated as either 'worse' or 'much worse' by 77.4 per cent of schools with lower broadband coverage, compared with 59.2 per cent of schools with higher broadband coverage (Chi-squared $=9.1$, $p=0.03$ ), suggesting a potential link between student engagement with learning and the availability of high-speed broadband at home.

\section{FIGURE 3.2 GROUP WORK BY AVAILABILITY OF HIGH-SPEED BROADBAND}

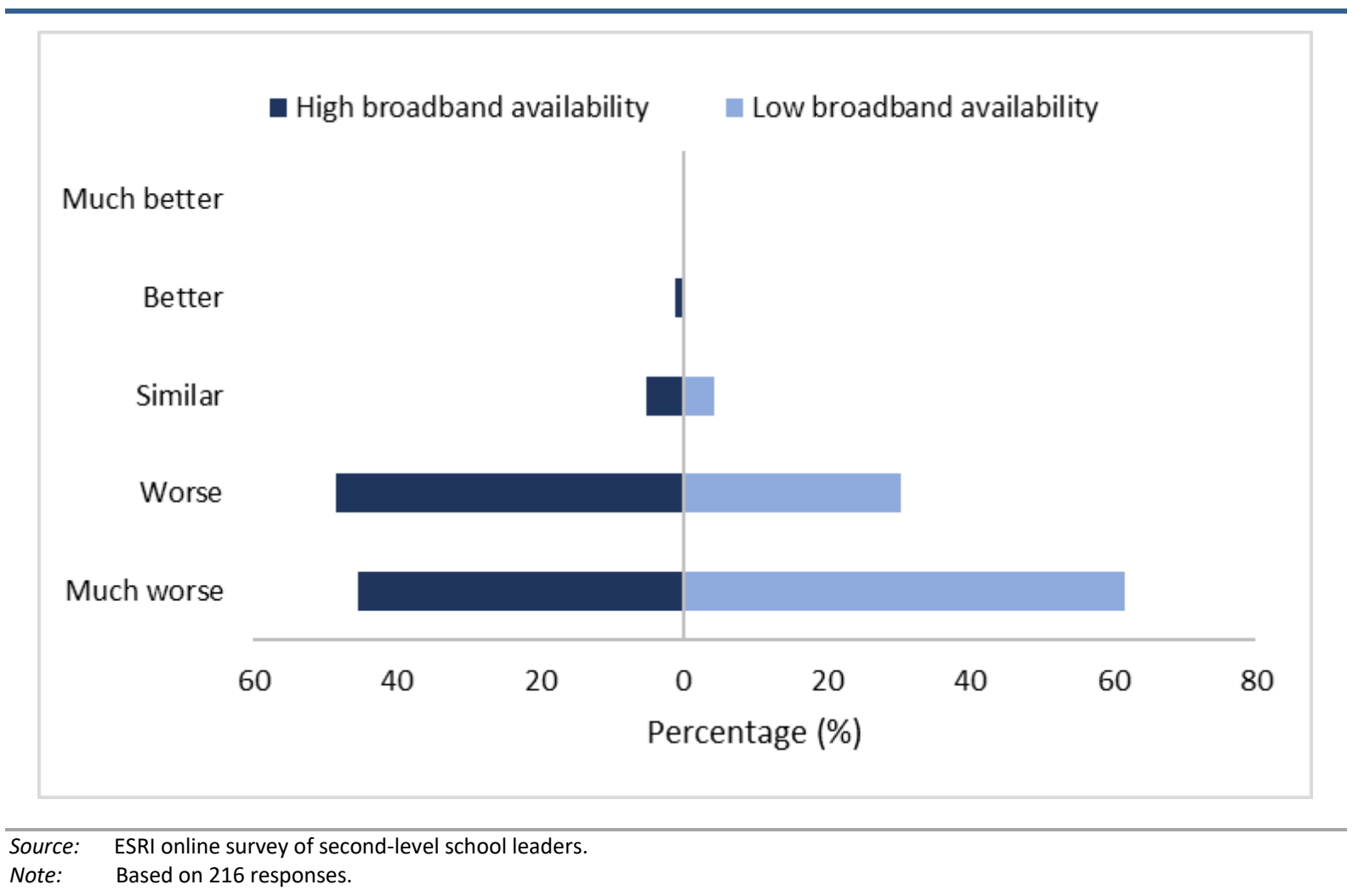


The negative impact of distance learning on both student engagement and participation in lessons also appears to have been more pronounced among DEIS schools, with participation rated as either 'worse' or 'much worse' by 88.7 per cent of DEIS schools compared with 69.7 per cent of non-DEIS schools (Chi-squared $12.8, p=0.01)$. This difference is illustrated in Figure 3.3.

\section{FIGURE 3.3 STUDENT ATTENDANCE AND PARTICIPATION IN LESSONS BY DEIS STATUS}

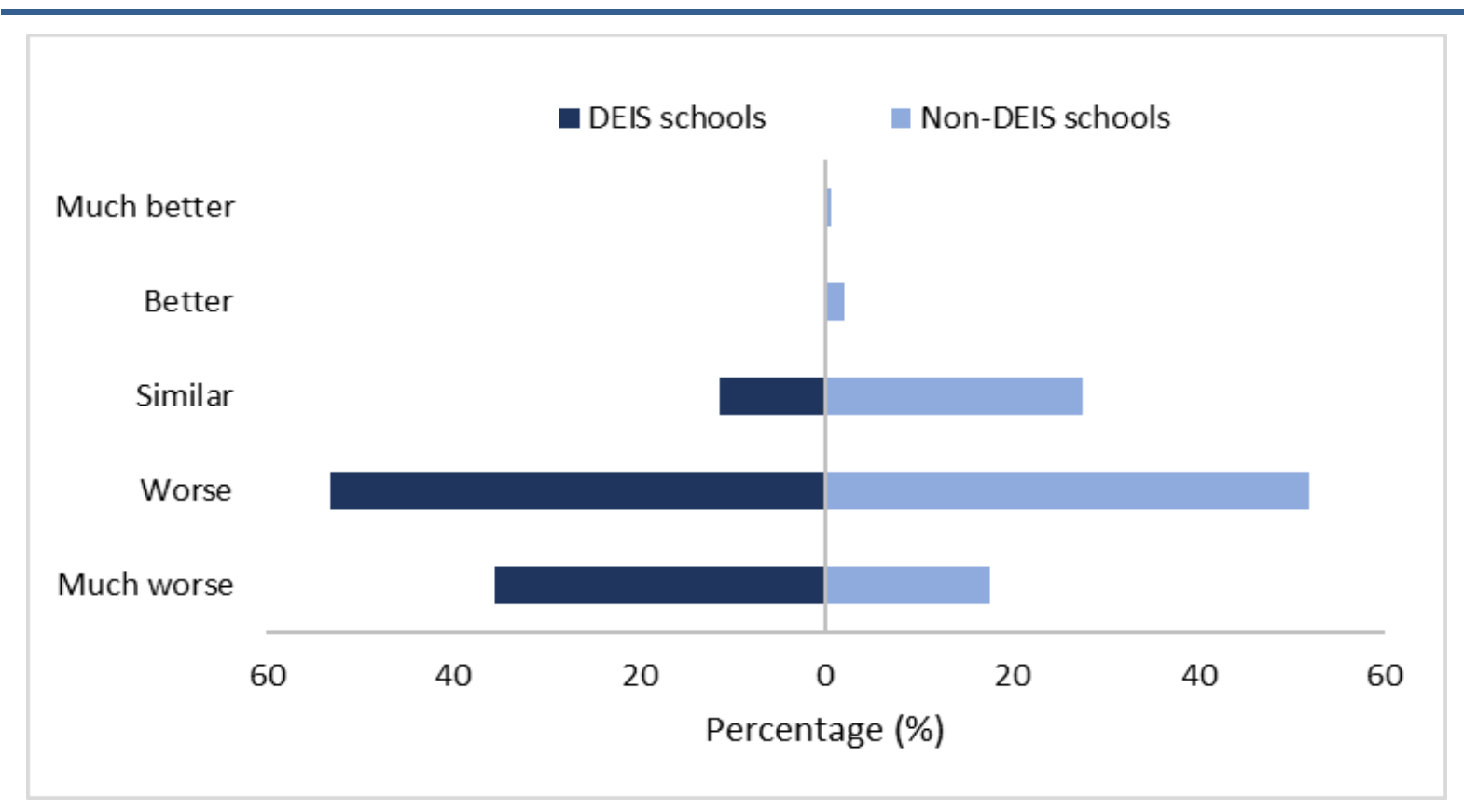

Source: ESRI online survey of second-level school leaders.

Note: $\quad$ Based on 216 responses.

\subsection{CHALLENGES IN DISTANCE LEARNING: TEACHERS}

School leaders indicated the extent to which they agreed with various factors being considered as challenges faced by teaching staff in moving to distance learning. These challenges are summarised in Figure 3.4. There was no statistically significant difference in these results when focusing on the sub-sample of DEIS schools. 


\section{FIGURE 3.4 CHALLENGES FACED BY TEACHERS IN DISTANCE LEARNING}

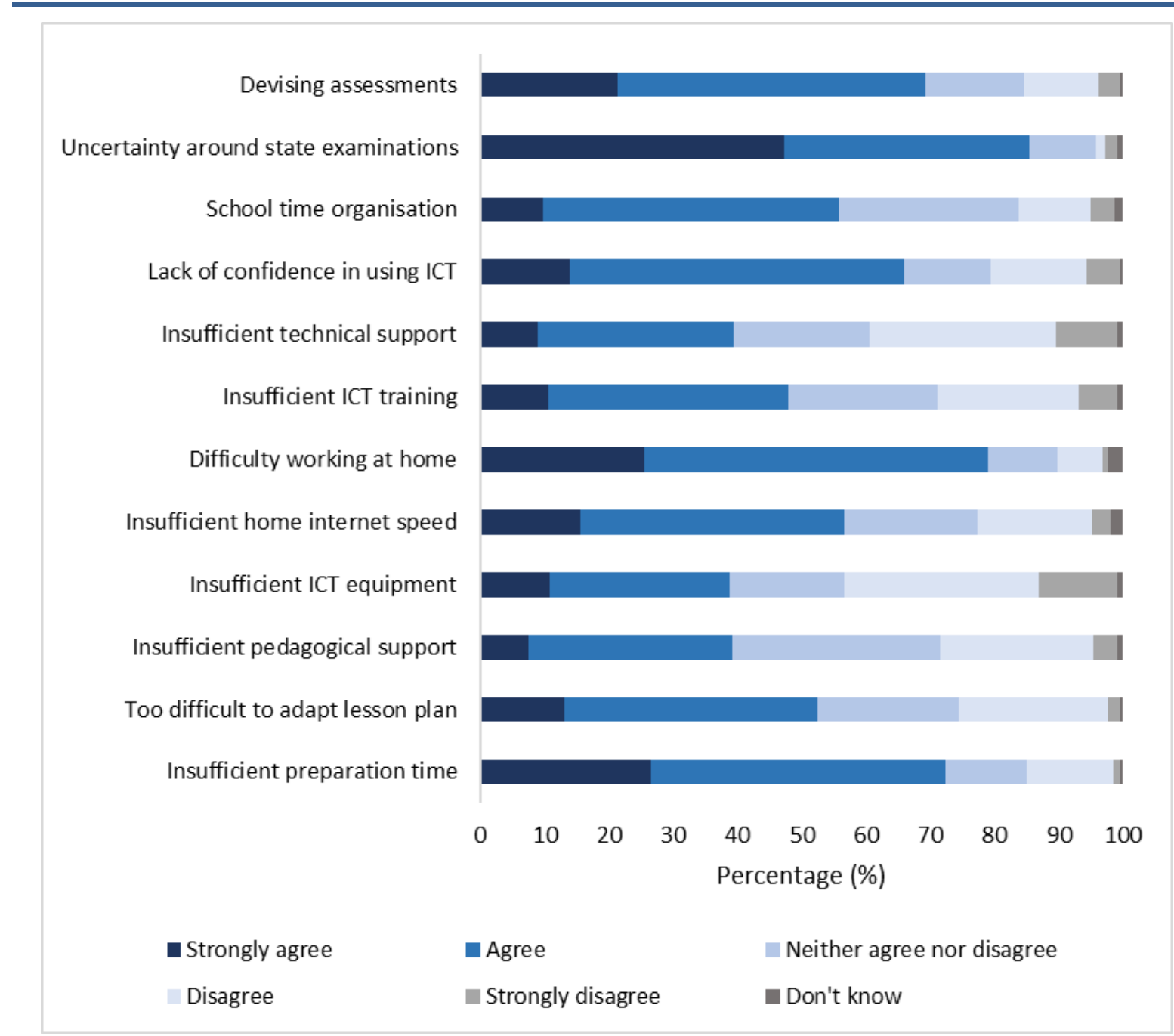

Source: ESRI online survey of second-level school leaders.

Note: Based on 212 responses.

Uncertainty surrounding the administration of State examinations appears to have been particularly challenging for teachers, with 85.5 per cent of school leaders affirming this as a challenge for teaching staff. Insufficient time to prepare lessons, devising remote assessments, and difficulties relating to working from home such as access to quiet space, caregiving responsibilities or needing to mind children also featured as particularly pertinent challenges in survey responses.

Another challenge faced by teachers from many schools has been insufficient internet bandwidth or speed at home. Unsurprisingly, as shown in Figure 3.5, this was a considerably more widespread issue for schools in areas with lower availability of high-speed broadband, with 69.7 per cent of schools with lower broadband coverage indicating insufficient internet speed at home as an issue, compared with 40.8 per cent of schools in areas with higher broadband coverage (Chi-squared $=27.1, p=0.00$ ). This issue also appears to have been more pronounced for schools for which household income across the catchment area is 
below the average across schools, as illustrated in Figure 3.6. In areas of lower income, 70.3 per cent of schools indicated slow internet speed was a challenge, a significantly higher proportion than the 40.4 per cent of schools in areas of higher income (Chi-squared $=26.5, p=0.00$ ). This may reflect the two-dimensional challenge in distance learning in relation to home internet speed discussed in Chapter 2, whereby more successful distance learning requires both local availability of high-speed broadband and sufficient levels of household income to purchase suitable devices with which to access such broadband.

FIGURE 3.5 INSUFFICIENT HOME INTERNET SPEED AMONG TEACHERS BY AVAILABILITY OF HIGHSPEED BROADBAND

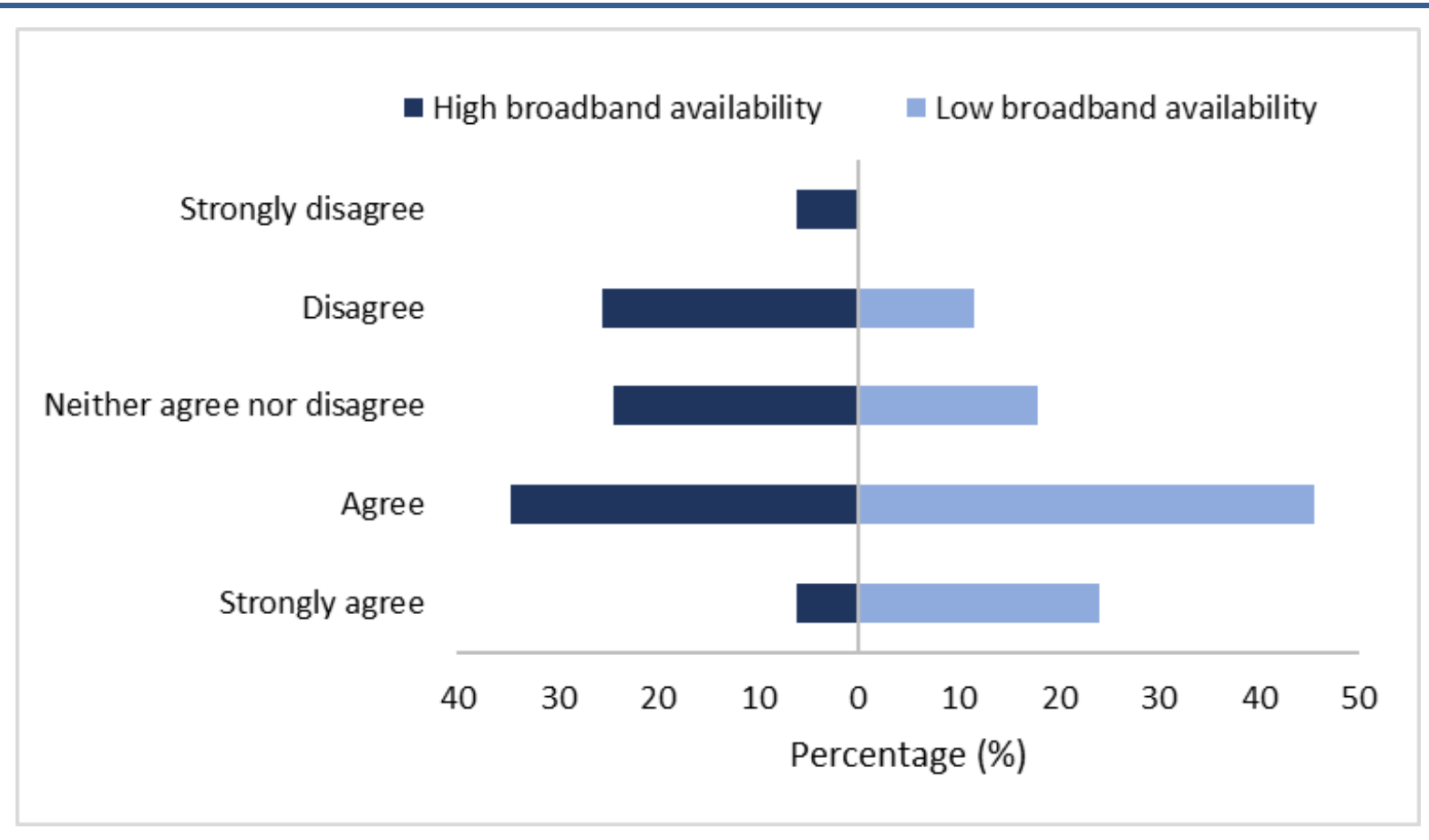

Source: ESRI online survey of second-level school leaders.

Note: $\quad$ Based on 212 responses. 


\section{FIGURE 3.6 INSUFFICIENT HOME INTERNET SPEED AMONG TEACHERS BY AVERAGE HOUSEHOLD INCOME IN CATCHMENT AREA}

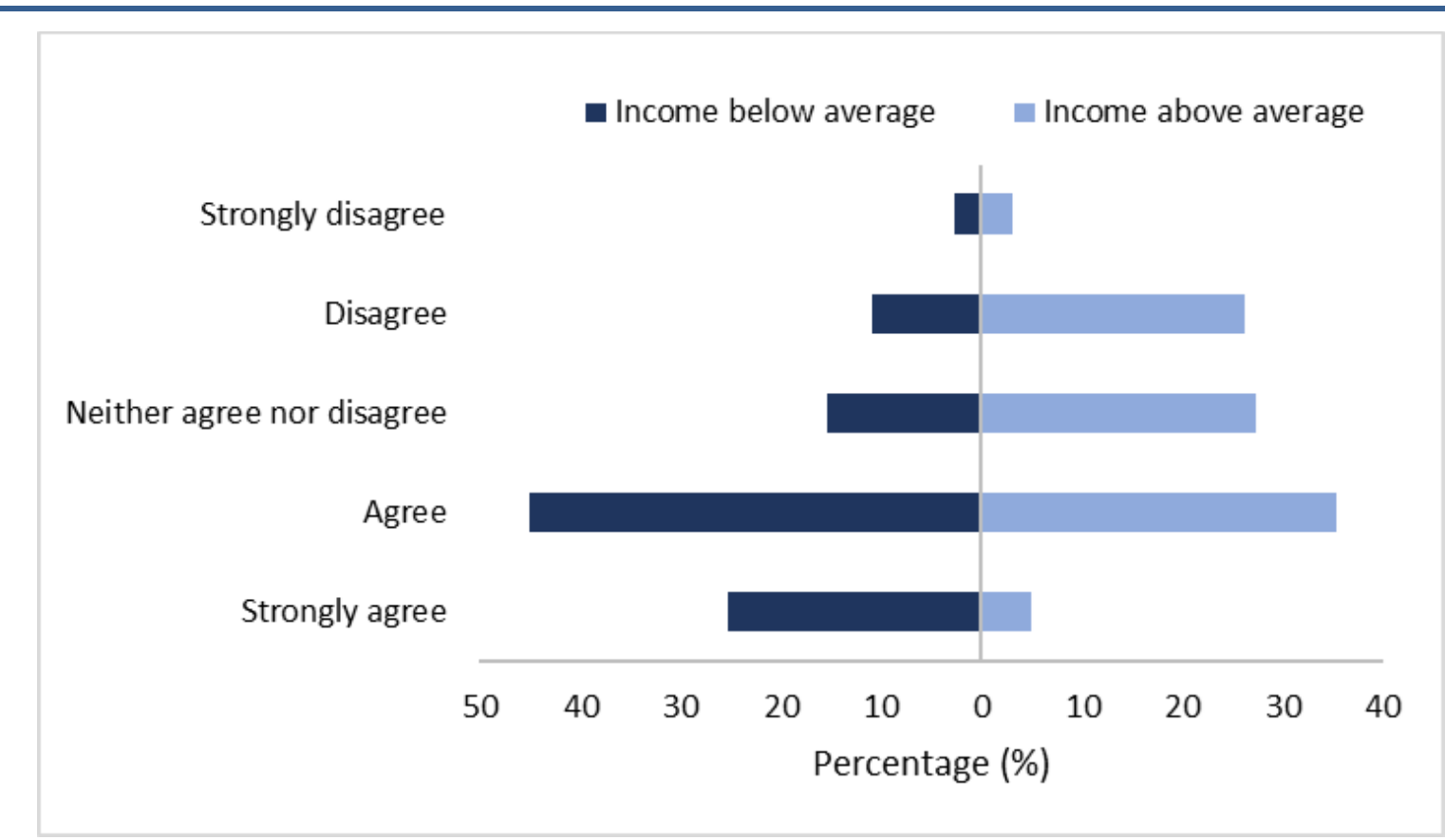

Source: ESRI online survey of second-level school leaders.

Note: $\quad$ Based on 212 responses.

\subsection{ADAPTING TO DISTANCE LEARNING: TEACHERS}

Survey responses from school leaders paint a picture in which many second-level teachers have been able to adapt to distance learning despite the considerable challenges they had to face. This is illustrated in Figure 3.7, where 72.9 per cent of school leaders indicated that less than 20 per cent of teaching staff have struggled to adapt. Conversely, over 80 per cent of teaching staff were reported to have 'adapted very well' in 32.7 per cent of schools, and between 61 and 80 per cent of teachers have 'adapted very well' in a further 32.2 per cent of schools. Again, there was no statistically significant difference in these results when focusing on DEIS schools. 


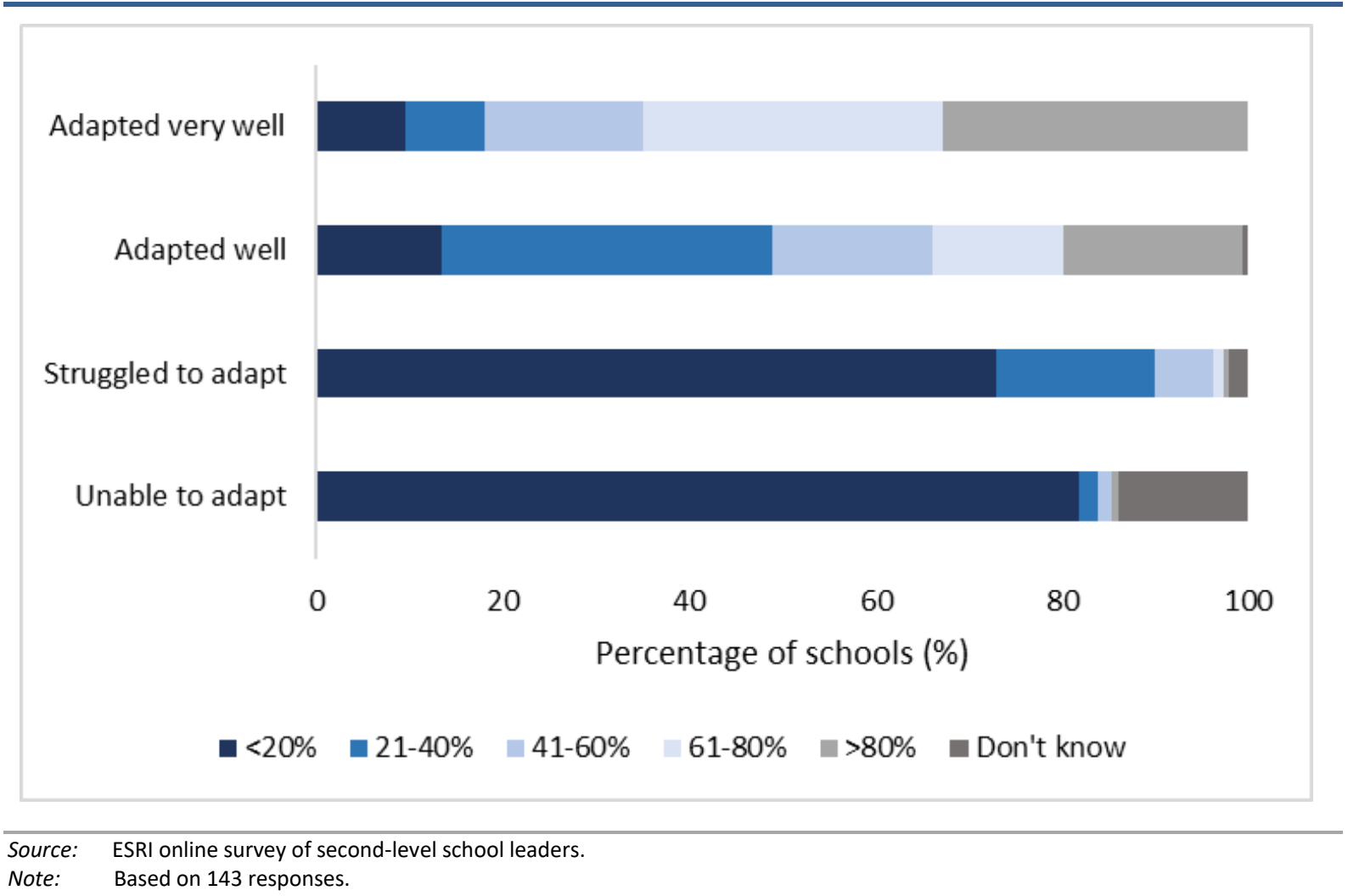

This clearly suggests widespread success among second-level teachers in adapting to distance learning. It is worth considering various factors that may have contributed to how successfully teachers have adapted. School leaders were asked to rate different potential factors depending on how helpful they have been in this regard. Responses to this are depicted in Figure 3.8, and there were no significant differences when comparing DEIS and non-DEIS schools. Contact with other teachers in the school appears to have been particularly helpful in supporting teachers to adapt to distance learning, a factor categorised as 'very helpful' in 67.9 per cent of schools and as 'somewhat helpful' in a further 25.4 per cent of schools. Another particularly helpful factor seems to have been teaching experience, which was classified as either 'very helpful' or 'somewhat helpful' by 87.9 per cent of schools. On the other hand, while 40 per cent of school leaders rated guidance from the DES as having been 'somewhat helpful', 44.3 per cent regarded this as 'not helpful'. Overall, this is indicative of teachers relying to a large extent on both their own teaching experience and on the experience of each other in successfully adapting to distance learning. 


\section{FIGURE 3.8 FACTORS IMPACTING TEACHERS' ADAPTATION TO DISTANCE LEARNING}

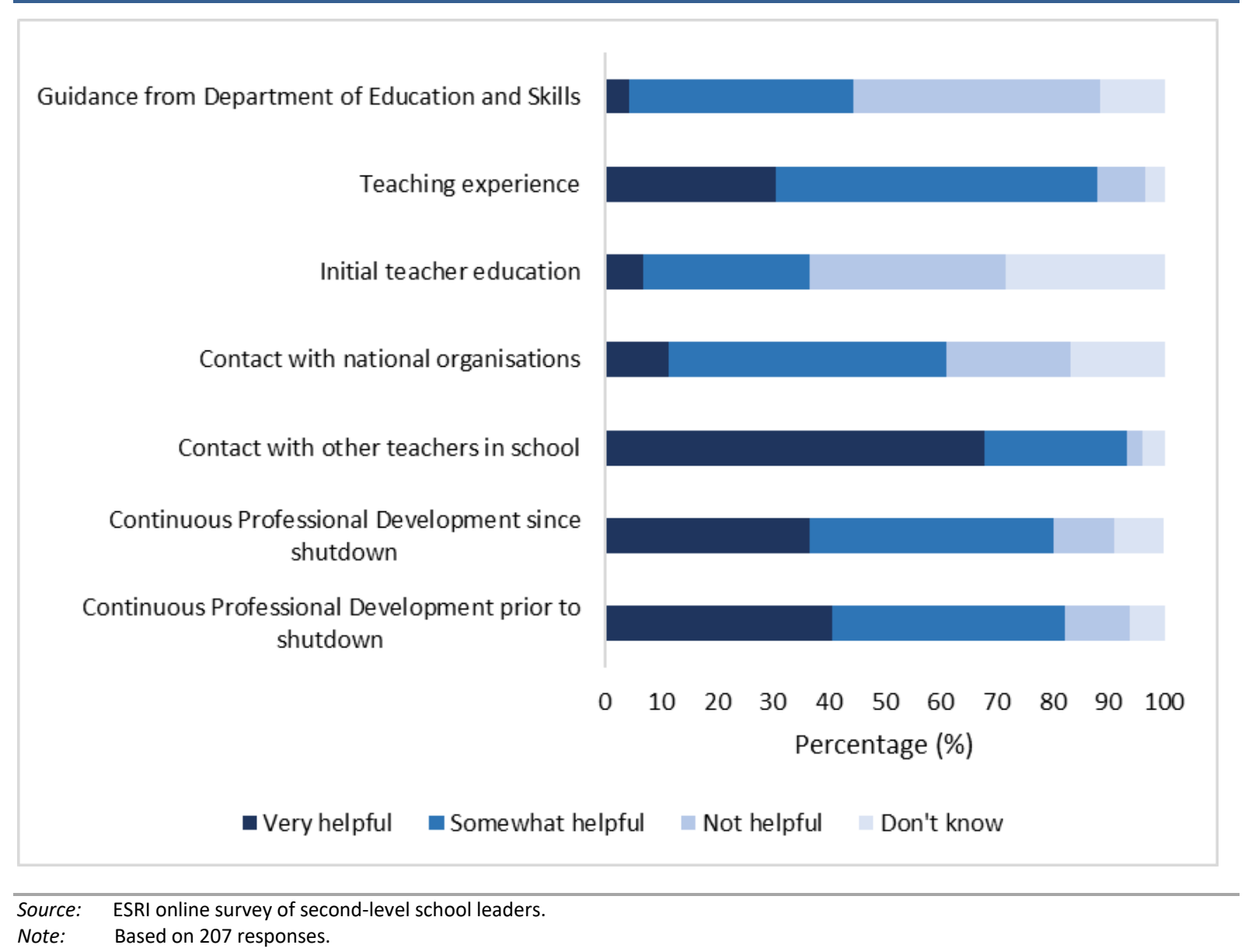

\subsection{CHALLENGES IN DISTANCE LEARNING: STUDENTS}

Students faced many similar challenges to teachers in distance learning, as illustrated in Figure 3.9. As was the case among teachers, uncertainty around State examinations was considered by school leaders to be particularly challenging; 80.4 per cent of schools indicated they 'strongly agree' that this was a challenge to students. 


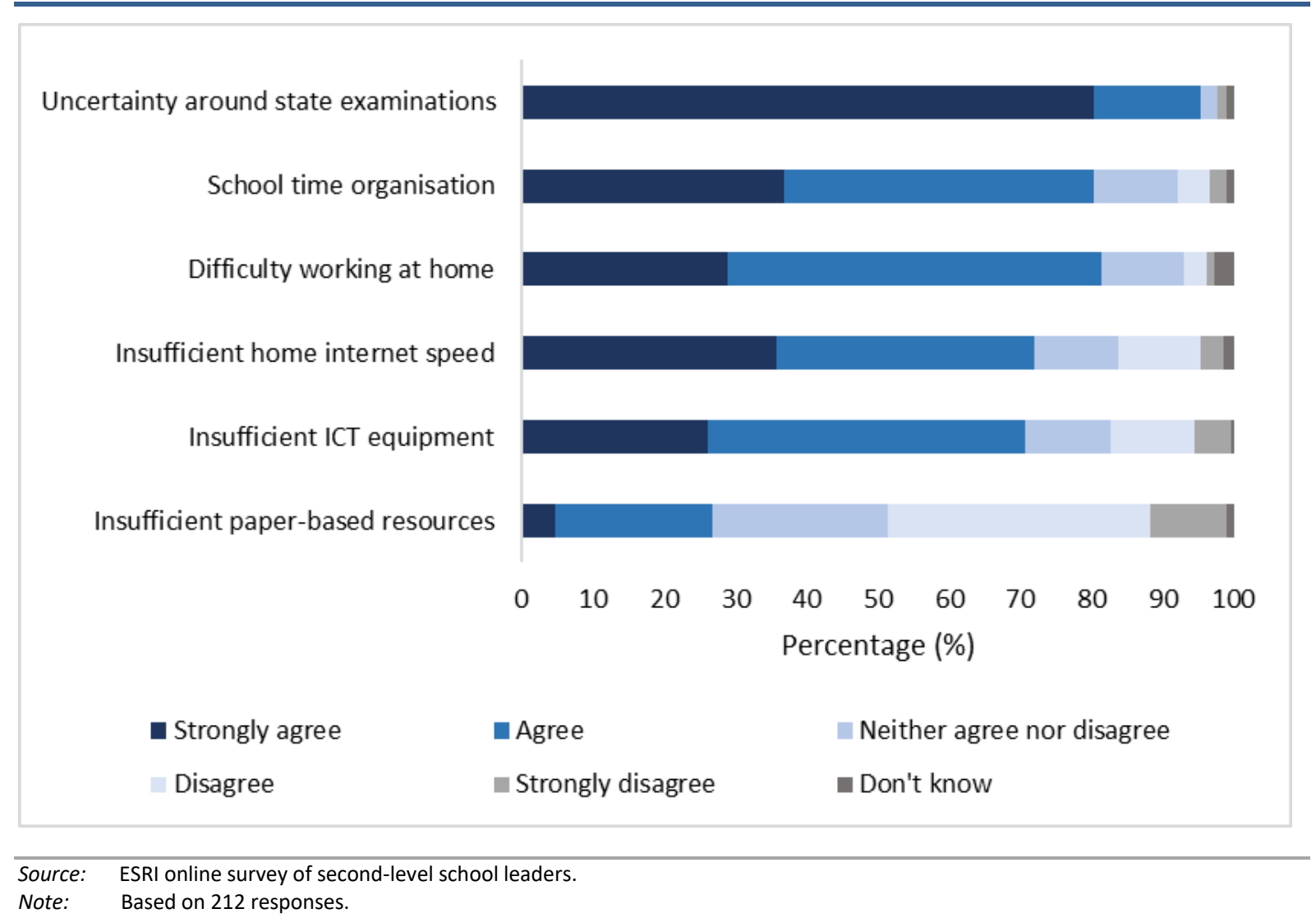

Compared with other challenges suggested to school leaders in our survey, a lack of paper-based resources such as textbooks, exercise booklets or worksheets does not appear to have been a major obstacle to students in distance learning, and there were no statistically significant differences in this finding between DEIS and non-DEIS schools. Insufficient home internet speed and ICT equipment, such as computers or laptops at home, were regarded as more problematic for students. We noted significant differences in the extent to which insufficient ICT equipment was considered a problem by DEIS school status, local broadband availability and income. Of DEIS schools, 87.1 per cent regarded insufficient ICT equipment as a challenge to students; the figure for non-DEIS schools was 63.6 per cent (Chi-squared $=14.4, p=0.01$ ). This percentage was 80.5 per cent among schools in areas with higher broadband availability, and 59.0 per cent among schools with lower local broadband coverage (Chi-squared $=16.1, p=0.01$ ). Moreover, as shown in Figure 3.10, 78.6 per cent of schools in areas of lower household income indicated that this was a problem for students, compared with 61.4 per cent of schools in areas of higher household income (Chi-squared $=15.8, p=0.01$ ). A similar pattern of statistically significant discrepancies was evident in the case of insufficient home internet speed among the student population, with descriptive statistics by local broadband availability (Chi-squared $=35.0, p=0.00$ ) presented in Figure 3.11. This may also reflect the two-dimensional challenge found in relation to home internet speed, where both availability of high-speed broadband and sufficient household income with which to purchase suitable devices are required by distance learning. 


\section{FIGURE 3.10 INSUFFICIENT ICT EQUIPMENT AT HOME AMONG STUDENTS BY AVERAGE HOUSEHOLD INCOME}

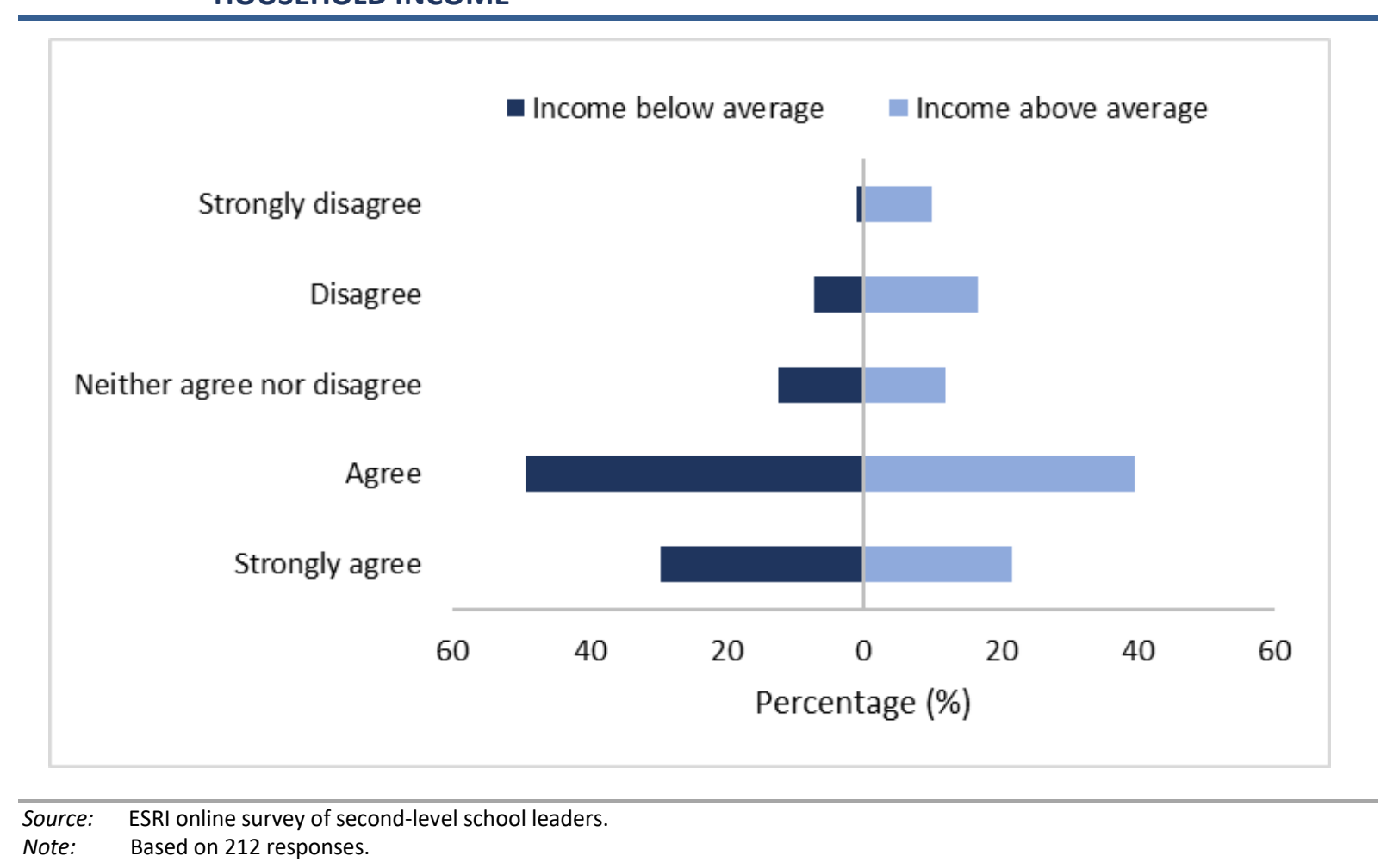

FIGURE 3.11 INSUFFICIENT HOME INTERNET SPEED AMONG STUDENTS BY AVAILABILITY OF HIGHSPEED BROADBAND

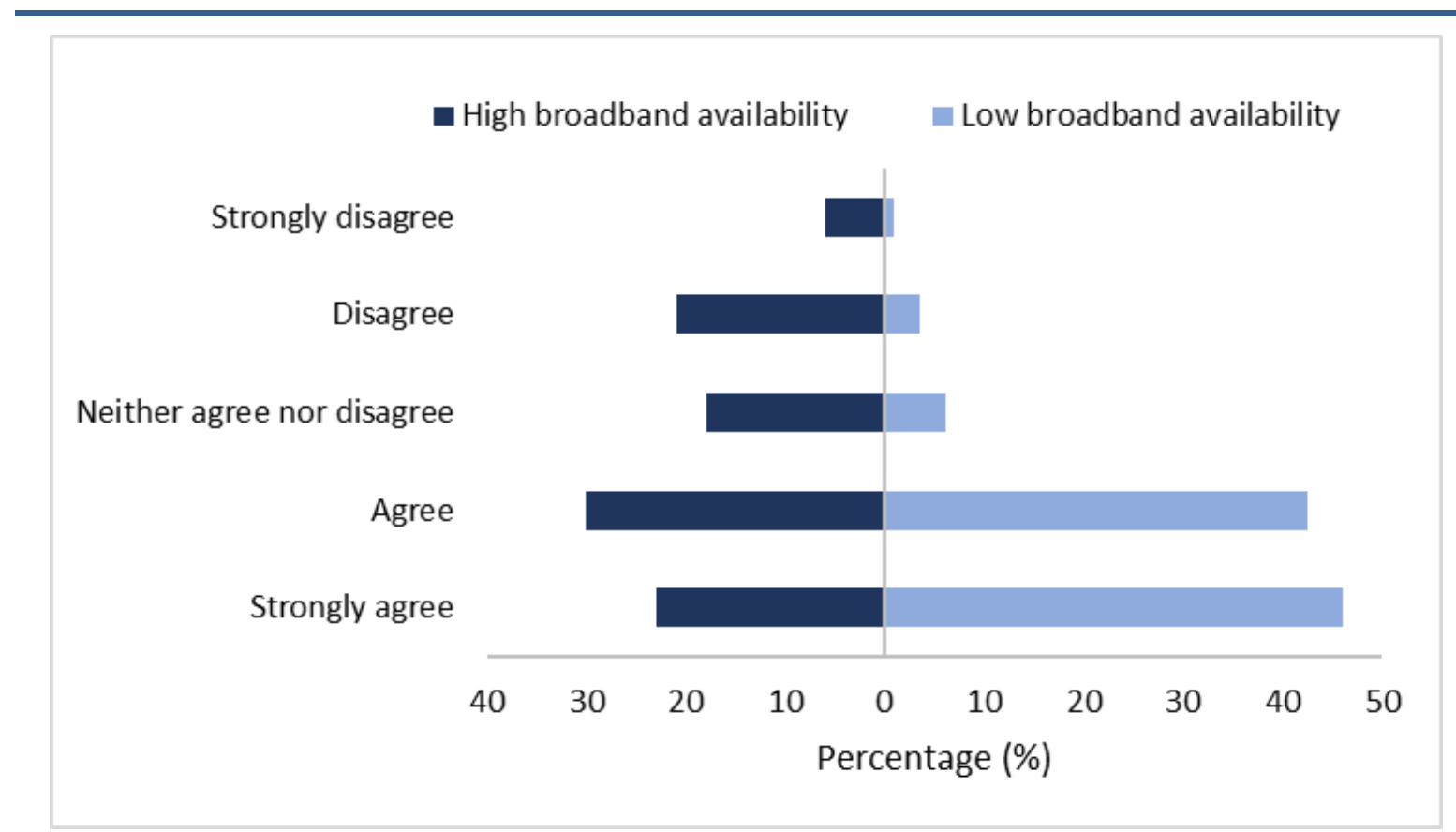

Source: ESRI online survey of second-level school leaders.

Note: $\quad$ Based on 212 responses.

Working from home was also considered to be particularly difficult for students by school leaders, and particularly by leaders of DEIS schools, for example due to a 
lack of access to quiet space or a need to mind siblings. While 77.5 per cent of non-DEIS schools perceived working from home to be a challenge for students, 90.3 per cent of DEIS schools reported this to be an issue (Chi-squared $=15.9$, $p=0.01)$.

\subsection{ADAPTING TO DISTANCE LEARNING: STUDENTS}

A similar picture to that of teachers is evident in our survey data in relation to how school leaders perceived the adaptation of students to distance learning, as summarised in Figure 3.12. In 77.2 per cent of schools, less than 20 per cent of students were reported to have been unable to adapt. From the perspective of school leaders, it appears students have generally been equally able to adapt to learning remotely as teachers have been able to adapt to teaching remotely.

\section{FIGURE 3.12 HOW STUDENTS HAVE ADAPTED TO DISTANCE LEARNING}

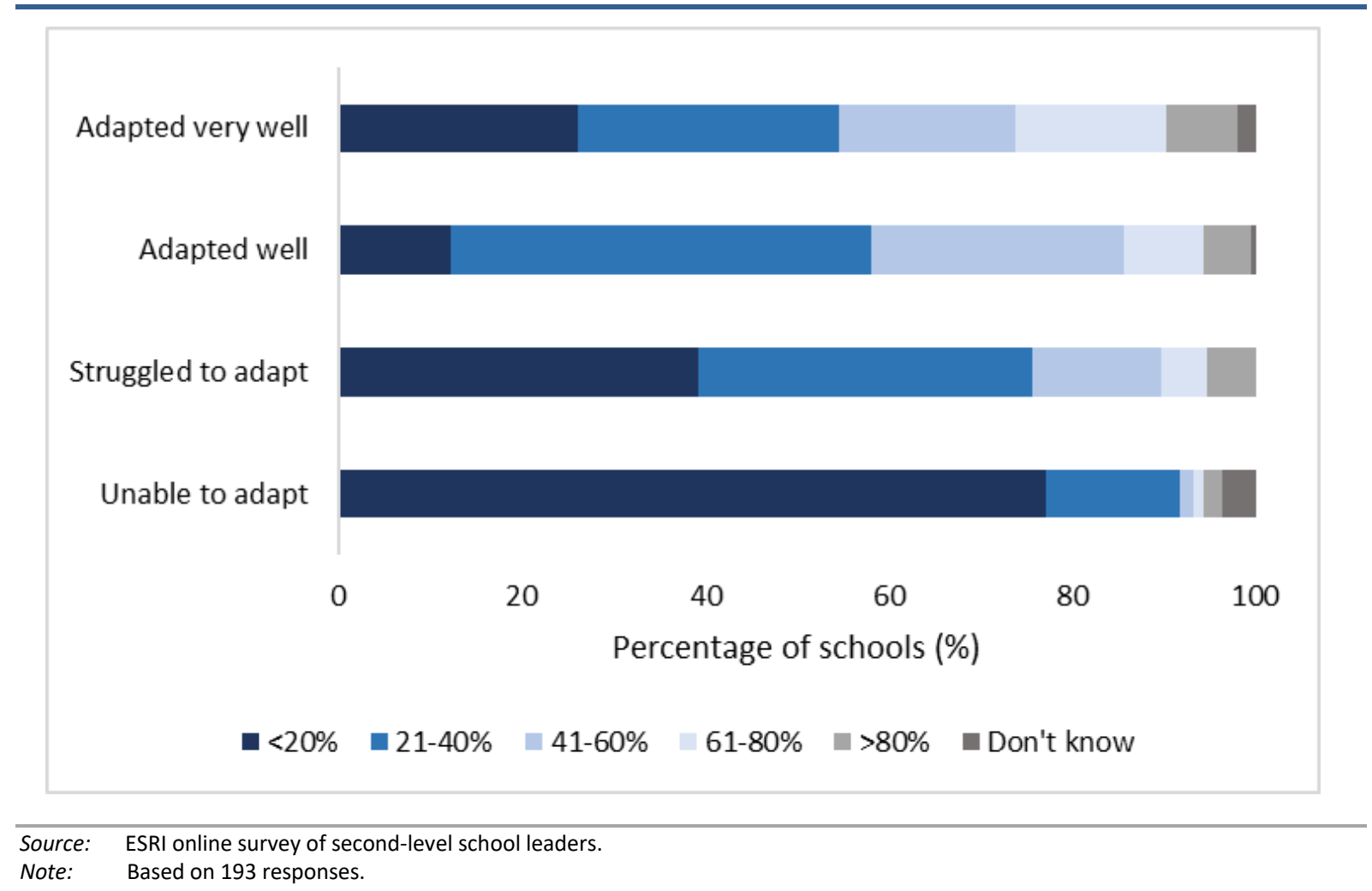

The percentage of students perceived to have adapted 'very well' was reported to be lower among DEIS schools, however, as shown in Figure 3.13. Of DEIS schools, 42.4 per cent indicated that less than 20 per cent of students had adapted 'very well', whereas the corresponding figure for non-DEIS schools is only 19.2 per cent, suggesting increased difficulty among students of DEIS schools in successfully adapting to distance learning. 


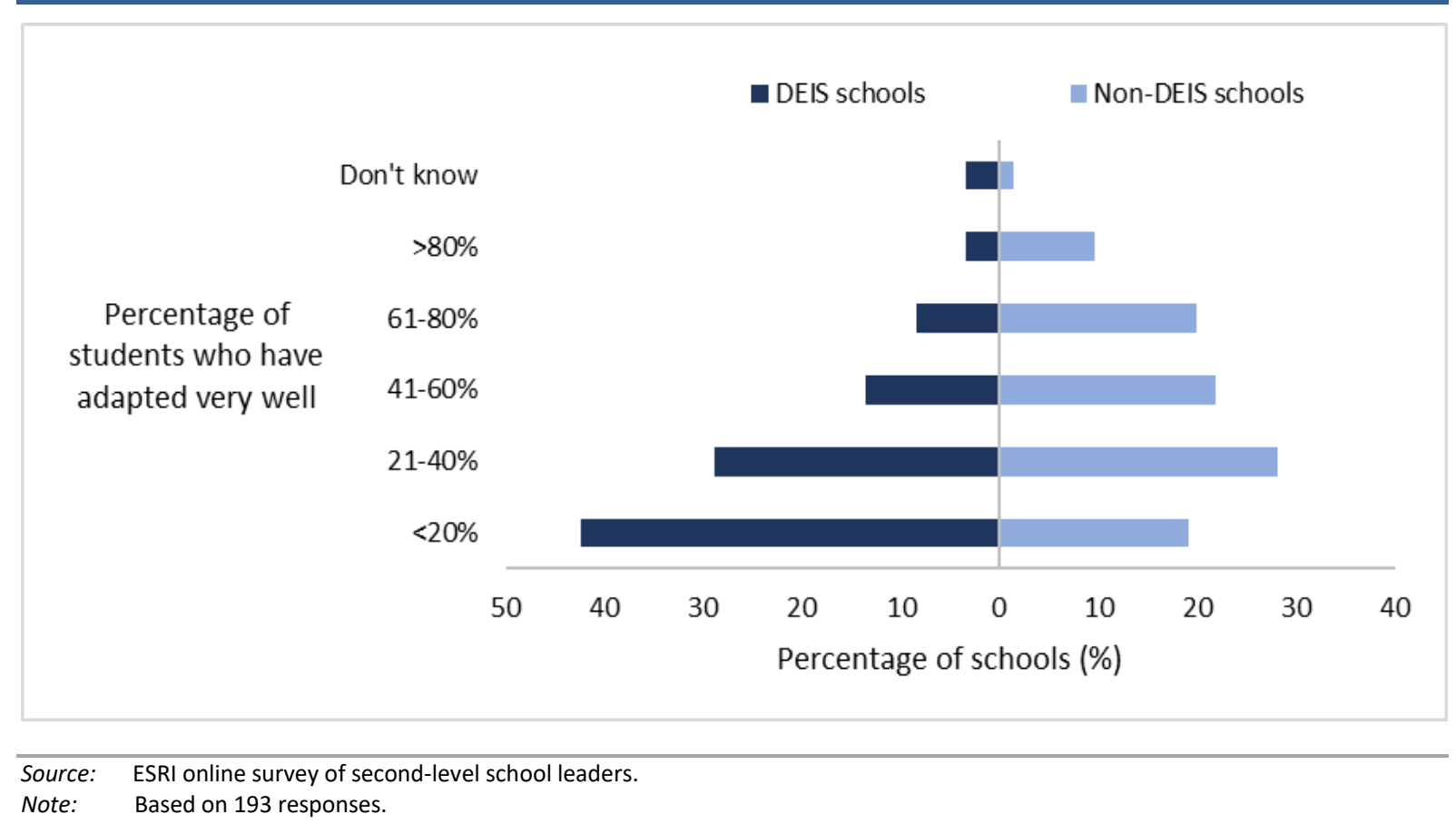

\subsection{ABILTY OF SCHOOLS TO COVER PRACTICAL WORK}

For many subjects, practical work is a key element of the second-level curriculum. Modern Foreign Languages, Irish, Materials Technology, Art, Music and the Sciences all involve practical work, and the abrupt transition to distance learning clearly affected the ability of schools to cover these practical elements. Figure 3.14 illustrates how school leaders considered the ability of their schools to cover practical work relative to usual. Unsurprisingly, for all subjects, the majority of schools reported their ability to cover practical work to be either 'worse' or 'much worse'. Modern Foreign Languages and Irish appear to have fared best relative to the other subjects, with 34.3 per cent and 33.2 per cent of schools respectively reporting their ability to cover practical work to be similar via distance learning. However, other subjects where laboratories and equipment are required for practical elements of the curriculum, such as Materials Technology, Art and the Sciences, have been badly affected by the transition to distance learning, for example with 84.8 per cent of schools reporting either a 'worse' or 'much worse' ability to cover practical work in the Sciences. 


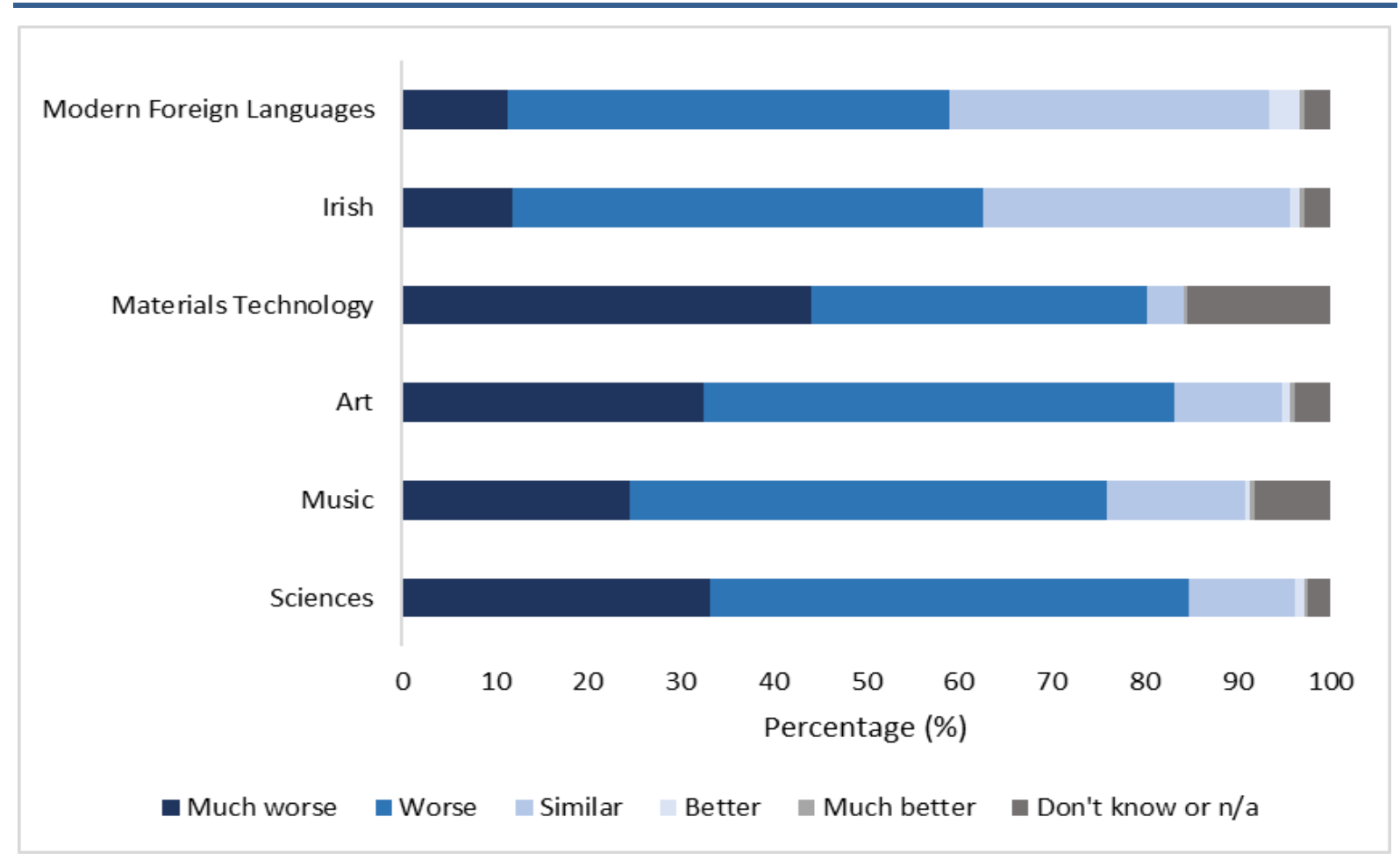

Source: ESRI online survey of second-level school leaders.

Note: $\quad$ Based on 202 responses.

\subsection{END-OF-YEAR ASSESSMENTS}

A further element of the experience of second-level schools in the transition to distance learning worth considering is the approach to end-of-year assessments. For sixth year students, the approach was obviously uniform across schools, with Leaving Certificate examinations cancelled in favour of calculated grades in May 2020. The Junior Certificate examinations were cancelled in April 2020, with schools free to decide how to assess third year students at the end of the year. Our survey asked school leaders to indicate how students would be assessed the end of term in first and second year, third year, and fifth year, with responses depicted in Figure 3.15. The two most preferred methods of assessment across all three groups of students appear to have been a final presentation and an open-book exam. For first and second years, the most popular method of end-of-year assessment across schools was a final presentation, while open-book exams were preferred for third years and fifth years, with 28.3 per cent and 30.7 per cent of schools respectively opting for this approach. 


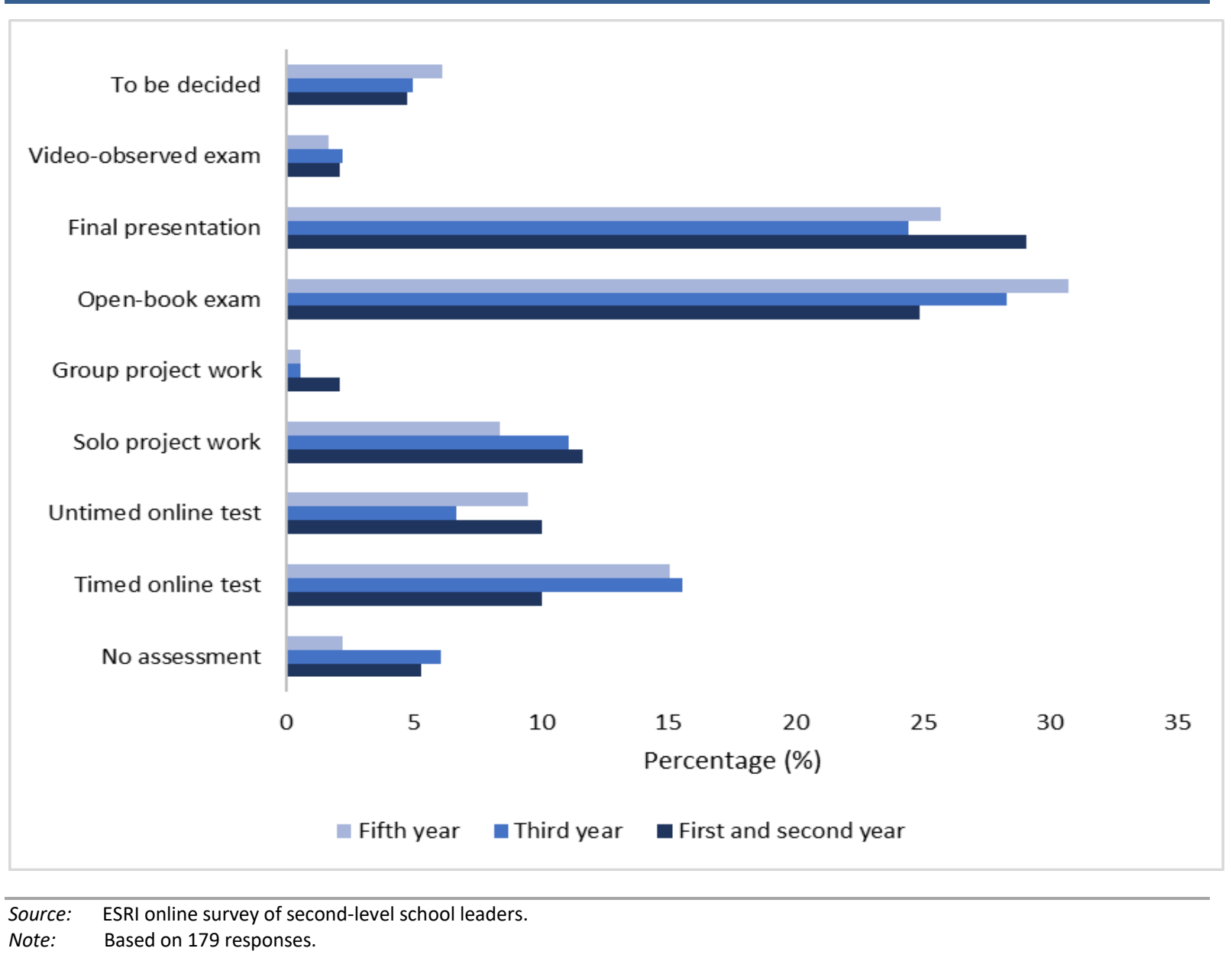

Clearly, different assessment options than usual were required by distance learning. While challenging, this affords a unique opportunity to consider how chosen methods compare with regular practice. Figure 3.16 depicts how school leaders rated remote end-of-year assessments relative to usual assessments. Group work was considered to compare poorly under remote assessment methods by 78.7 per cent of schools, reflecting broader findings in relation to how poorly group work has been facilitated and fostered by distance learning. However, in terms of students taking responsibility for completing their own learning, $54.6 \mathrm{per}$ cent of schools indicated that remote assessment methods compare favourably or similarly to standard assessment methods. 


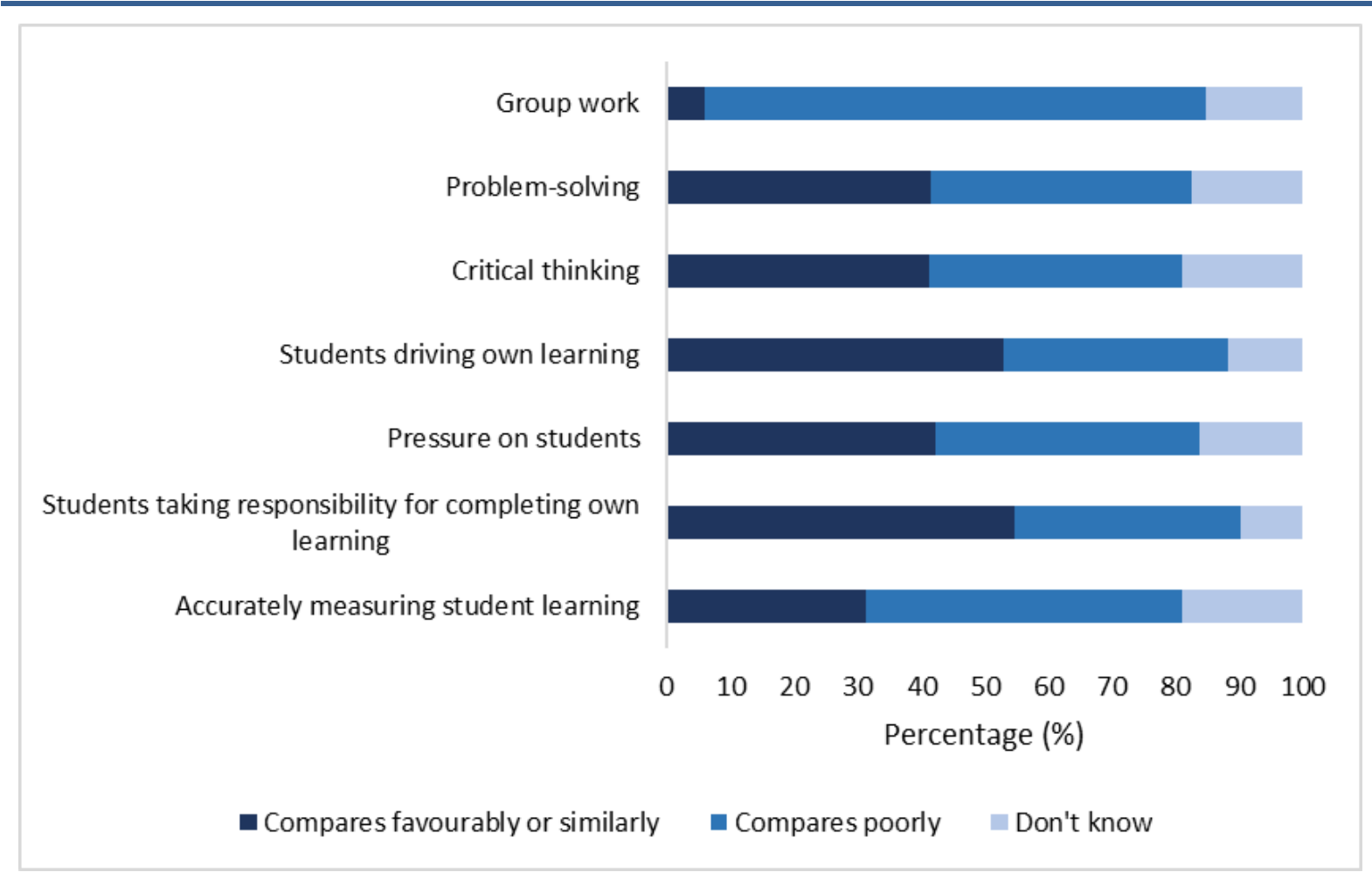

Source: ESRI online survey of second-level school leaders.

Note: $\quad$ Based on 202 responses.

The critical thinking and problem-solving components of end-of-year assessments were considered to compare favourably or similarly by 41.3 per cent and 41.6 per cent of schools, respectively. These percentages were significantly higher among schools in areas with high levels of broadband coverage, however, with critical thinking reported to compare favourably or similarly by 51.1 per cent of such schools compared with 33.9 per cent of schools in areas with lower broadband coverage (Chi-squared $=7.5, p=0.02$ ). This difference is illustrated in Figure 3.17, although the reasons behind this finding are unclear. 


\section{FIGURE 3.17 HOW END-OF-YEAR ASSESSMENT COMPARES TO NORMAL FOR CRITICAL THINKING BY AVAILABILITY OF HIGH-SPEED BROADBAND}

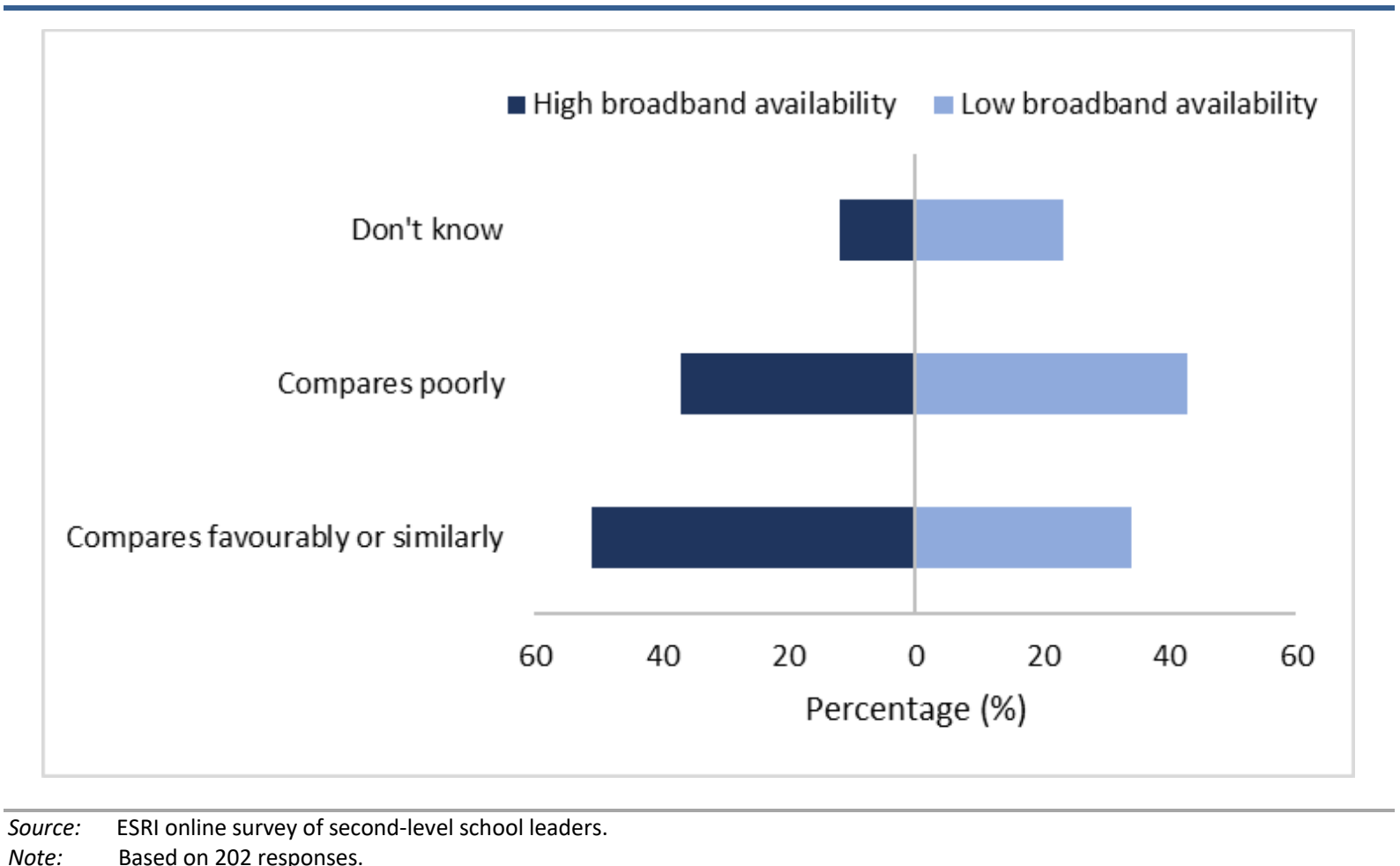

Note: $\quad$ Based on 202 responses.

\subsection{QUALITATIVE FINDINGS}

Within the qualitative evidence, school leaders provided a nuanced account of what was needed for effective distance learning, what impeded successful distance learning and positives they drew from their school's experience of distance learning. Across these three themes the data suggest areas where schools need support to improve their remote provision, areas where distance learning has been as effective as or even more effective than normal in-school learning and areas where distance learning is perceived to be incapable of matching the usual school environment.

\subsubsection{Essentials for distance learning}

Several crucial components to distance learning were identified by this study, though within some of these components there was debate about the most effective way of achieving the identified goal. The essentials which will be discussed in this section are all linked, emphasising the need for holistic, wholeschool approaches. School leaders recognised the need to plan and organise differently and more meticulously than usual in order to maintain a high standard of provision, the importance of staff support and (as in Section 2.4.2) the central role of communication in determining the success of everything else schools were striving to achieve. Finally, the use of digital learning and classroom ICT before the lockdown is essential for a smooth transition to distance learning - as one interviewee put it, being a 1:1 iPad school made the process 'not painfree but less painful' (Principal 9, Non-DEIS, Dublin). 


\section{The need to plan and organise}

The importance of planning and organisation is evident across two distinct but related levels: plans in place before the lockdown enabled a smoother transition to distance learning while planning and organisation during the lockdown ensured that responses to the developing situation were proactive and sustainable rather than reactive and short term. Effective structures were highlighted by many respondents and interviewees as the key to their successful adaptation to distance learning. Some of these structures were long-standing and directly relevant to the move to online planning. Strong digital strategies in particular were highlighted as helpful for many schools.

Other structures pre-existed the lockdown but had their focus refashioned to tackle the new situation. In particular, management teams were used by some schools to delegate work and ensure that everything that needed to be done was done. In a time where communication was more difficult, clear chains of command were identified as vital to the smooth running of the school.

Ad-hoc structures set up during the lockdown also proved effective in many schools. Organised tracking of student engagement through a centralised Excel database allowed school leaders in one school to gauge levels of participation and to reach out to students who were not engaging.

Effective structures and planning were important across a range of areas from student engagement to staff up-skilling. The bulk of these existed at the schoollevel, and different approaches were taken by different schools according to their context and resources. The structures described above represent a number of successful approaches, but the variety of these structures suggest that this is a question with many correct answers. Future research to evaluate and elaborate these structures more fully is necessary, but in the absence of such best practice guidelines many schools have shown themselves capable of acting autonomously.

\section{Staff support}

As discussed in Section 2.4, teaching staff rose to the challenge of distance learning under challenging circumstances. The question of how best to support them as they did so was answered differently across different schools, especially with regard to the school timetable.

Some schools stuck to the normal timetable, seeing it as imposing a necessary structure on the day. The importance of setting clear limits on the working day and working week to safeguard teacher and student wellbeing and avoid burnout was also voiced: 
We emphasised the importance of sticking to the school day as there was an expectation in the first few weeks that teachers should be available 24/7 and also some teachers were assigning work at all hours and this was causing stress for students. (Survey Response, NonDEIS, Leinster excluding Dublin)

Other schools emphasised the importance of flexibility and the need to recognise that radically different conditions called for a significant alteration to the timetable:

We are allowing flexibility to staff and students to manage their time as they see fit. This allows both groups to work outside of normal school hours to allow for childcare needs of teachers and to allow students to help with childcare at home if needs be. (Survey Response, Non-DEIS, Munster)

Our strategy is 'protect the core', so some subjects have been running less frequently outside that core group. (Survey Response, Non-DEIS, Leinster excluding Dublin)

Many school leaders were happy to leave this balancing to teachers themselves rather than imposing one particular structure on them:

We have kept in touch with people regularly to get a feel for what they were juggling. We advised people to pace themselves before they burnt out; some teachers were able to keep up a very high percentage of 'live' classes; others needed to vary their time between 'live', starting sessions 'live' and then assigning work to students (while remaining available for queries). Ultimately, we have to work; it was hard for all of us to juggle, and some teachers were doing serious amounts of work late in the evening as they could not do all their work during the day. (Survey Response, Non-DEIS, Dublin)

Along with the balancing of flexibility and structure, the balance of providing students with enough work to ensure they were learning somewhat comparably to normal without overloading and overwhelming them had to be worked out over time. As they were hearing from staff and many parents, school leaders played a central role in helping staff work out this balance:

After an initial flurry in the first week or two things have settled down - teachers were terrified that they would be accused of not working from home. Students began to complain about the volume of work they were receiving from teachers. Parents also contacted the school and complained. We now have created a policy of one piece of work 
per subject with definite online times set up that suit teacher and student. (Survey Response, DEIS, Dublin)

School leaders sometimes played a more executive role, as in the case of the division of teachers' time and energy across different year groups. In particular, Leaving Certificate students were prioritised by many schools (prior to the cancellation of the exams themselves, at least). Due to the eventual cancellation of the Leaving Certificate the impact of this prioritisation on sixth year students will never be seen. The impact on students in other years who were neglected as a result, however, may well become evident in the future. The decision to prioritise was a reasonable one given the stakes of the Leaving Certificate and the unique conditions under which students were expecting to sit it. However, the inability of many schools to provide full support to all students during online learning does raise questions about the sustainability of online learning under present conditions. Given that the current fifth years will have to participate in the Leaving Certificate in the next academic year, the question of how to balance competing demands on distance learning will remain a pressing one. The Leaving Certificate itself will be discussed in greater detail in Section 4.4.4.

Guidance to staff also covered specific advice on online learning platforms and methods, though this guidance was often a suggestion for those struggling to adapt rather than a prescription for all teachers. One area of divergence within the data was the question of 'live classes' or video classes delivered over Zoom, Microsoft Teams or Google Classroom in real time. Some schools saw live classes as the gold standard for distance learning and encouraged teachers to offer them as often as possible, while others recommended limiting the number of live classes as they placed too great a burden on teachers and students.

The place of live classes within a distance learning environment will likely continue to be determined at the school level (or even at the level of individual teachers). While there are many contextual factors which influence a school's ability to provide live classes, there are also more general questions around the effectiveness of live classes across multiple fronts - student learning, student engagement, student wellbeing, teacher wellbeing - which must be answered through focused research to enable schools to make fully informed decisions.

\section{Communication}

As discussed in Section 2.4.2, effective communication was key to the functioning of the school during the closure of school buildings. Without repeating the findings discussed in that section, there is one element of communication salient to schools' ability to provide distance learning specifically. Direct and immediate feedback on online learning platforms and methods was vital to schools' ability to adapt and 
improve their offerings. While this feedback was in some ways more difficult to gather than the immediate feedback students (directly and indirectly) provide in the classroom, some school leaders found it far more useful in shaping provision. The novelty of the situation and the potential for clear and immediate changes to student learning seem to have played a central role in this:

The focus on learning, I mean I'm in the game a long time now and before I was a principal, I was a special needs coordinator and I've never in any school l've been in seen the feedback loop so short and powerful. 'This doesn't work for me, change it', 'okay I'll change it', that's never happened before. (Principal 3, DEIS, Dublin)

As distance learning solidifies and becomes established practice, it is important that this receptiveness to feedback and willingness to adapt accordingly is not lost.

\section{Devices and platforms already in use}

Many schools managed to cope without pre-existing device and platform use. However, the qualitative data make it clear that the transition to distance learning was far more straightforward for schools who were using existing systems of online learning rather than creating new ones. 'iPad schools' in particular reported an almost seamless transition, as students and teachers were already familiar with working on the iPads and material could be adapted for distance learning quickly and easily.

Virtual Learning Environments (VLE) were also pointed to as smoothing the transition to distance learning in schools which had been using them prior to the shutdown. In particular, VLEs like Google Classroom and Microsoft Teams ensured that staff were able to contact students using a platform they were familiar with. Some school leaders highlighted the technical difficulties and teething issues involved in setting these platforms up initially, difficulties which were far easier to deal with in school than remotely.

While school leaders who were able to adapt systems already in use to remote learning were clear that this made the transition to distance learning easier, it is not clear from the data that any of these made for better distance learning for students. Further research is needed to explore the effectiveness of the various approaches beyond the transition, especially given the mixed literature on iPads in Irish schools (Marcus-Quinn et al., 2019a).

\subsubsection{Barriers to distance learning}

Stakeholders experienced multiple barriers in the transition to distance learning. Barriers were linked to school or student circumstances, teacher competence or 
confidence, the wider COVID-19 situation and the nature of distance learning itself. Some of the identified barriers will end with the return to normality or become less pronounced as we become accustomed to the 'new normal'. Some could be solved (straightforwardly but in many cases not cheaply or easily) through investment in schools or communities. Others are the result of longstanding social and educational issues and can only be ameliorated through further support for marginalised students and their families. Finally, the perceived inherent inadequacies of distance learning require further research; are certain elements of teaching and learning truly impossible to offer remotely or just very difficult? If the former, what does this mean for remote learning going forward?

It is also important to note that the barriers to distance learning often intersect, complicating any efforts to overcome them. Students' capacity to engage was impacted by their home circumstances, their access to broadband and ICT and their own motivation, all of which impact on each other as well. The effect of these interlocking barriers on vulnerable groups will be considered in greater detail in the next chapter.

\section{Broadband and ICT Access}

As discussed in Section 2.1, limitations on access to broadband and devices were a major barrier to distance learning. Staff access to devices and broadband determined which approaches were possible for them to use, while different levels of student access led to different levels of engagement. Efforts were made to extend student and staff access, mainly centring around the distribution of devices. Where this was not possible, schools reported reaching students through the post and by phone. Despite these efforts, online methods appear by far the most effective approach to distance learning. It is therefore imperative that schools and policymakers consider ways to ensure all staff can provide online teaching and all students can avail of it, should there be a need to return to widespread distance learning in the future.

In addition to digital access, digital skills among staff and, to a lesser extent, students and parents shaped what was offered to students and what was taken up by them. As discussed above, schools who were able to continue using devices and platforms which were in place prior to the lockdown reported fewer issues among staff in adapting to distance learning. For many teachers who did not have this direct experience, the learning curve was steep. As will be discussed in the next section, many of these skills were picked up by staff over the course of the lockdown.

Something which surprised several school principals was the lack of digital skills among certain students. This difficulty was generally confined to a small number 
of students, often students who struggled with distance learning more widely and faced deeper challenges in remaining engaged. It is important to note that even among the 'digital natives' the technical skills required to access online learning are not universal and support may be required.

The support needed by schools in terms of broadband and ICT access and ICT skills will be covered in greater depth in Chapter 5 , as it is key to planning for the new academic year.

\section{Student Engagement}

Securing and maintaining student engagement was a key challenge for schools during this period. Overall, the quantitative and qualitative data suggest that most students engaged throughout the lockdown, but some struggled to engage or disengaged entirely. As well as the difficulties posed by some students' inability to access online learning, school leaders pointed to the impact of student motivation, family circumstances and the loss of the school environment on students' capacity and desire to engage. The latter will be explored more thoroughly in the next section as it represents a fundamental difference between online learning and classroom learning.

The issues of student motivation and their family circumstances were closely linked in many responses and across the interviews. Motivation is a complex and multifaceted phenomenon, but it would seem that the lockdown impacted extrinsic motivation more than intrinsic motivation. Among students with high intrinsic motivation, some schools reported an increase in self-regulated learning, something which will be explored further in the next section. Several respondents pointed to a greater rate of disengagement among low attaining students, suggesting that academic ability or interest mediated the effects of the transition to distance learning.

Meanwhile, for students who rely on extrinsic motivation, many of the extrinsic motivators disappeared. Pull-factors which encourage school engagement like relationships with students and staff and non-academic school activities were lost. Push-factors like repercussions for non-engagement were also reduced or removed by the closure of school buildings. In the absence of these, student motivation became more dependent on their own intrinsic motivation, parental support and schools' attempts to reach out under the new conditions. For students without a high level of intrinsic motivation or parental support, direct contact from the school could be effective, but often it was not enough.

A low level of intrinsic motivation was exacerbated by a lack of effective parental support, according to many school leaders. Both were strongly impacted by 
students' family circumstances, which affected student engagement both directly and indirectly. Some students were unable to engage because they found themselves caring for family members, working or otherwise occupied by new responsibilities. For others, difficult home environments made engagement much more difficult.

One issue which schools struggled with was determining who was unable to engage in distance learning and who was simply unwilling. Recognising the difficulty of differentiating between the 'can'ts' and the 'won'ts', several school leaders chose to focus on positive interactions, reaching out to establish contact and offer support to all non-engaging students.

Even among students who were engaged at the start, school leaders noted dropping levels of engagement as time went on. This was especially the case among third and sixth years after their State examinations were cancelled. However, the struggle to maintain student engagement over the months was also felt among the school at large, suggesting that distance learning might have issues keeping students involved over the medium and long term.

\section{Challenges of Distance Learning}

The long-term decline in student engagement appears to be linked to the challenges of distance learning as an approach, and especially to its differences from normal teaching and learning. Many of these differences have been touched on previously, especially the lack of structure and social relations in a distance learning context. The importance of student-teacher interaction was pointed to by many respondents, generally in the context of the impossibility of providing such interaction during distance learning. Overall, the consensus that distance learning could not compare with classroom teaching was overwhelming:

The greatest challenge is on the teaching and learning which are based on face-to-face interactions between teachers and students. Students do not have the support of their peers, teachers cannot pick up on the students who are struggling i.e. those students who are silent. Those students who by their body language would indicate that they do not understand what is being taught. It takes twice sometimes three times as long to do anything. Teachers are spending infinite hours preparing work, uploading work, scheduling Zoom classes and correcting work. (Survey Response, Non-DEIS, Dublin)

While schools would therefore prefer to operate as normal, there is the possibility that they will not be able in the immediate future. It is therefore vital that further work is done on establishing effective methods for distance learning, and so the next section will explore schools' positive experiences of distance learning. As well 
as preparing for the next crisis, many of these experiences may inform future provision in the everyday classroom.

\subsubsection{Positive experiences}

Even for those who had access, digital skills were pointed to as a barrier for teachers, parents and even students, leading to calls for training and support for each. On the positive side, the forced shift to distance learning gave many schools a newfound appreciation for the potential of ICT in the classroom, and there was a huge amount of upskilling among staff during the first few weeks of lockdown as they adapted to distance learning on the fly.

While the distance learning provided by schools did not (and could not) match their usual provision, overall school leaders were happy with how they had adapted to the new situation. Many highlighted the speed and effectiveness of their school's adaptation. Above all, the upskilling of teachers in a short period of time was hailed as a positive development which will have long lasting effects.

Beyond this successful reaction to adverse circumstances, school leaders pointed to certain aspects of distance learning which they found to be more effective than normal provision:

Distance learning has created opportunities to encourage more autonomous learning and creative teaching. It has helped to bring parents more on board. It has encouraged better staff collaboration. If closure had not happened due to a crisis and more time for preplanning had been afforded it could have been most effective. (Survey Response, DEIS, Munster)

In particular, the value and potential of certain platforms and methods was shown by teachers' and students' experiences with them over the course of the lockdown:

Teachers learned a lot of other types of app they could use. Flipgrid became a very useful app where they could introduce lots of different resources from various places and put them up together in class plans that they work with the students as well. The general resources that they were developing and making available on Teams improved dramatically from the start. (Principal 10, Non-DEIS, Leinster excluding Dublin)

Beyond the incorporation of new techniques and tools into their school's repertoire, some school leaders reflected deeply on what education should look like, especially in terms of assessment: 
There has [..] been some great learning on the various options of delivering learning by teachers and some great creativity of what has been learned shown by students... It has shown the options for assessment also, something that needs to be considered urgently now. The state terminal exams have been removed this year; we should move to a form of continuous assessment now. (Survey Response, Non-DEIS, Munster)

The possibility of different learning methods to reach students who are not thriving before the lockdown was also noted in several different contexts. One interviewee pointed to the improved engagement of some average attaining students compared to normal, suggesting that the different learning style suited some students even as it hindered others. As shall be discussed in the next chapter, a small cohort of students with special educational needs also fared better with distance learning than previously, suggesting that online learning platforms could be helpful in providing for these students in the future.

Overall, the lockdown period was a time of massive creativity and innovation in schools. The online learning systems which were created from scratch will continue to be available to schools, as will the skills acquired in building and operating them. While distance learning may never be able to fully match classroom teaching and learning, schools now have a clearer understanding of the essential components of an online system, the barriers facing distance learning and the potential of online learning. This will be of vital importance should online or blended learning be necessary again in the next academic year, but it will also have wider and deeper effects on the incorporation of ICT in Irish schools over the next decade. 



\section{CHAPTER 4}

\section{Impact on key groups}

This Chapter focuses on how particular groups within the school population have been impacted by the shutdown of school buildings and the rapid transition to distance learning. In particular, we consider Leaving Certificate students and Junior Certificate students, in addition to other groups such as students with Special Educational Needs, low-income students and students learning English as a foreign language.

\subsection{LEAVING CERTIFICATE STUDENTS}

First, we consider Leaving Certificate students. The preparations of sixth year students for sitting the Leaving Certificate examinations in June 2020 were suddenly disrupted by the shutdown of school buildings. Moreover, students were faced with a prolonged period of uncertainty over the fate of State examinations as the pandemic progressed. Practical examinations, including oral examinations in Irish and Modern Foreign Languages, were cancelled shortly after the closure of school buildings in March 2020, with students to be awarded full marks for any such examinations. Later, in May 2020, the cancellation of all written Leaving Certificate examinations was announced, with students instead being awarded calculated grades, including for all practical examinations for which they were previously to receive full marks. This effectively marked the end of Senior Cycle education, and indeed of all second-level education, for Leaving Certificate students at a time when they were at home under national travel restrictions. Not only were Leaving Certificate examinations cancelled, but significant events in the lives of students such as school graduations could only be held remotely. Clearly, this is a key group in the second-level school population that may have been significantly affected by the shutdown.

Figure 4.1 depicts how school leaders reported the impact of the shutdown on Leaving Certificate students across different domains. In each domain, most schools indicated either a 'negative' or a 'very negative' impact on Leaving Certificate students. Student wellbeing stands out in our results as having been particularly affected, with 83.8 per cent of schools perceiving a reduction in wellbeing among this group. Student learning and student motivation also appear to have been significantly affected at a time that would otherwise have represented the culmination of Senior Cycle learning for Leaving Certificate students, with 68.5 per cent and 65.4 per cent of school leaders indicating detrimental effects, respectively. 


\section{FIGURE 4.1 IMPACT OF SHUTDOWN ON LEAVING CERTIFICATE STUDENTS}

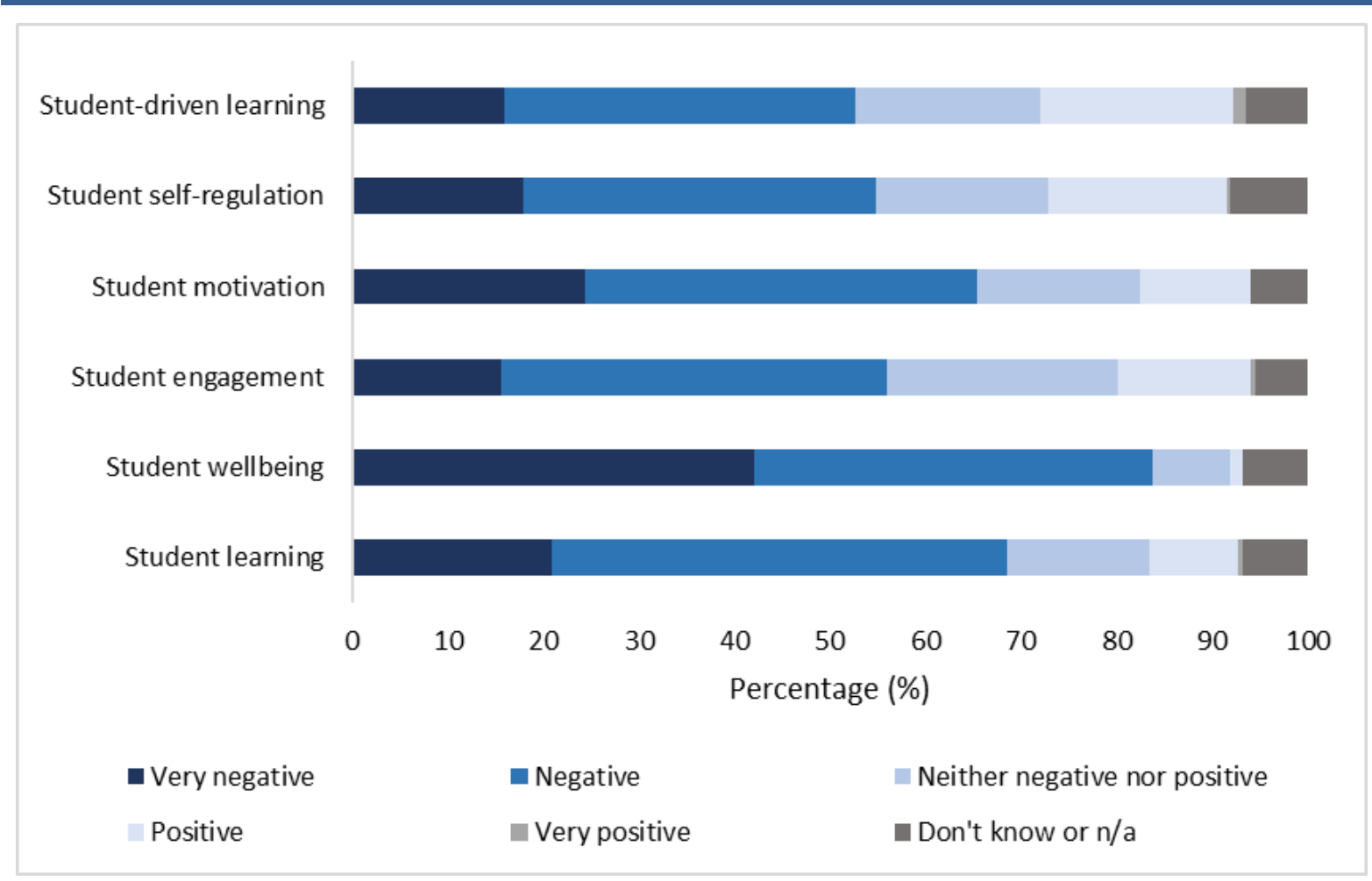

Source: ESRI online survey of second-level school leaders.

Note: $\quad$ Based on 232 responses.

These results point to a widespread negative impact on Leaving Certificate students across all schools. However, our results suggest certain inequalities in that some negative effects were exacerbated among DEIS schools. For example, as shown in Figure 4.2, 83.3 per cent of DEIS schools reported either a 'negative' or 'very negative' impact on student learning among Leaving Certificate students, compared with 62.3 per cent of non-DEIS schools (Chi-squared $=14.4, p=0.01$ ). An even greater difference between DEIS and non-DEIS schools was evident for student-driven learning specifically, with 72.3 per cent of DEIS schools and 44.6 per cent of non-DEIS schools reporting student-driven learning to be worse following the shutdown (Chi-squared $=19.1, p=0.00$ ). Similarly, student self-regulation also appears to have been worse affected among DEIS schools in our sample (Chi-squared $=17.0, p=0.01$ ). In terms of student learning, we also noted a difference between schools based on the availability of high-speed broadband in their catchment areas. While 67.0 per cent of schools in areas with higher broadband availability reported a detrimental effect on student learning, the corresponding figure among schools in areas with lower coverage was 69.4 per cent (Chi-squared $=11.2, p=0.05)$. 
FIGURE 4.2 IMPACT OF SHUTDOWN ON LEAVING CERTIFICATE STUDENT LEARNING BY DEIS STATUS

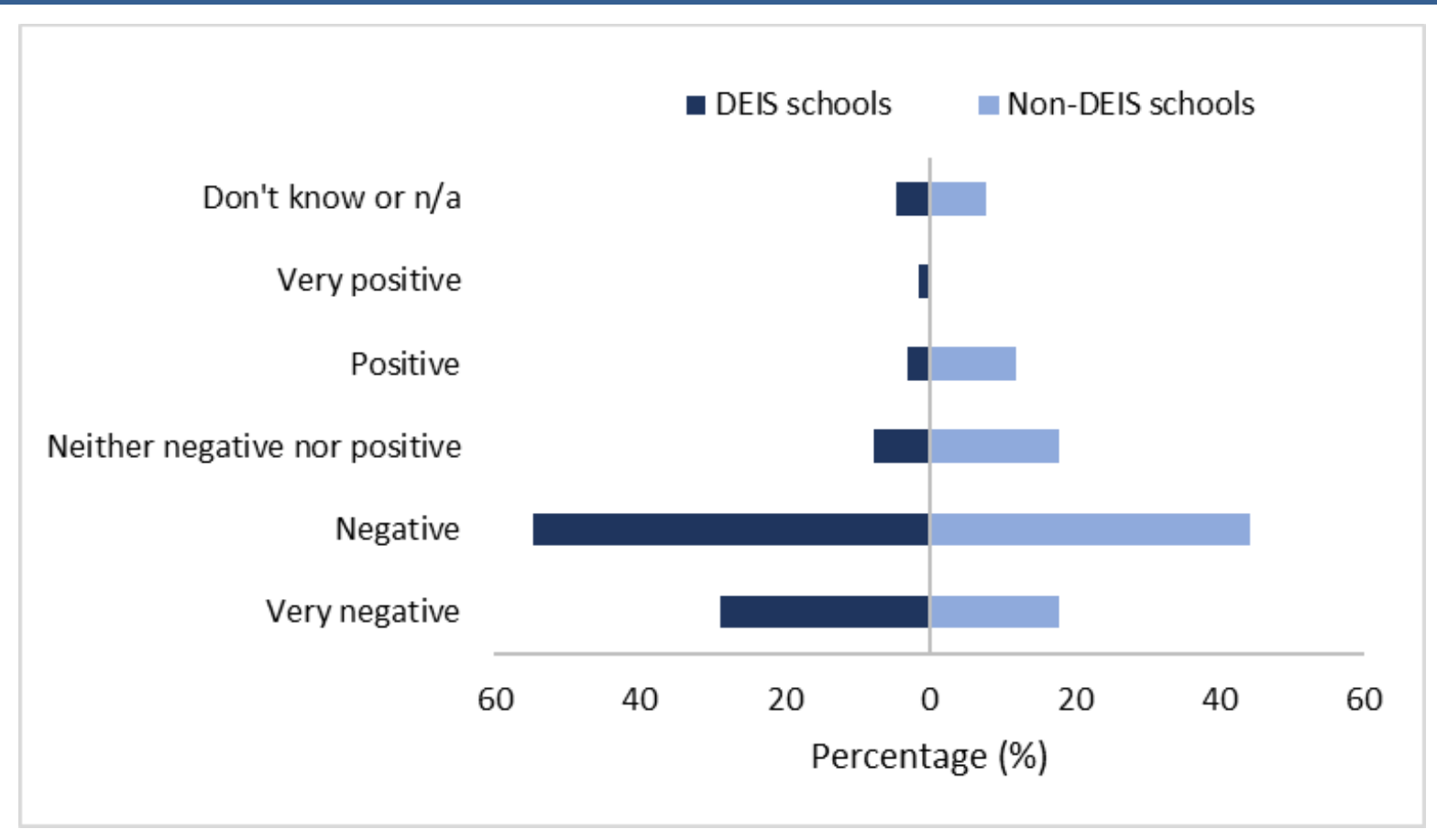

Source: ESRI online survey of second-level school leaders.

Note: $\quad$ Based on 232 responses.

Another example of inequality in the impact of the shutdown on Leaving Certificate students was the effect on student engagement. As illustrated in Figure 4.3, student engagement was perceived to have decreased in 74.2 per cent of DEIS schools in our sample, compared with 48.8 per cent of non-DEIS schools (Chi-squared $=17.6, p=0.00$ ). Again, a difference was also evident by local broadband availability with a detrimental effect reported by 57.3 per cent of schools in areas with lower broadband availability, compared with 54.6 per cent of schools in areas with higher coverage (Chi-squared $=11.4, p=0.04)$. 
FIGURE 4.3 IMPACT OF SHUTDOWN ON LEAVING CERTIFICATE STUDENT ENGAGEMENT BY DEIS STATUS

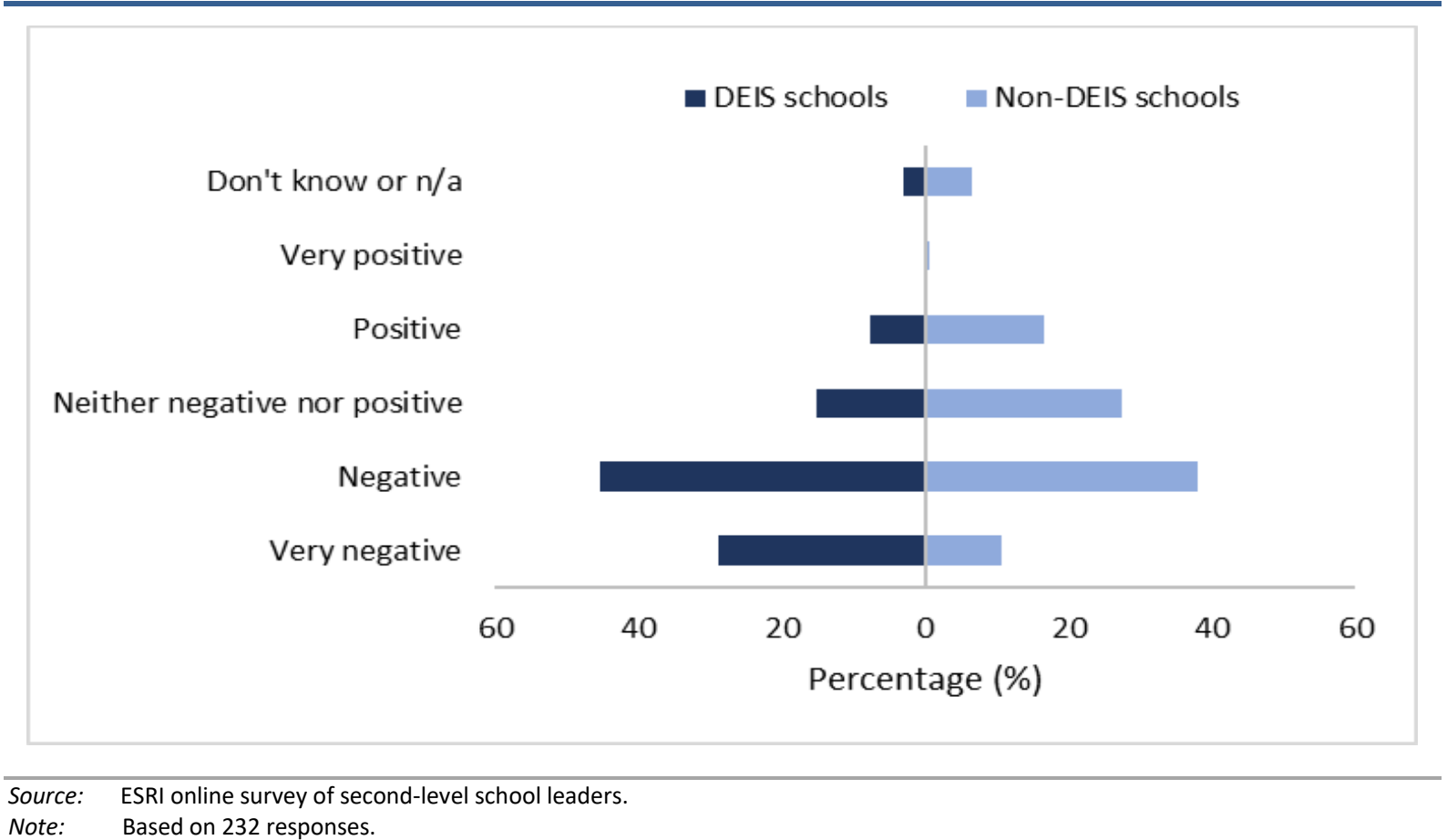

Note: Based on 232 responses.

\subsection{JUNIOR CERTIFICATE STUDENTS}

Junior Certificate students are another key group worth considering in detail. In April 2020, it was announced that Junior Certificate examinations, due to be undertaken by third year students in June 2020, were cancelled. Instead, individual schools were free to devise their own end-of-year assessments for third year students, without the involvement of the State Examination Commission (SEC). This meant that third year students completed their Junior Cycle education without sitting any State examination, which can be considered a dramatic change in the experience of Junior Certificate students. In our survey, school leaders were asked to indicate the effect the shutdown had on third year students across several domains, and responses are presented in Figure 4.4. In all domains, most schools indicated that the impact of the shutdown was either 'negative' or 'very negative' for Junior Certificate students. For example, 74.6 per cent of schools reported that the shutdown impacted negatively on student motivation, an understandable result given the abrupt cancellation of State examinations which Junior Certificate students had been striving towards. Student wellbeing was also considered to be negatively impacted by 76.2 per cent of schools. 


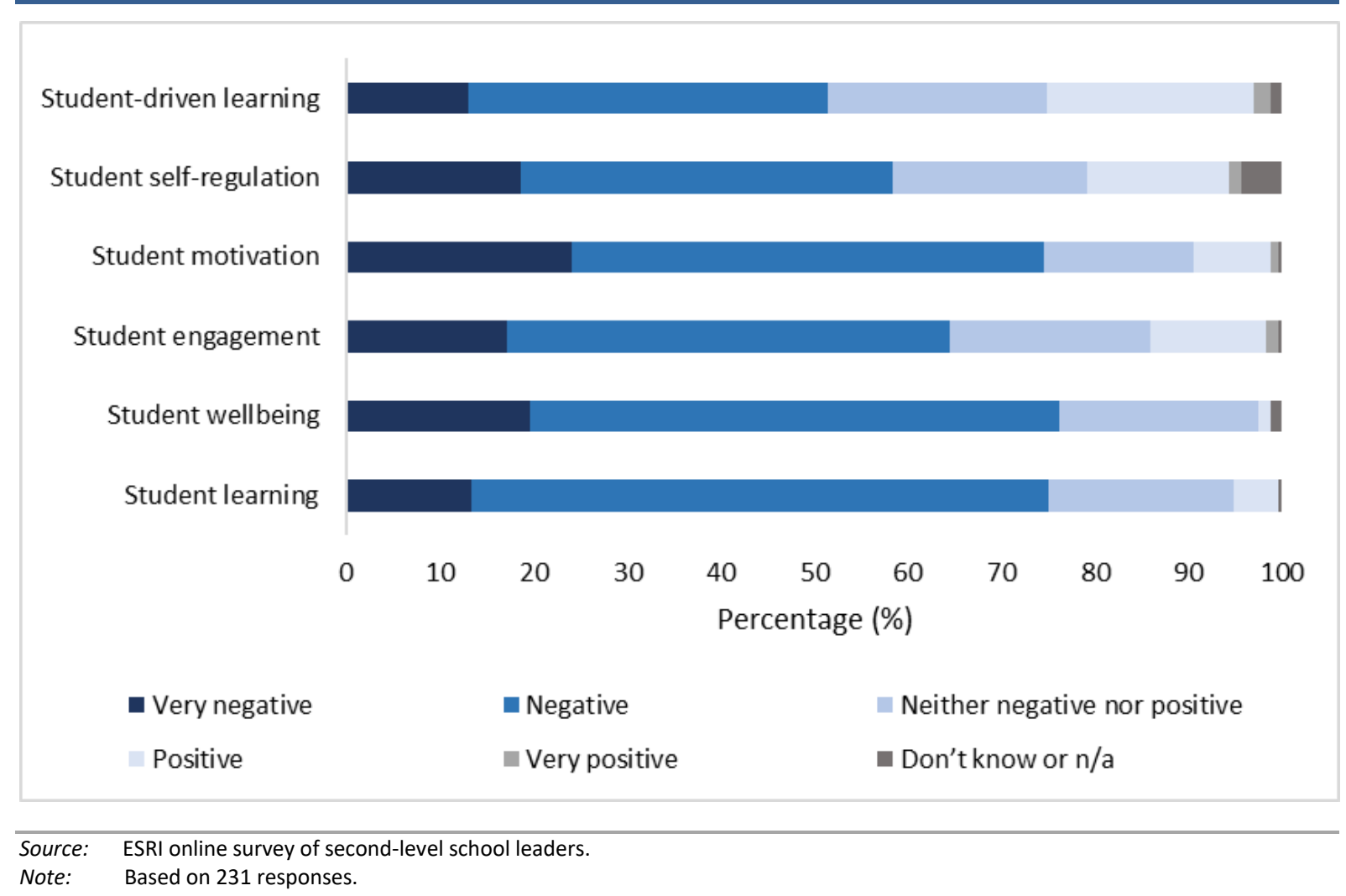

These results suggest that Junior Certificate students from the 2019-2020 academic year are a key group who may have been particularly negatively affected by the shutdown of school buildings and the move to distance learning, and in their case by the cancellation of Junior Certificate State examinations as well. As was the case for Leaving Certificate students, this impact appears to have been even more pronounced among DEIS schools, with significantly higher percentages of leaders of DEIS schools reporting negative impacts on student learning, student wellbeing, student motivation and student-driven learning among Junior Certificate students compared to leaders of non-DEIS schools. For example, 80.3 per cent of DEIS schools indicated either a 'negative' or 'very negative' impact on student wellbeing, compared to 74.3 per cent of non-DEIS schools (Chi-squared $=12.2$, $p=0.02$ ). This difference was even larger in relation to student engagement, as illustrated in Figure 4.5, with 78.8 per cent of DEIS schools and 59.0 per cent of non-DEIS schools reporting lower levels of student engagement as a result of the shutdown (Chi-squared $=34.3, p=0.00$ ). 
FIGURE 4.5 IMPACT OF SHUTDOWN ON JUNIOR CERTIFICATE STUDENT ENGAGEMENT BY DEIS STATUS

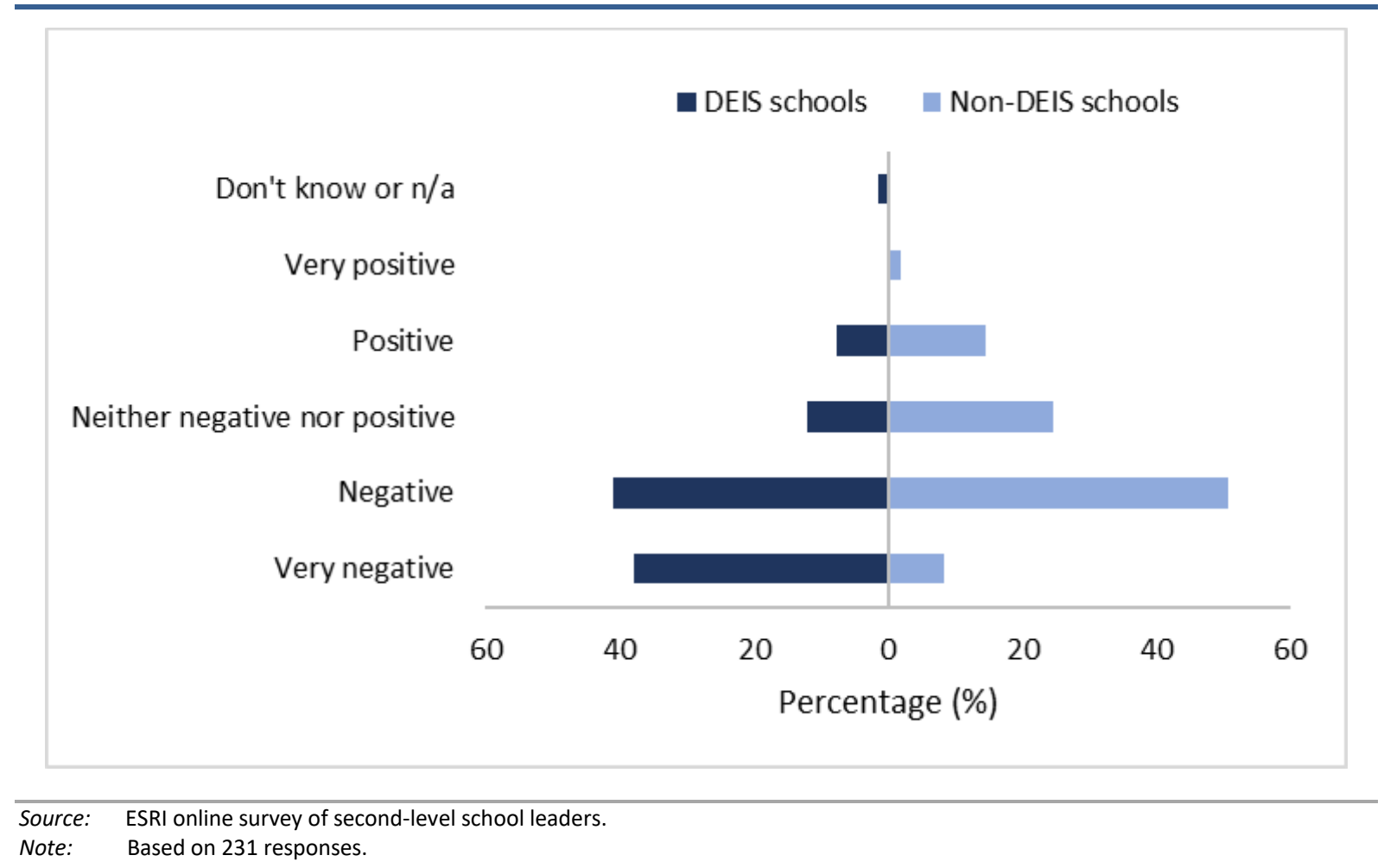

\subsection{OTHER KEY GROUPS}

Other key groups in the school population that may have been particularly affected include students with Special Educational Needs, students from low-income backgrounds, students studying English as a foreign language, and Transition Year students. Figure 4.6 summarises how the shutdown of school buildings affected these groups according to responses from school leaders. As expected, the shutdown appears to have had a largely negative impact on each of these groups. In particular, an overwhelming majority of 89.3 per cent of schools reported a detrimental impact on students with Special Educational Needs, while 86.4 per cent of schools reported the same for low-income students. For each of these two groups, a majority of schools categorised this impact as 'very negative'. These effects appear to have applied in similar measure across all school types, for example with no statistically significant differences between responses from DEIS and non-DEIS schools. Clearly, therefore, these are other key groups of the student population who have been particularly negatively affected by the shutdown of school buildings. 


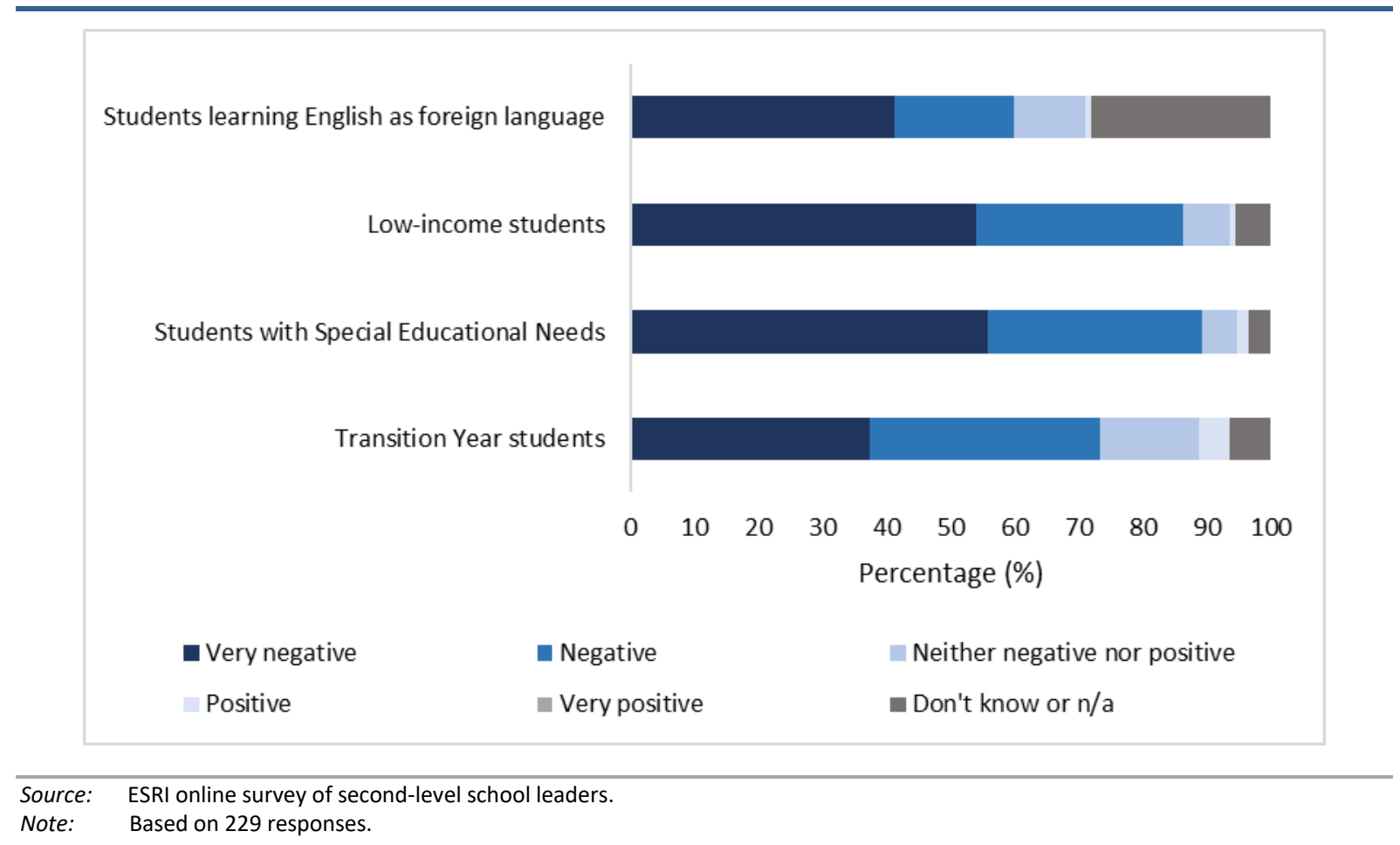

\subsection{QUALITATIVE FINDINGS}

The qualitative research presented here also demonstrates that while the closure of school buildings impacted all second-level students, its effects were not felt by all equally. Perhaps the strongest finding was that many of the disproportionate impacts reflected pre-existed disparities and inequalities and will likely serve to exacerbate these inequalities among the cohorts affected. In particular, students from socioeconomically disadvantaged backgrounds and students with special educational needs were deeply affected by the shift to distance learning. Students in rural areas were also disproportionately affected by the digital divide, particularly in relation to broadband access. As well as these groups, specific year groups were more impacted by the lockdown than others, especially sixth year students. School leaders also voiced concerns about the lockdown's impact on current fifth years.

\subsubsection{Students from disadvantaged backgrounds}

Educational disadvantage is a multi-faceted issue, and many of the linked or underlying phenomena were affected by the COVID-19 lockdown. Students from disadvantaged backgrounds often also lacked access to adequate broadband and devices and for many a difficult home life was made even more difficult by the social and economic consequences of the pandemic and lockdown.

Above all, some of the issues facing these students went far beyond their day to day learning - one interviewee based in a DEIS school described the level and 
nature of support students required from school:

...we're part of the DEIS scheme so we were still handing out food and we decided to pursue that every Wednesday. Instead of lunches we adapted that to bags of foodstuffs that would be usable by families over a week. And that increased week on week. I think we were giving out 75 packs of food every Wednesday. So that's around 60 families. (Principal 8, DEIS, Munster)

In general, students from disadvantaged backgrounds are more likely to require more intense support for a number of reasons. The lockdown strained these networks of support, and some students lost touch with them altogether:

Students miss school and each other and no matter how hard we work to connect students to each other, their learning and the school, it is no comparison to the real thing.... I have huge admiration for the resilience students and staff have shown. Remote school has been a particular challenge for some students with additional needs and I worry for them if the closure continues into the next academic year. We run the risk of a minority of students never returning to school at all. The gap in their learning will be too great and the return may seem too daunting. (Survey Response, Non-DEIS, Dublin)

As discussed in Section 3.8.2, motivation and parental support were also issues for these students, as students' lower enjoyment of education and belief in its value as well as a lack of family experience with education and capacity to assist students' learning at home compounded to reduce student engagement. In general, the role of parents in their children's education and the impact of students' home situations on their ability to engage with learning have both been intensified by the lockdown. School leaders thus fear that one outcome of the lockdown will be a widening of the gap as pre-existing advantage and disadvantage are compounded:

The most stark learning from the whole episode is the level of educational disadvantage has increased since closure and it is very difficult for schools to know how to bridge that gap. (Survey Response, Non-DEIS, Leinster excluding Dublin)

Disadvantaged students are further disadvantaged; disparity of opportunity is widened between the socioeconomic groups. (Survey Response, Non-DEIS, Munster)

\subsubsection{Students with SEN}

As with students from socioeconomically disadvantaged backgrounds, students with special educational needs experience adverse outcomes in the school system at the best of times. For many, the impact of lockdown was strongly negative, 
cutting them off from vital school-based supports while also bringing new pressures to bear on them.

In particular, meeting the specific learning needs of students with SEN was pointed to as a key struggle. This difficulty providing suitable differentiated learning for students with SEN while teaching online was no doubt exacerbated by the difficult conditions under which the shift to distance learning took place, but many of the issues were linked by school leaders to the nature of distance learning itself. Without one-to-one contact and face-to-face interaction teachers struggled to provide the personalised instruction needed by students.

Issues which indirectly affected students' engagement like the shock to students' routine and wellbeing were also noted. For the former, several school leaders found that working with students on creating a new daily structure was successful.

In terms of student wellbeing, the Special Needs Assistance (SNA) role was pointed to as a support that students with SEN missed during distance learning, but one which could be adapted to provide useful support to students in their own homes. SNAs in many schools remained in close contact with students and offered advice to students and parents on managing student learning.

As well as affecting students' academic progress, school leaders feared the shift to distance learning would impact negatively on students' social skills and selfregulation. The shortcomings of distance learning discussed in Section 3.8.2 are amplified for students with SEN, for whom personal development is particularly dependent on strong in-school supports.

One unexpected finding was that for a small subset of students with SEN the shift to distance learning was a generally positive experience. Some students who experienced anxiety around school as a social setting preferred online interactions. Several interviewees mentioned that school refusers with a number of additional needs and mental health issues reengaged after the shift to distance learning. While these were a small number of students, they all remained engaged throughout the lockdown period, even as engagement more widely was dropping.

This phenomenon suggests that distance learning has potential for keeping school refusers engaged in education, as well as for generally improving the experiences of some students with SEN. As schools begin to return to school-based learning, ways to preserve and build on this progress should be explored. For most students with SEN, however, school leaders perceived distance learning to be a negative 
experience. Reconnecting with these students and making up for lost learning (academic and non-academic) will be vitally important in the new academic year.

\subsubsection{Rural schools}

As discussed in Sections 2.1 and 3.8, the digital divide in access to broadband was in many ways also an urban/rural divide. Both staff and students in rural areas were affected, meaning that even those with access to broadband themselves could be negatively affected by others' lack of access.

Another negative impact unique to rural schools was felt among a specific subset of those students whose ability to engage with distance learning was affected by their having to work outside the home. Several rural schools reported that students had to work on their farms during the lockdown. While this was flagged as an issue by many school leaders, it is not clear how many students were affected or how much more of their time was taken up by farm work this year than in an average year.

\subsubsection{Leaving Certificate students}

Much of the worst of the impacts of the lockdown appear to have been felt by sixth year students, who experienced a particularly intense version of the uncertainty and anxiety which impacted all students. The stress which generally accompanies the high stakes exam became overwhelming for many students:

[There had been] Increased stress for the students who have worked extremely hard for the past 5/6 years. Students who would have got their Leaving Cert started to disengage, especially in rural areas. (Survey Response, Non-DEIS, Munster)

The lack of clarity over what the rescheduled Leaving Certificate would look like further impacted these students' ability to plan and organise their learning and their wellbeing in general:

Huge impact on mental health and stress, caused by uncertainty regarding the Leaving Cert... good students couldn't see the end line and worried they could maintain the work they were doing; weaker students couldn't see an end so many gave up. Students felt unmotivated and unheard and wondered did anyone know what they were doing. In a time of national uncertainty, they felt forgotten and an after-thought. (Survey Response, Non-DEIS, Munster)

The uncertainty regarding the holding of the exams has created huge anxiety. Vulnerable students have gone off the grid completely. All find it hard to engage remotely. (Survey Response, Non-DEIS, Munster) 
The issues around distance learning in general, from the lack of social connection to the struggle to motivate oneself to the challenge of adapting to new platforms and approaches were felt particularly keenly by sixth year students as the usual pressure of the Leaving Certificate combined with the unprecedented situation:

It has caused a lot of anxiety due to uncertainty regarding the Leaving Certificate. It has knocked many students out of their routine as things such as supervised study are also unavailable. Learning and teaching online is extremely tiring, according to reports from our students and teachers... With the best will in the world teachers also are not as accessible as they are in school, given that they are at home minding their own families and children etc. This also impacts sixth years negatively, as they may be more isolated. (Survey Response, Non-DEIS, Leinster excluding Dublin)

Regarding the eventual decision to cancel the Leaving Certificate examinations and replace them with Calculated Grades, opinion was mixed. Some school leaders felt that sitting the exams in July would have been fairer and more justifiable. Others, however, saw the idea of continuing with the exams as untenable, especially given the cloud of speculation surrounding them. Differences in students' capacity to engage with distance learning during the lockdown was highlighted as a particular concern; if the exams had gone ahead many school leaders felt vulnerable groups would have been particularly impacted. The level of disengagement reported among sixth years even before the announcement of the cancellation bears this out, suggesting that many students would have performed poorly or not participated at all had the exams gone ahead.

Calculated Grades were seen as generally fair, if far from perfect. Several school leaders had told staff to mark 'benignly', to credit students with what they believed they were capable of achieving. They noted that some students, particularly boys, who may have 'knuckled down' after Easter would likely fare worse with Calculated Grades than they would in the exams but felt that this was unavoidable.

A small number expressed deeper concerns with the Calculated Grades process, generally relating to communication and guidance from the DES and the SEC. The stress it placed on teachers was mentioned by many school leaders, though this was generally felt to be manageable with support from senior management and other staff. One school had its first cohort of Leaving Certificate students this year, and were unsure of how grades would be treated by the SEC. Another school leader expressed frustration with the communication around student levels (Higher versus Ordinary) in the grading process, tying it into wider frustrations with communication from the DES. 
Beyond the impact of the decision itself, the intense media coverage of the Leaving Certificate decision-making process and ultimate result was identified by some school leaders as contributing to students' anxiety and uncertainty and ultimately making a difficult situation worse:

Huge stress and anxiety especially with the constant bouncing of State exams around as a topic in the mass and social media. (Survey Response, DEIS, Leinster excluding Dublin)

As well as these challenges, some school leaders did report on positive aspects of the experience, chiefly centred on students' quick adaptation and effective use of remote learning, as well as a perception of higher engagement among sixth years than other years. A rise in students' ability to manage their own learning was also reported by a small number of school leaders, a development which could prove hugely helpful for students transitioning to third-level.

As well as being a high stakes exam, the Leaving Certificate is also a significant rite of passage for Irish students, and the loss of this and other milestones was noted by many school leaders. Second-level schooling is a place of personal as well as academic development, and the abrupt end of sixth years' time at school was pointed to as a huge loss to students:

Heart breaking for them. Their six years has finished abruptly on a Friday afternoon following the Minister's announcement that the Leaving Certificate exams were no more. These students have planned a rite of passage and the end of the journey involves school graduation and saying their goodbyes. All of this is gone. (Survey Response, NonDEIS, Connacht)

\subsubsection{Fifth years}

A number of school leaders articulated concerns for their current fifth year students, as they would be facing into sixth year in the autumn having missed a significant period of normal schooling. Again, there was a worry that the impact would fall disproportionately on vulnerable students who were more likely to have fallen behind over this period. School leaders worried that some of these students would not come back to school at all, especially if normal social interactions in the classroom and non-academic activities remained severely restricted:

...we probably have a bigger concern about our fifth years [than sixth years]. We've [over] a hundred... fifth years and a not insignificant number haven't been engaging with the work. As the time went on the numbers who were engaging began to fall so, we'd have a concern 
about those students for next year. (Principal 6, Non-DEIS, Leinster excluding Dublin)

Several schools were planning ways to re-engage students and bring them up to speed in the autumn, generally through providing these students extra class time in key subjects and prioritising them in any reopening plans. One school leader, however, felt that the issue was too large to be tackled at the individual school level and that a national level approach was needed. Such a national response will also need to ensure that a full complement of higher education places will be available to first-time applicants in 2021.

The current fifth years will need additional support in the area of wellbeing next year as they are the ones stressing most at present because they know that the learning has not been as good, and they know the traditional Leaving Cert will return next year. Support and changes to the Leaving Certificate will be needed for this cohort of students. (Survey Response, Non-DEIS, Connacht). 



\section{CHAPTER 5}

\section{Planning for future reopening}

In general school leaders were confident that they could provide students with a high standard of teaching and learning in the new academic year, provided they received certain necessary supports. There was widespread uncertainty over what schools and classrooms would look like upon reopening, with school leaders preparing for everything from fully online provision to a return to normality. The prospect of some level of blended learning where students would receive a mix of classroom and distance learning was seen as the most likely outcome by many, even as they prepared plans for the full spectrum of possibilities.

Considering this range of possibilities, the biggest demand of schools was for clarity. Several interviewees just wanted to receive guidelines and restrictions, whatever type of return those guidelines and restrictions looked like. School leaders were clear in stating that clarity and detail were vital to any instructions as they needed to be able to act on them without constantly having to refer back with queries. Within these clear and detailed guidelines, however, school leaders wanted to retain a measure of autonomy in order to be able to act based on their own judgement and local context.

As well as enhanced communication from the DES, schools reported a need for concrete supports in order to provide for students upon the commencement of the new academic year. Principals were asked 'Are further supports for your school required from DES as a consequence of the pandemic?' - in response a number of key areas were prominent, these included: ICT/broadband support, COVID-19 management support, communication, financial support, CPD/training and supports for students.

\section{ICT Support}

Requests for ICT funding centred around devices, for both students and staff. Several mentioned that the emergency DES ICT grant had been used up and now further funding was required. The need for a device for every student and every teacher was articulated by many respondents and in several interviews.

As well as devices, a small number of respondents mentioned the need for funding for online classroom platforms like Schoology. More than funding for these platforms, school leaders wanted guidance in selecting the best platform for their school. Many reported being overwhelmed by recommendations and advertising, struggling with too much choice rather than too little. School leaders felt that there 
was no source they could trust for advice, as the DES and Non-Governmental Organisations were seen as offering lots of recommendations but no concrete endorsements, and anyone else they discussed platforms with was generally trying to sell them something. As schools look to consolidate or expand their online learning methods for next year, support in selecting effective platforms will be crucial.

\section{Broadband availability}

High-speed broadband access was a key driver of unequal capacity to engage in online learning and so calls for support in extending it to staff and students are no surprise. The responses in the survey and especially in the interviews generally recognised that extending this access through infrastructural investment in rural Ireland was necessary in the long run but unlikely to bear results in the short term.

In the more immediate future, several possibilities were mentioned by school leaders. Providing students with mobile credit directly so that they could use mobile data was seen as a solution for a small number of cases, if not widely feasible. Ensuring that students were not capped in their data usage was mentioned by several school leaders as necessary to enable students using mobile data to access data-heavy online learning methods like live or recorded video classes. Providing students with mobile data dongles was also suggested.

School leaders were not clear on how these supports would be provided or who would be responsible for them - broadband access is a challenge that needs to be solved but one without straightforward solutions.

\section{COVID-19 management support}

Another pressing area of concern for schools was how they would ensure staff and student health and safety when reopening. Communication over the necessary protocols was central to these responses, as discussed above. The need for funding and support in actually setting up and maintaining the protocols was also voiced by some but not all schools. Personal Protective Equipment (for both staff and students), hand sanitising equipment, screens and deep cleaning were all mentioned as areas where schools needed support.

In the interviews, some school leaders also mentioned the issues they would have with space in their school and suggested that support in acquiring more space could allow more students to take part in classroom learning. One interviewee also pointed to the possibility of using community halls or similar spaces to accommodate students to provide a suitable environment for remote learning for those with inadequate space or broadband at home. 
A number of responses indicated that further funding in general would be needed without specifying a particular area:

As we look to September... Yes, we are in the Voluntary Secondary School Sector and the school budget has always been very tight. We are just managing to keep going financially. (Survey Response, NonDEIS, Munster)

\section{Training or CPD}

While many school leaders saw the lockdown as a period of rapid upskilling among their staff, many still felt that there was the need for formal training should blended or remote learning continue when schools reopen in August. One school leader identified the move to virtual CPD as a positive of the wider shift to remote working, enabling more teachers to participate in training than would be possible if they had to travel to a single location.

One interviewee suggested that schools should set aside one week at the start of term to prepare teachers for blended or remote learning, even if it meant students started later.

\section{Student support}

A variety of supports which students would need to cope and thrive were identified by school leaders. Schools who participated in the School Meals programme were especially concerned about how students and their families would cope over the summer, while one school which was not part of the programme had nonetheless found itself supporting families in need with food parcels. Depending on economic developments over the next few months, more families could find themselves needing a greater level of this kind of support across DEIS and non-DEIS schools.

Student wellbeing was also identified as a key concern, with several school leaders suggesting that an increased allocation of guidance counsellors would be helpful, especially in the case of continued remote or blended learning. Greater access to external supports like CAMHS (Child and Adolescent Mental Health Service) and NEPS (National Educational Psychological Service) was also highlighted as crucial. Additional support for students who had suffered a bereavement during the pandemic was mentioned by a very small number of schools, reflecting the limited spread of the outbreak in Ireland.

\section{Additional staff}

In order to run a functioning school while ensuring adequate social distancing, many school leaders felt that more staff would be needed both inside and outside the classroom. More teachers would be needed to cope with the restricted class sizes, more cleaning staff to meet health and safety standards and potentially more 
non-teaching staff to supervise students taking place in online learning in school. One interviewee put the number for a blended learning return at 1.25 times the current allocation of teachers.

In the event of blended learning or a return to distance learning, school leaders emphasised the need for staff members responsible for technical support. Many schools had identified an ICT postholder or a staff member(s) who was informally responsible for technical support but felt that this was not adequate or sustainable for continued online teaching.

\section{Curriculum management}

The issue of 'lost time' in terms of covering the curriculum was raised by several respondents, particularly in relation to current fifth year students as discussed above, but also for current second years. In order to prepare these students for their State examinations next year, school leaders were planning a variety of inschool measures, but some felt that this is unlikely to be sufficient. In order to avoid the uncertainty surrounding this year's Leaving Certificate, several school leaders wanted to see a clear plan for next year, possibly featuring reduced curricula or allowing students to reduce the number of subjects taken.

\section{Support for students with SEN}

A general call for more support for students with SEN and a call for a greater allocation of SNAs were the only external supports mentioned specifically for students with SEN. While students with SEN were mentioned only twice in the responses to this particular question, they featured heavily as a concern of school leaders - as discussed in Section 4.4.2.

\section{Staff wellbeing}

One survey respondent mentioned the need for support for staff wellbeing across the whole school team:

Yes - in particular around staff wellbeing. This has taken a huge toll on people's mental health, in particular senior management. (Survey Response, Non-DEIS, Munster)

In the interviews, several school leaders mentioned the need for support for staff wellbeing, particularly in the case of remote or blended learning. In particular, they emphasised that the last few months had left teachers and management exhausted and that stronger supports and structures to prevent burnout needed to be implemented when schools reopened. The use of the summer to plan for the return and create these structures and supports was seen as the best way of avoiding the frantic adaptation which had characterised much of the lockdown. In addition, enhanced counselling support for school staff was also highlighted as much-needed ongoing support. 


\section{CHAPTER 6}

\section{Conclusion}

\section{$6.1 \quad$ INTRODUCTION}

There is little systematic evidence on how second-level schools have responded to the period of school closure and how this is impacting on school leaders, teachers, learners and their parents across the diversity of school settings in Ireland. This study set out to address that dearth of evidence, drawing on survey data and indepth qualitative research with leaders of second-level schools. In doing so, the study provides insights from those at the coalface in addressing this unique period in Irish education. This discussion reviews how this evidence can shape policy, not only in both the immediate planning and support of distance learning strategies, but also in terms of broader school policies and practices that can act as 'drivers' of improvement and systemic change.

We can potentially learn a lot from what other educational systems have 'got right' and from the measures that have not succeeded. However, it is vital that, in drawing on such evidence, we do not fall into the trap of advocating 'policy borrowing'. The nature and structure of national educational systems reflect a multiplicity of historical, social, cultural and economic factors, making it impossible to 'transplant' certain measures from one country to the other. We can, however, usefully engage in 'policy learning', by reflecting on existing international research and policy development through the specific lens of the Irish educational system and its societal context (McCoy and Smyth, 2013). Our study is thus set in the context of international evidence on how school closures have impacted teaching and learning within and across societies but is fundamentally concerned with understanding experiences in the Irish context. There is little doubt that enormous efforts have been made across school leaders, teachers and stakeholders, but we now have a unique opportunity to assess what worked well and what did not. How have Irish schools, teachers, students and parents responded to the crisis and what can we learn from this?

\subsection{SUMMARY OF FINDINGS}

While much of the discourse in Ireland thus far has reflected international responses to COVID-19, there is an urgent need for a robust evidence base within Ireland, to guide our reflections on this period and the policy learnings we glean. In working with school leaders, and adopting a mixed-method approach, the study provides a rich insight into transitions to distance learning across diverse school settings. The results provide evidence for supporting post-lockdown transitions, as well for ameliorating the adverse impacts of the pandemic on particular groups of students. 
School leaders reflected on the challenges posed to staff and students by the 'new normal', the lack of an opportunity to prepare for the closure of school buildings and the difficulty in short-term and medium-term planning under constant uncertainty. The transition to distance learning was in general more straightforward for schools who were using existing systems of online learning rather than creating new ones. 'iPad schools' in particular reported an almost seamless transition, and VLE were also pointed to as smoothing the transition to distance learning in schools which had been using them prior to the shutdown. However, a digital divide, relating to access to both high speed broadband and digital devices, was reported for nearly half of schools, assuming a greater prominence for DEIS schools. In providing digital devices to students, schools made great efforts to overcome the barriers experienced by some students.

However, school leaders report that the move to distance learning impacted on student engagement and participation. Student engagement with learning also appears to be linked with local availability of high-speed broadband - the impact on student engagement is greater in areas with poorer broadband coverage, suggesting a frustration with their capacity to engage with online learning modes. Student engagement is seen as particularly adversely impacted in DEIS schools, raising concerns over the potential longer-term impact on achievement and retention at DEIS schools. The move to distance learning has impacted particularly severely on the capacity of students to engage with group work and practical work, but has promoted the development of independent learning skills, particularly where high-speed broadband availability is high. These findings point to a greater impact of school closures on student's extrinsic motivation than intrinsic motivation. Among students with high intrinsic motivation, some schools reported an increase in self-regulated learning. But for students who rely on extrinsic motivation, many of the extrinsic motivators disappeared.

Teachers too were impacted by local broadband availability and experienced a range of difficulties in working from home, including workload and challenges in creating digital content. School leaders were almost unanimous in their praise of staff, pointing to their dedication to their role and their eagerness to adapt successfully to distance learning. However, many also pointed to a difficulty in maintaining staff morale and promoting staff wellbeing during the period and raised questions about the sustainability of schools' efforts to provide distance learning. While teachers were seen to have benefited from supports from colleagues and school leaders, they were seen to be less positive about the guidance they received from the DES. 
Schools are, at heart, communities, and the challenges of maintaining these communities and continuing to provide the usual range of supports to everyone in the community were immense. The school building is a vital location for human contact which many school leaders found difficult if not impossible to replace. The efforts of staff to maintain the community and effective communication were recognised by many respondents. Various methods of communication were praised as possible replacements to in-person contact, for the duration of the crisis at least. However, maintaining the school community and a supportive school environment was difficult. Perhaps most importantly, the school's pastoral care for students became exponentially more difficult with the move to distance learning, with wellbeing an area of particular concern. The evidence in this study and the recent figures published by the CSO as discussed in Section 1.3.1 highlights the adverse impact of COVID-19 on mental health and wellbeing for many young people. The difficulties are seen to be particularly pronounced in DEIS schools, for students with additional needs and those from low-income families.

Overall, students from socioeconomically disadvantaged backgrounds and students with special educational needs have been deeply affected by the shift to distance learning. The role of parents in their children's education and the impact of students' home situations on their ability to engage with learning have both been intensified by the lockdown. School leaders thus fear that one outcome of the lockdown will be a widening of the gap as pre-existing advantage and disadvantage are compounded. For many students with additional needs, the impact of lockdown was also seen as strongly negative, cutting them off from vital school-based supports while also bringing new pressures to bear on them. Students in rural areas were also disproportionately affected by the digital divide, particularly in relation to broadband access. As well as these groups, specific year groups were more impacted by the lockdown than others, especially sixth year students. School leaders also voiced concerns about the lockdown's impact on current fifth years and called for a timely response at a national level, ensuring a full complement of higher education places for first time applicants in 2021.

\subsection{POLICY IMPLICATIONS}

In the context of constrained public resources, it is important that policy, both immediate and longer term, is informed by sound evidence. We identify a range of policy implications emerging from this study, the emphasis being on guiding policy at national and school levels, and less on feeding into the practice of individual teachers.

COVID-19 has exposed wide disparities in access to digital devices and high-speed broadband. It has long been understood that many parts of the country have no prospect of receiving a commercial high-speed broadband service without 
government support, and the National Broadband Plan promises to close this gap over time. The COVID-19 pandemic has brought this gap into sharp focus within the education domain. Our results show that schools in areas with limited broadband availability have had to respond differently from those that could rely on better digital connectivity to their students. Moreover, digital learning requires not just a network connection but a suitable access device, and not all students have one. Some also lack the skills to use these tools appropriately. When a subset of students lacks connectivity or has to rely on inadequate access devices, this can potentially disadvantage not only those students but also other students in the school with better access, because teachers have to adjust their methods to cater for all their students.

The pandemic brought with it an extraordinarily sudden, unanticipated and farreaching need to switch to distance learning. Ireland's second-level school system could hardly have anticipated this, and one might argue that no system would have been designed to accommodate such a contingency. Nevertheless, technologysupported learning will be part of the future of education (and central to many other aspects of life including telehealth, employment, accessing supports, social connectivity). While measures are in place to extend high-speed broadband infrastructure to underserved areas, there are policies that could be considered that relate to socio-economic environment, with students from lower socioeconomic groups having less access to technology than their more well-resourced peers. Lack of access to devices and appropriate skills among some groups may be amenable to action in the short-medium term, and indeed many schools have tried to address these gaps in various ways during the initial pandemic response. Interventions to benefit the most vulnerable families might be delivered through the newly targeted DEIS programme. For example, DEIS schools could be resourced to provide a rostered system of digital devices which students could take home. Home-school support systems will also assume greater importance in the coming period, including the Home-School-Community Liaison Scheme and the School Completion Programme, as well as school meals and other 'non-educational' supports.

While schools have varied widely in their approach to - and perceived impact of distance learning, as we look towards the new school year, we do not know how much distance learning will be needed in schools (not least because the future course of the pandemic is thoroughly unpredictable). As a consequence, the appropriate set of actions will likely depend upon that. In the event of a return to distance learning, the evidence suggests that schools and teachers will need ongoing resources and professional development to support the effective pedagogical use of technology in the classroom, as well as providing distance education. The Digital Strategy for Schools had as a core commitment the inclusion of ICT skill development as embedded components in Initial Teacher Education 
Programmes and Continuing Professional Development for established teachers; ongoing efforts in this regard will be important. Evidence also suggests that teachers are eager to learn from one another, highlighting the importance of creating time and space for them to collaborate with, and learn from, their peers on developing engaging learning experiences.

Concerns have been repeatedly raised about the implications for vulnerable groups; without one-to-one contact and face-to-face interaction teachers struggled to provide the personalised instruction and routine needed by students with additional and complex needs. While the 'summer programme'11 of education for children with disabilities and those from disadvantaged backgrounds has now been announced (DES, 2020i), these programmes will provide important supports, as well as opportunities for learning. Looking to late-August and September, particular supports will be needed for those making the transition from primary education (which, in normal times, is already more challenging for students with additional needs, see McCoy et al., 2019b). In the event of further periods of school closure, every effort should be made to ensure normal school provision is maintained for students with additional needs.

School leaders have raised concerns in relation to fifth year students and the impact of the pandemic on their progress. One possible response is reducing the coursework requirements for the Leaving Certificate in 2021. However, doing so would likely impact on students' learning and crucially their preparedness for higher education. However, incoming sixth year students will need to be prioritised as schools reopen in September and efforts made to make up for any lost learning time. Practical components of courses should be prioritised once the schools reopen, given the difficulty in undertaking this work during the pandemic. Teaching time for examination subjects should be prioritised, perhaps through some reduction in time on non-examination subjects - but some balance between examination and other subjects will need to be maintained to support student wellbeing. Consideration might also be given to the removal of mock examinations this year, to be replaced with classroom assessments by teachers. The Department of Education and Skills might consider providing supplementary resources for schools, to enable teachers to provide additional classes for sixth year students; some schools operate one half-day per week, so perhaps this time could be considered for additional classes. A further pressing issue is potential for increased competition for college places in 2021. In the first instance, higher education institutions might consider restricting or placing a cap on the deferral of college places this year. Substantial intervention in the form of the provision of additional college places, on a once-off basis, in 2021, may be warranted. 
Student wellbeing has been identified as a key challenge, and a focus on wellbeing will be paramount as schools reopen.

Schools, no matter what medium, can be hubs of response and recovery,

a place to support emotional recovery and promote social togetherness and this is as important as achievement gains (John Hattie, 7 April 2020). ${ }^{12}$

This extends to the importance of social and emotional learning, to ameliorate the significant impact on the emotional wellbeing of young people. Social and emotional learning skills can be developed even through distance learning and could be further supported through NEPS and PDST-Wellbeing and the Junior Cycle Wellbeing programme.

Internationally experts suggest that now is the time for fundamental change, an opportunity to think of 'school' in deeply different ways. ${ }^{13}$ However, policy in Ireland is already experiencing significant change, through the Framework for Junior Cycle, the review of Senior Cycle, the innovative pilot School Inclusion Model and a range of other key policy measures. These all underline the integration of innovative approaches to teaching and assessment and specialist student supports with the chief aim of enhancing students' overall experiences within school. In many ways a 're-imagining' of second-level education has already begun.

John Hattie, 7 April 2020, https://opsoa.org/application/files/2215/8689/0389/Infuences-during-Corona-JH-article.pdf Darling-Hammond, L. (2020). 'A New “New Deal” for Education: Top 10 Policy Moves for States in the Covid Era', Forbes, 19 May 2020. 


\section{REFERENCES}

Allen, M., E. Mabry, M. Mattrey, J. Bourhis, S. Titsworth and N. Burrell (2004). 'Evaluating the effectiveness of distance learning: A comparison using meta-analysis', Journal of Communication, 54(3), 402-420.

Anders, J., L. Macmillan, P. Sturgis and G. Wyness (2020). 'Home schooling during lockdown: Inequalities in inputs and perceptions'. https://blogs.ucl.ac.uk/cepeo/2020/06/05/homeschooling-during-lockdown-inequalities-in-inputs-and-perceptions/

Andersen, S.C. and H.S. Nielsen (2019). 'Learning from Performance Information', Journal of Public Administration Research and Theory.

Blodgett, C. and J.D. Lanigan (2018). 'The association between adverse childhood experience (ACE) and school success in elementary school children', School Psychology Quarterly, 33(1), 137.

Bol, T. (2020, April 30). 'Inequality in homeschooling during the Corona crisis in the Netherlands. First results from the LISS Panel'. https://doi.org/10.31235/osf.io/hf32q

Bridges, D. (2008). 'Evidence-based Reform in Education: A Response to Robert Slavin', European Educational Research Journal, 7 (1): 129-133.

Brooks, S.K., L.E. Smith, R.K. Webster, D. Weston, L. Woodland, I. Hall and G.J. Rubin (2020). 'The impact of unplanned school closure on children's social contact: rapid evidence review', Eurosurveillance, 25(13), 2000188.

Buabeng-Andoh, C. (2012). 'Factors influencing teachers' adoption and integration of information and communication technology into teaching: A review of the literature', International Journal of Education and Development using ICT, 8(1).

Burgess, S. and H. Sievertsen (2020). 'Schools, skills, and learning: The impact of COVID-19 on education'. https://voxeu.org/article/impact-covid-19-education

Burke, J. and M. Dempsey (2020). 'Covid-19 Practice in Primary Schools in Ireland Report. Maynooth University Department of Education'. https://www.into.ie/app/uploads/2020/04/Covid-19Practice-in-Primary-Schools-Report-1.pdf

Cavanaugh, C., K.J. Gillan, J. Kromrey, M. Hess and R. Blomeyer (2004). 'The effects of distance education on K-12 student outcomes: A meta-analysis'. Learning Point Associates/North Central Regional Educational Laboratory (NCREL). https://files.eric.ed.gov/fulltext/ED489533.pdf

Cavanaugh, C.S. (2001). 'The effectiveness of interactive distance education technologies in K-12 learning: A meta-analysis', International Journal of Educational Telecommunications, 7(1), 7388.

Central Statistics Office (2020). 'Social Impact of COVID-19 Survey April 2020'. Cork: CSO. https://www.cso.ie/en/releasesandpublications/ep/p-sic19/socialimpactofcovid19surveyapril2020/well-being/

ComReg (2020). 'Impact of Covid-19 on Home Broadband use in Ireland'. Dublin: ComReg. https://www.comreg.ie/publication/market-research-impact-of-covid-19-on-homebroadband

Coyne, B., N. Devitt, S. Lyons and S. McCoy (2016). 'Perceived Benefits and Barriers to the Use of HighSpeed Broadband in Ireland's Second-Level Schools', Irish Educational Studies, 34(4): 355-378. 
Cullinane, C. and R. Montacute (2020). 'COVID-19 and Social Mobility Impact Brief \#1: School Shutdown'. https://www.suttontrust.com/wp-content/uploads/2020/04/COVID-19-ImpactBrief-School-Shutdown.pdf

Dahl, G. B. and L. Lochner (2012). 'The impact of family income on child achievement: Evidence from the earned income tax credit', American Economic Review, 102(5), 1927-56.

Darling-Hammond, L. (2020). 'A New “New Deal” for Education: Top 10 Policy Moves for States in the Covid Era', Forbes, $19 \quad 2020$. https://www.forbes.com/sites/lindadarlinghammond/2020/05/19/a-new-new-deal-foreducation-top-10-policy-moves-for-states-in-the-covid-20-era/\#7a5478be6266

Dempsey, M. and J. Burke (2020). 'Covid-19 Practice in Primary Schools in Ireland Report: A Twomonth Follow-up'. Maynooth University Department of Education. http://mural.maynoothuniversity.ie/13001/

Dempsey, S., S. Lyons and S. McCoy (2019). 'Later is better: mobile phone ownership and child academic development, evidence from a longitudinal study', Economics of Innovation and New Technology, 28(8), 798-815.

Dempsey, S., S. Lyons and S. McCoy (2020). 'Early mobile phone ownership: influencing the wellbeing of girls and boys in Ireland?', Journal of Children and Media, 1-18.

Department of Communications, Climate Action and Environment (2019a). 'High Speed Broadband Map County Coverage Statistics Q3 2019'. Dublin: DCCAE. https://www.dccae.gov.ie/documents/County\%20Statistics.pdf.

Department of Communications, Climate Action and Environment (2019b). 'Delivering the National Broadband Plan'. Dublin: DCCAE. https://www.dccae.gov.ie/documents/Delivering\%20the\%20National\%20Broadband\%20Pla n.pdf

Department of Communications, Climate Action and Environment (2019c). 'School Digital Champion Programme'. Dublin: DCCAE. https://www.dccae.gov.ie/enie/communications/topics/Digital-Strategy/schools-and-education/school-digitalchampion/Pages/School-Digital-Champion-National-Programme-2017.aspx

Department of Communications, Energy and Natural Resources (2015). 'Schools 100 Mbps Project'. https://www.dccae.gov.ie/en-ie/communications/topics/Broadband/Pages/default.aspx

Department of Education and Skills (2015a). Digital Strategy for Schools 2015-2020 Action Plan. Dublin. www.education.ie/en/Publications/Policy-Reports/Digital-StrategyAction-Plan-2017.pdf.

Department of Education and Skills (2015b). Digital Strategy for Schools 2018-2020 Enhancing Teaching Learning and Assessment. Dublin. www.education.ie/en/Publications/PolicyReports/Digital-Strategy-for-Schools-2015-2020.pdf

Department of Education and Skills (2015c). 'Framework for New Junior Cycle'. Dublin: DES. https://www.education.ie/en/Publications/Policy-Reports/Framework-for-Junior-Cycle2015.pdf

Department of Education and Skills (2016). 'Looking at Our School 2016: A Quality Framework for PostPrimary Schools'. Dublin: DES. https://www.jct.ie/perch/resources/leadership/looking-atour-school-2016-a-quality-framework-for-post-primary-schools.pdf 
Department of Education and Skills (2018a). 'Digital Strategy for Schools 2015-2020 Action Plan 2018'. Dublin: DES. https://www.education.ie/en/Publications/Policy-Reports/Digital-StrategyAction-Plan-2018.pdf

Department of Education and Skills (2018b). 'Junior Cycle for Teachers: Learning Log 2 Digital Key Skills, Whole School CPD'. Dublin: DES. https://www.jct.ie/perch/resources/wholeschool/digitalkey-skills-cpd-booklet.pdf

Department of Education and Skills (2018c). 'Consultation with the school community including teachers, students and parents on the use of smart phones and tablet devices in schools', Circular 0038/2018. Dublin: DES.

Department of Education and Skills (2019a). 'Post-Primary Schools List 2019-2020'. Dublin: DES.

Department of Education and Skills (2019b). 'Action Plan for Education 2019: Empowering through learning'. Dublin: DES. https://www.education.ie/en/Publications/CorporateReports/Strategy-Statement/action-plan-for-education-2019.pdf

Department of Education and Skills (2020a). 'Guidance on Continuity of Schooling for Primary and Post-Primary Schools'. Dublin: DES. https://www.education.ie/en/SchoolsColleges/Information/guidance-on-continuity-of-schooling.pdf

Department of Education and Skills (2020b). 'Guidance on Continuity of Schooling: Supporting Students with Special Educational Needs, For Post-Primary Schools'. Dublin: DES. https://www.education.ie/en/Schools-Colleges/Information/National-Emergencies-PublicHealth-Issues/guidance-continuity-of-schooling-supporting-students-with-sen-postprimary.pdf

Department of Education and Skills (2020c). 'Guidance on Continuity of Schooling: Supporting Students at Risk of Educational Disadvantage, For Post-Primary Schools'. Dublin: DES. https://www.education.ie/en/Schools-Colleges/Information/National-Emergencies-PublicHealth-Issues/guidance-support-pupils-at-risk-post-primary.pdf

Department of Education and Skills (2020d). 'Challenges of Organising Examinations with Social Distancing Requirements'. Dublin: DES. https://www.education.ie/en/Learners/Information/State-Examinations/challenges-oforganising-examinations-with-social-distancing-requirements.pdf

Department of Education and Skills (2020e). 'A Guide to Calculated Grades for Leaving Certificate Students 2020'. Dublin: DES. https://www.education.ie/en/Learners/Information/StateExaminations/a-guide-to-calculated-grades-for-leaving-certificate-students-2020.pdf

Department of Education and Skills (2020f). 'Circular 0037/2020 Implementation of Calculated Grades Model For Leaving Certificate 2020 - Guide for Schools on Providing Estimated Percentage Marks and Class Rank Orderings'. Dublin: DES. https://www.education.ie/en/Circulars-andForms/Active-Circulars/cl0037_2020.pdf

Department of Education and Skills (2020g). 'Minister McHugh announces ICT funding for Schools including $€ 10$ million top-up funding'. Dublin: DES. https://www.education.ie/en/PressEvents/Press-Releases/2020-press-releases/PR20-04-22.html

Department of Education and Skills (2020h). 'Covid-19 - Statement from the Department of Education and Skill's. Dublin: DES. https://www.education.ie/en/Press-Events/Press-Releases/2020press-releases/12-march-2020-statement-from-the-department-of-education-and-skills.html 
Department of Education and Skills (2020i). 'Government announces new Summer Provision 2020'. Dublin: DES. https://www.education.ie/en/Press-Events/Press-Releases/2020-pressreleases/PR20-06-12.html

Dorn, E., B. Hancock, J. Sarakatsannis and E. Viruleg (2020). 'COVID-19 and student learning in the United States: The hurt could last a lifetime'. https://www.mckinsey.com/industries/publicsector/our-insights/covid-19-and-student-learning-in-the-united-states-the-hurt-could-lasta-lifetime

Doyle, O. (2020). COVID-19: 'Exacerbating Educational Inequalities?'. http://publicpolicy.ie/papers/covid-19-exacerbating-educational-inequalities/

Dunne, C., C. O'Dalaigh and A. Marcus-Quinn (2020). 'Report of the Independent Review Group (IRG) on the use of tablet devices in Ratoath College (RC)'. https://www.ratoathcollege.ie/images/pdfs/ParentLetters/Report_of_the_Independent_Re view_Group_03_03_2020.pdf

European Commission (2016). 'Connectivity for a Competitive Digital Single Market - Towards a European Gigabit Society'. https://ec.europa.eu/digital-singlemarket/en/news/communication-connectivity-competitive-digital-single-market-towardseuropean-gigabit-society

European Commission (2020). 'Connectivity is essential during emergency situations'. 31 March 2020 https://ec.europa.eu/digital-single-market/en/news/connectivity-essential-duringemergency-situations

Hagan, T. (2013). 'The Potential of Online Technologies and Social Media in 21st Century Teacher Professional Development and Practice: A Mixed Methods Study Exploring Teachers' Personal, Professional Development and/ or Classroom Use of Online Technologies in Ireland and the United States of America'. Dissertation. http://doras.dcu.ie/19396/

Hallas, D. (2020). 'COVID-19 remains a major threat to our nation's health and well-being'. https://www.contemporarypediatrics.com/pnp-corner/covid-19-remains-major-threat-ournations-health-and-well-being

Kuhfeld, M., J. Soland, B. Tarasawa, A. Johnson, E. Ruzek and J. Liu (2020). 'Projecting the potential impacts of COVID-19 school closures on academic achievement'. https://www.edworkingpapers.com/ai20-226

Laprairie, K.N. and J.M. Hinson (2006). 'When disaster strikes, move your school online', Journal of Educational Technology Systems, 35(2), 209-214.

Lavy, V. (2015). 'Do differences in schools' instruction time explain international achievement gaps? Evidence from developed and developing countries', The Economic Journal, 125(588), F397-F424.

Lee, J. (2020). 'Mental health effects of school closures during COVID-19', Lancet Child Adolescent Health, 4 (6).

Lingard, B. (2010). 'Policy Borrowing, Policy Learning: Testing Times in Australian Schooling', Critical Studies in Education, 51 (2): 129-147.

Lucas, M., J. Nelson and D. Sims (2020). 'Schools' Responses to Covid-19: Pupil Engagement in Remote Learning. Slough: National Foundation Education Research'. https://www.nfer.ac.uk/media/4073/schools_responses_to_covid_19_pupil_engagement_i n_remote_learning.pdf 
Marcus-Quinn, A. and O. McGarr (2015). 'Teachers' use of reusable learning objects in teaching English poetry: exploring the influence of prevailing pedagogical practices'. Educación XX1, Vol. 18, pp. 325-344.

Marcus-Quinn, A., T. Hourigan and S. McCoy (2019a). 'The Digital Learning Movement: How Should Irish Schools Respond?', The Economic and Social Review, Winter 2019.

Marcus-Quinn, A., T. Hourigan and S. McCoy (2019b). 'Digital Education in Ireland'. Unpublished report to the European Commission.

Marcus-Quinn, A., T. Hourigan and S. McCoy (2019c). 'How Should Second-Level Schools Respond in an Era of Digital Learning?' in Ireland's Yearbook of Education 2019/2020. Dublin: Education Matters. https://irelandsyearbookofeducation.ie/irelands-yearbook-of-education-20192020/second-level/how-should-second-level-schools-respond-in-an-era-of-digital-learning/

Mayer, S. (2002). 'The Influence of Parental Income on Children's Outcomes. Wellington: Ministry of Social Development'. https://www.msd.govt.nz/documents/about-msd-and-ourwork/publications-resources/research/influence-parental-income/influence-of-parentalincome.pdf

McCoy, S. and E. Smyth (2013). 'Improving Second Level Education', p.34-37, in O'Toole, F. (Ed) Why Education Matters? The Importance of Education to Ireland's Economy and Society. Dublin: ASTI. https://www.esri.ie/system/files/media/file-uploads/2015-07/JACB201327.pdf

McCoy, S., A. Quail and E. Smyth (2012). Influences on 9-Year-Olds' Learning: Home, School and Community. Dublin: ESRI.

McCoy, S., D. Byrne, J. O'Sullivan and E. Smyth (2019a). The Early Impact of the Revised Leaving Certificate Grading Scheme on Student Perceptions and Behaviour. Dublin: ESRI Research Series, 85. https://www.esri.ie/system/files/publications/RS85_1.pdf

McCoy, S., E. Smyth, D. Watson and D. Darmody (2014). 'Leaving School in Ireland: A Longitudinal Study of Post School Transitions'. Dublin: ESRI. https://www.esri.ie/system/files/media/fileuploads/2015-07/RS36.pdf

McCoy, S., L. Lyons, B. Coyne and M. Darmody (2016). 'Teaching and Learning in Second-Level Schools at the Advent of High-Speed Broadband'. Dublin: ESRI Research Series, No. 51. https://www.esri.ie/system/files?file=media/file-uploads/2016-04/RS51.pdf

McCoy, S., M. Shevlin and R. Rose (2019b). 'Secondary School Transition for Students with Special Educational Needs', European Journal of Special Needs Education, 35(2): 154-170.

McGarr, O. and K. Johnston (2019). 'Exploring the Evolution of Educational Technology Policy in Ireland: From Catching-Up to Pedagogical Maturity', Educational Policy.

Means, B., Y. Toyama, R. Murphy and M. Baki (2013). 'The effectiveness of online and blended learning: A meta-analysis of the empirical literature', Teachers College Record, 115(3), 1-47.

Montacute, R. (2020). 'Social mobility and Covid 19. Implications of the Covid-19 crisis for educational inequality'. https://www.suttontrust.com/wp-content/uploads/2020/04/COVID-19-andSocial-Mobility-1.pdf

NCCA (2016). 'Short Course in Digital Media Literacy'. Dublin: NCCA. https://curriculumonline.ie/getmedia/71b6b946-971b-4003-8bfa-028932cc4daa/NCCA-JCShort-Course-DML.pdf 
OECD (2015). 'Students, Computers and Learning: Making the Connection, PISA, OECD Publishing'. http://dx.doi.org/10.1787/9789264239555-en

OECD (2020). 'Ireland Country Note'. http://www.oecd.org/education/Ireland-coronaviruseducation-country-note.pdf

Outhwaite, L. and A. Gulliford (2020). 'Briefing Note: Academic and Social and Emotional Interventions in Response to Covid-19 School Closures', Centre for Education Policy and Equalising Opportunities (CEPEO) University College London. www.ucl.ac.uk/ioe/cepeo

Panayiotou, M., N. Humphrey and M. Wigelsworth (2019). 'An empirical basis for linking social and emotional learning to academic performance', Contemporary Educational Psychology, 56, 193-204.

PDST (2017). 'Digital Learning Framework for Post-Primary Schools', Dublin: PDST. https://www.pdsttechnologyineducation.ie/en/Planning/Digital-Learning-Framework-andPlanning-Resources-Post-Primary/Domain-1-Learner-Outcomes.pdf

Raffe, D. (2011). 'Policy Borrowing or Policy Learning? How (Not) to Improve Education Systems'. Edinburgh: CES Briefing.

Rice, K.L. (2006). 'A comprehensive look at distance education in the K-12 context', Journal of Research on Technology in Education, 38(4), 425-448.

Roblyer, M.D. and J.C. Marshall (2002). 'Predicting success of virtual high school students: Preliminary results from an educational success prediction instrument', Journal of Research on Computing in Education, 35(2), 241-255.

Sahlberg, P. (2015). Finnish lessons 2.0: What can the world learn from educational change in Finland?. Teachers College Press.

Slavin, R.E. (2004). 'Education Research Can and Must Address “What Works" Questions', Educational Researcher, 33: 27-28.

Smyth, E., S. McCoy and J. Banks (2019). Student, Teacher and Parent Perspectives on Senior Cycle Education. Dublin: ESRI.

Stake, R.E. (2010). Qualitative Research: Studying How Things Work. New York: The Guilford Press.

Sublett, C. and Y.C. Chang (2019). 'Logging in to press on: an examination of high school dropout and completion among students with disabilities in online courses', Journal of Special Education Technology, 34(2), 106-119.

UNESCO (2020a). 'UNESCO Covid-19 Education Response: Education Sector Issue Notes'. Note No. 2.1, April 2020.

UNESCO (2020b). 'COVID-19 Impact on Education'. https://en.unesco.org/covid19/educationresponse

Vasquez III, E. and C. Straub (2012). 'Online instruction for K-12 special education: A review of the empirical literature', Journal of Special Education Technology, 27(3), 31-40.

Wiseman, A.W. (2010). 'The Uses of Evidence for Educational Policymaking: Global Contexts and International Trends', Review of Research in Education, 34: 1-24.

Zhao, Y., J. Lei, B. Yan, C. Lai and H.S. Tan (2005). 'What makes the difference? A practical analysis of research on the effectiveness of distance education', Teachers College Record, 107(8), 1836.0 


\section{APPENDIX MEASURING BROADBAND AVAILABILITY AND HOUSEHOLD INCOME}

We spatially linked every residence in Ireland with the 2019 National Broadband Plan map to create an indicator of broadband availability for each residence. The National Broadband Plan map, illustrated in Figure A.1, specifies (a) areas where high-speed broadband is currently available, (b) areas where there is no high-speed broadband available but where a commercial entity plans to roll out fibre broadband in the future, and (c) areas where there is no high-speed broadband available and where state intervention is required to provide broadband through the National Broadband Plan. For the purposes of this study, we consider (b) and (c) to be equivalent in that these areas do not yet have access to high-speed broadband. We also assign each residence the household median gross annual income of the electoral division they are located in.

\section{FIGURE A.1 NATIONAL BROADBAND PLAN MAP FOR REPUBLIC OF IRELAND, QUARTER 32019}

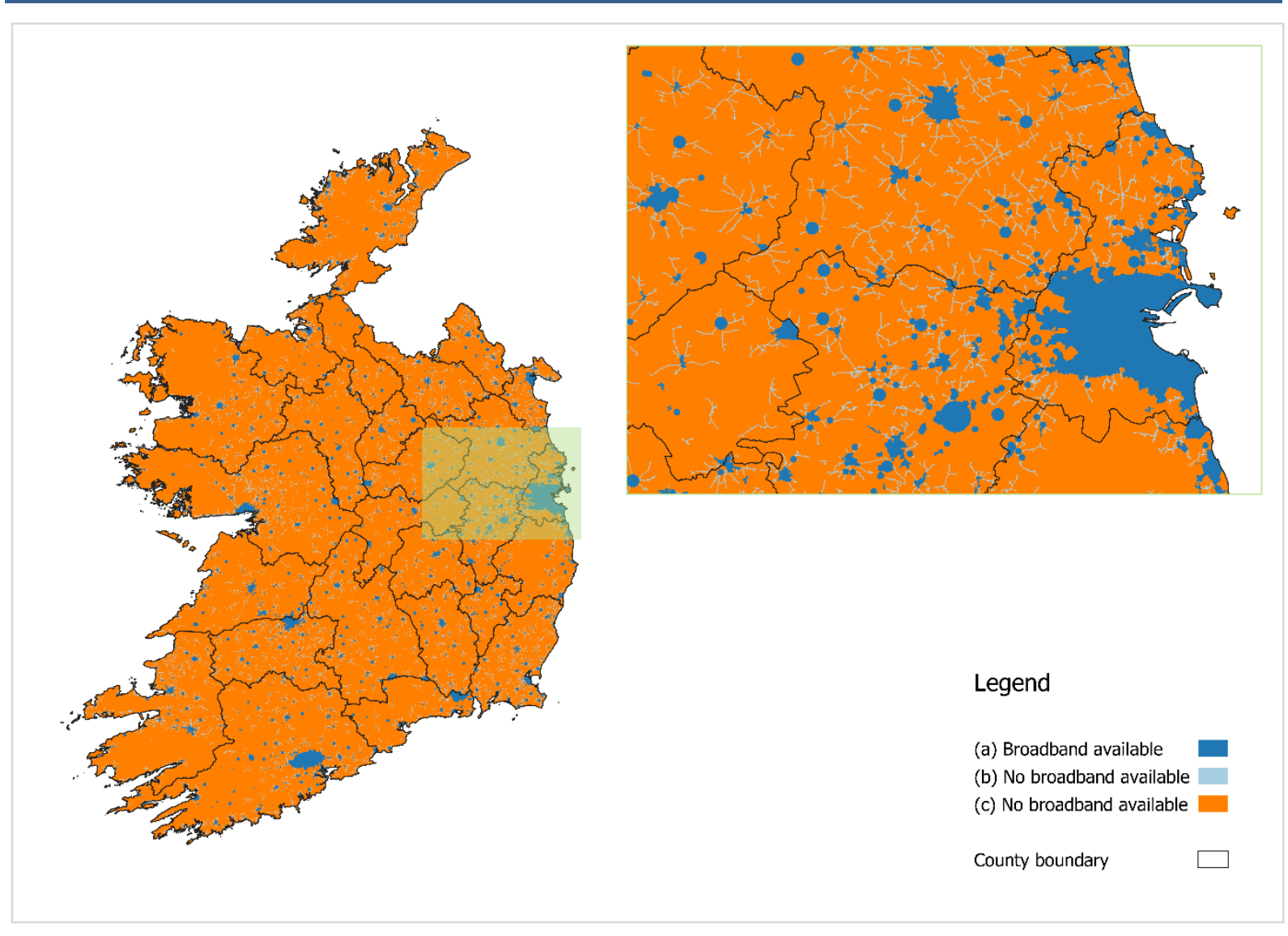

Source: Department of Communications, Climate Action and Environment (2019a).

We then generated a circular buffer around each second-level school as a proxy for schools' respective catchment areas. The distance of a school's buffer was determined by the extent to which the school's surrounding area was urban, with a distance of eight kilometres assigned to schools in highly urban areas and 
24 kilometres assigned to schools in highly rural areas. The proportion of residences for which high-speed broadband was available was measured, and gross annual household income was averaged, within each school's buffer. Spatial linking was completed using a Geographic Information Systems (GIS) platform, QGIS3. The following provides further details on our methodology for defining the catchment areas of schools.

First, we categorised every residence in the 2018 Geodirectory as either urban or rural depending on whether they were located within an urban area as defined by the Central Statistics Office (CSO) in 2016. The CSO defines an urban area as a settlement with a total population of over 1,500 people (see Figure A.1). Second, we assigned each Geodirectory residence to its nearest school. The proportion of urban residences assigned to a school was then used to measure the extent to which that school's surrounding area is urban. Next, this proportion was used to define the distance of a school's circular buffer on a scale between eight kilometres for schools in highly urban areas and 24 kilometres for schools in highly rural areas. Finally, having previously categorised residences in terms of their broadband availability using the 2019 National Broadband Plan map (see Figure A.2), and having assigned each residence the household median gross annual income of their electoral division (see Figure A.3), residences were further linked to any school whose circular buffer they were located in. The proportion of residences for which high-speed broadband was available was measured, and household median gross income was averaged, within each school's buffer. 

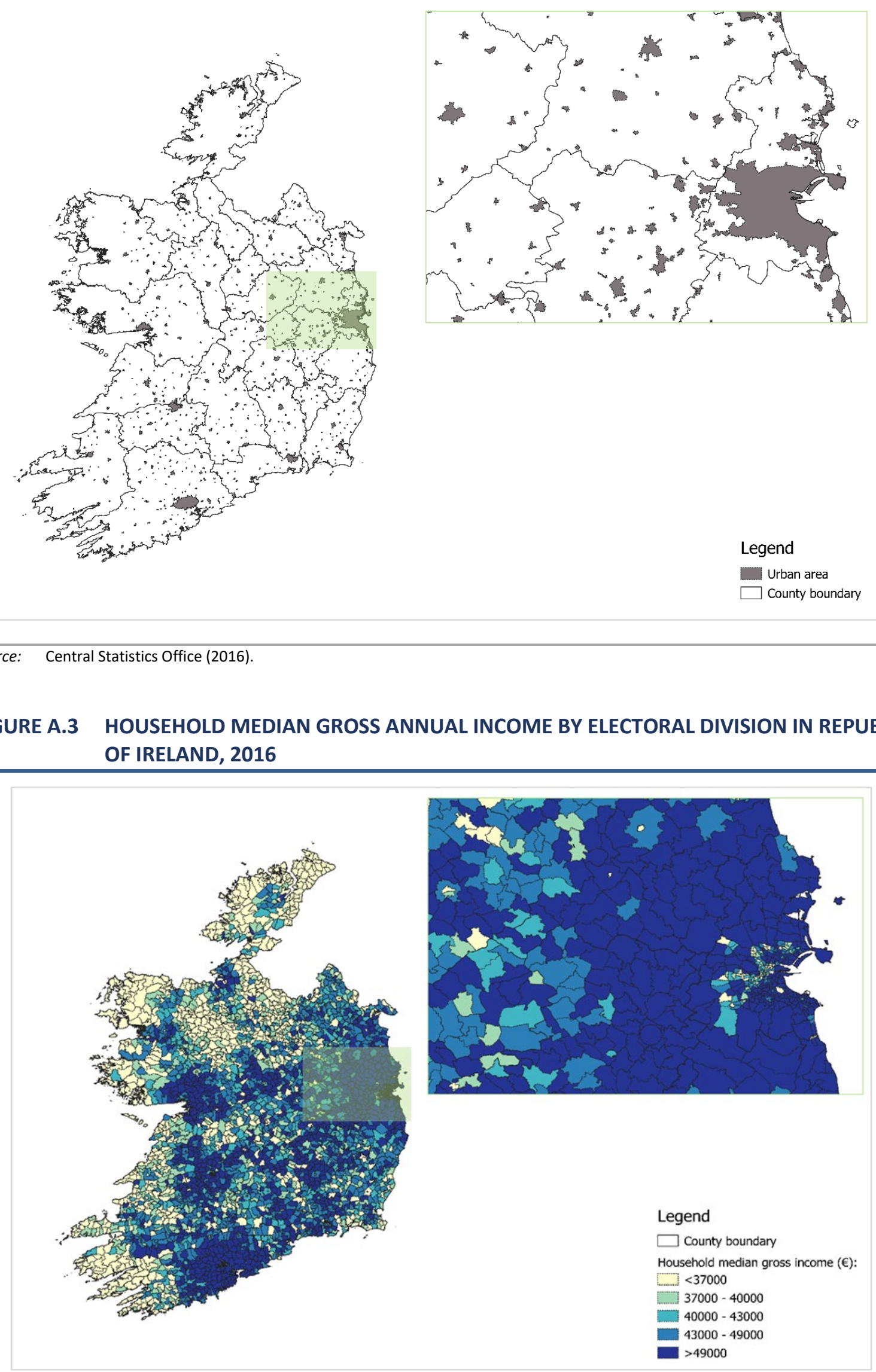


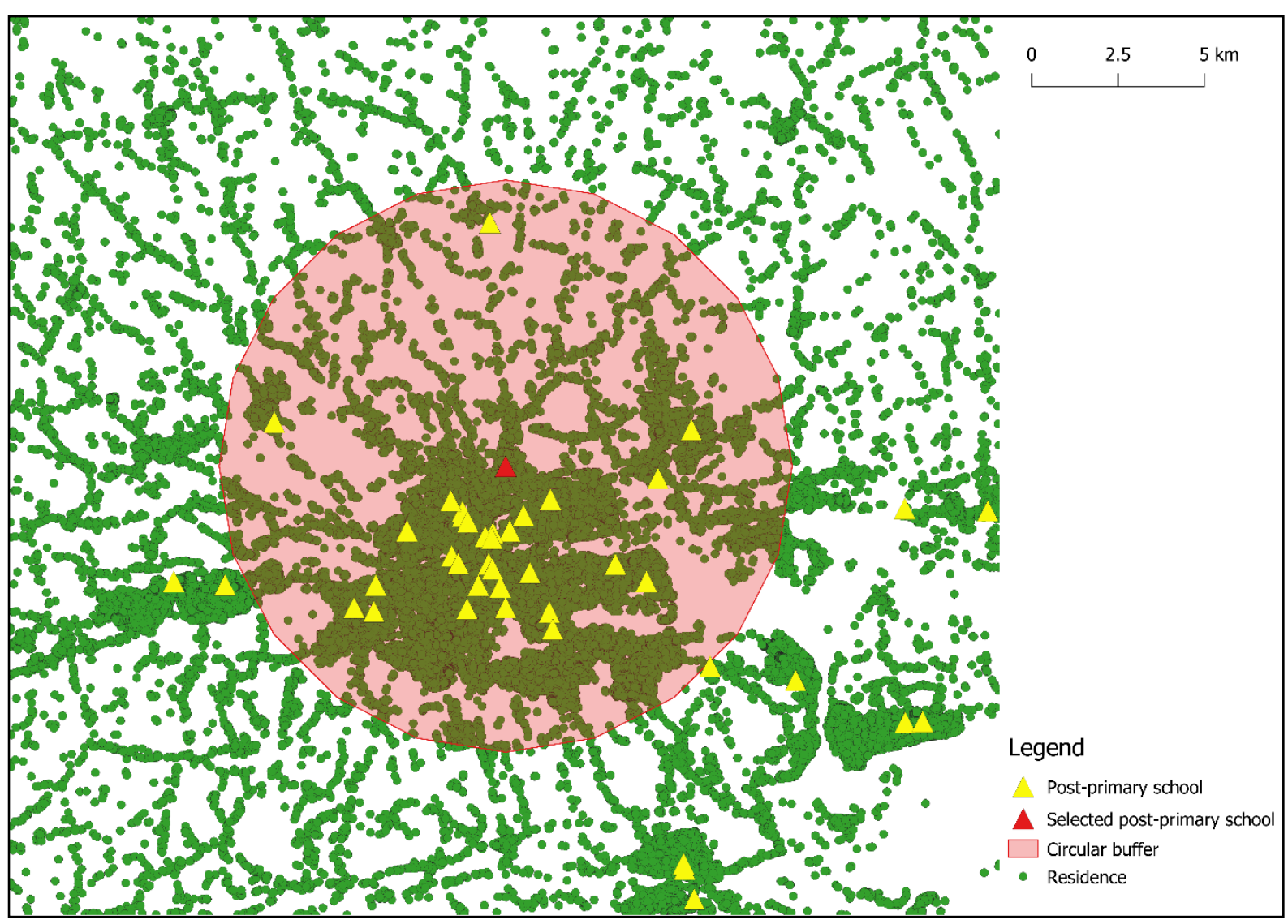

Sources: Department of Education and Skills (2019a), Geodirectory (2018).

Figure A.4 depicts a worked example of how one school's catchment area is defined. All residences that were located within the red circular buffer were linked to the school marked in red. This process was repeated for every second-level school in the country.

We assume a buffer distance of eight kilometres is appropriate for highly urban areas, and 24 kilometres for highly rural areas, based on a combination of data from the National Household Travel Survey 2017 and from the Growing Up in Ireland survey (GUI). In the GUI survey, 92 per cent of respondents in the cohort of children aged 13 years who lived in Dublin reported to be living within eight kilometres of their second-level school. Since 98 per cent of residences in Dublin are located in urban areas, we assume that most students living in any urban area in Ireland live within eight kilometres of their second-level school.

In other regions, however, large proportions of GUI respondents lived over eight kilometres from their school, the highest possible response in the survey. To define an upper bound on the distance travelled to second-level school in rural areas, we instead draw on data from the National Household Travel Survey 2017. This survey is limited to persons over the age of 18 and thus cannot accurately capture 
distances travelled to school, but 88 per cent of general journeys from rural areas were within 30 kilometres of the respondent's residence, while 85 per cent of journeys from Dublin city were within ten kilometres. This indicates a ratio of three to one in terms of journey distance in rural areas relative to urban areas in Ireland. In measuring the average distances of services from residences, the CSO also indicated in 2019 that services are typically located three times further away in rural areas than in urban areas in Ireland. By applying this ratio to the data captured in GUI on distances travelled to school, we thus assume that most second-level students in rural areas in Ireland live within 24 kilometres of their school.

It should be noted that it is possible that there is a relationship between the proportion of residences in a school's catchment area and the average household income of that area, in that some lower-income areas may well have no high-speed broadband available. For example, these two variables may each be measuring some degree of rurality versus urbanity. The correlation between these two variables is 0.6 , and Figure A.5 illustrates this relationship.

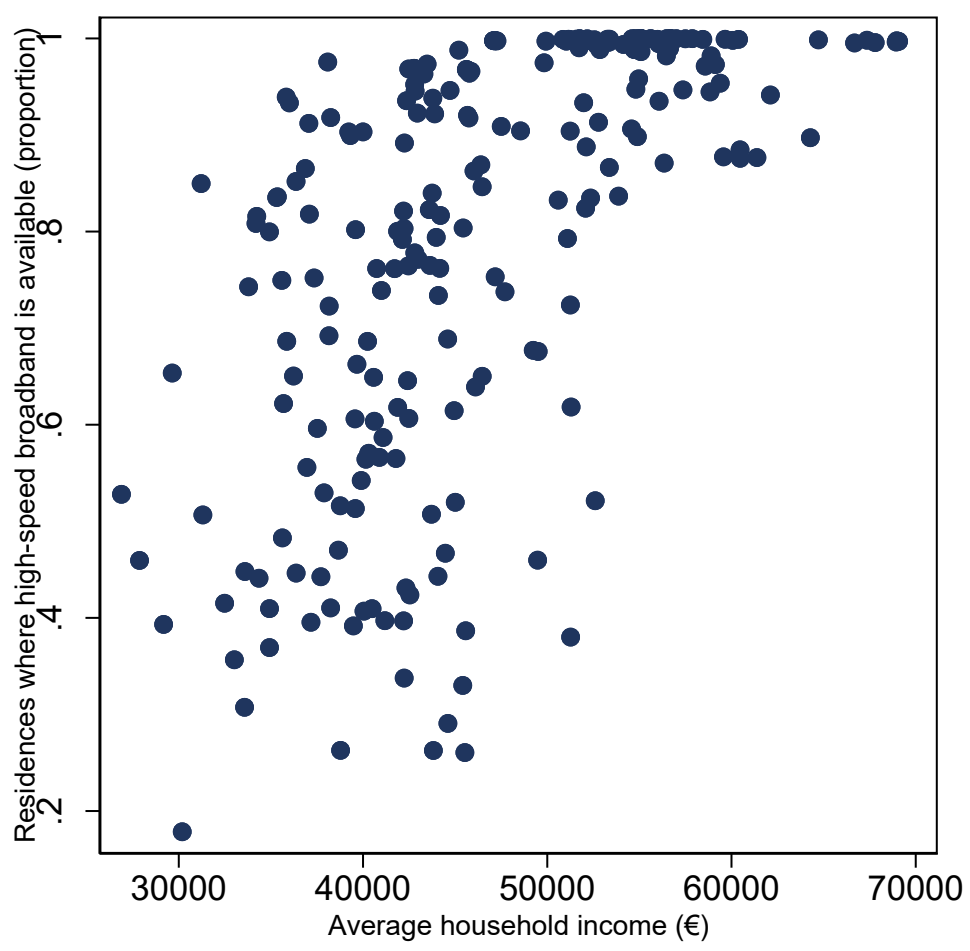

Sources: Department of Education and Skills (2019a), Geodirectory (2018). 
Whitaker Square,

Sir John Rogerson's Quay, Dublin 2

Telephone +35318632000

Email admin@esri.ie

Web www.esri.ie

Twitter @ESRIDublin

ISBN 978-0-7070-0529-4 